\title{
AN ECONOMIC APPRAISAL OF HOLE CLEANING USING HYDRAULIC HORSEPOWER AND JET IMPACT FORCE
}

By

James Alfred Wright

RECOMMENDED:

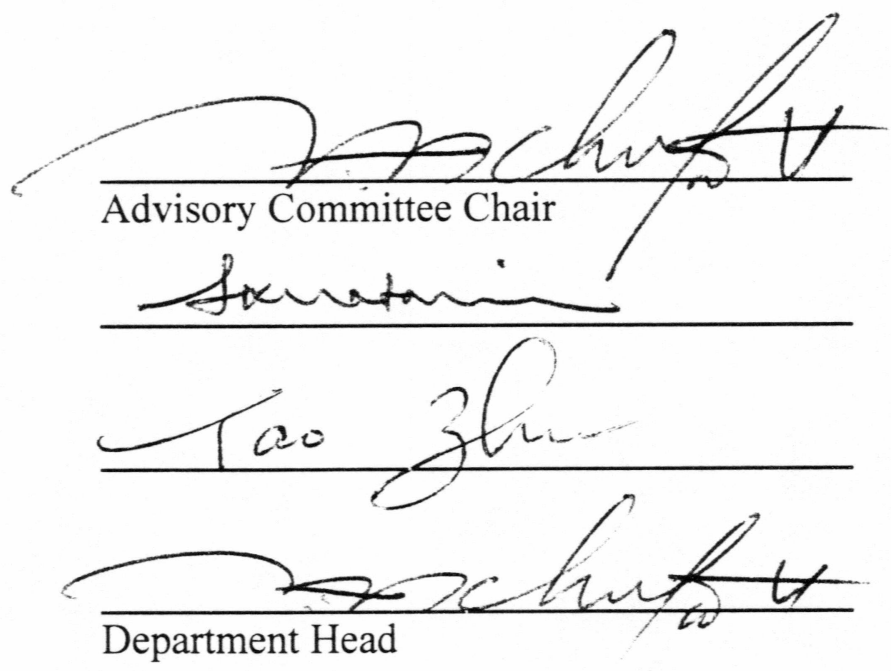

APPROVED:

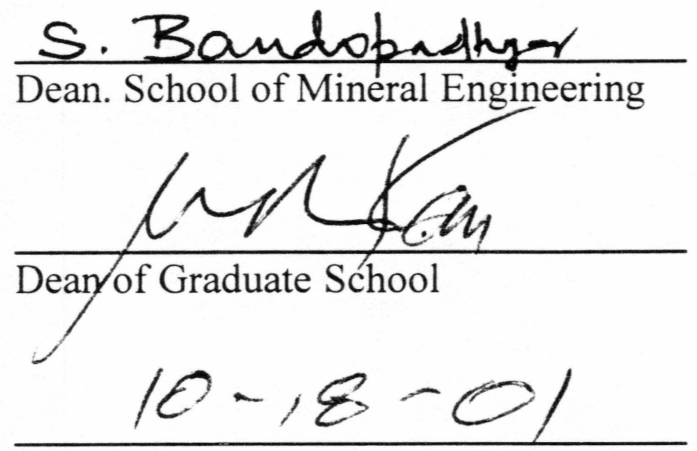

Date 


\title{
AN ECONOMIC APPRAISAL OF HOLE CLEANING USING HYDRAULIC HORSEPOWER AND JET IMPACT FORCE
}

\author{
A \\ THESIS \\ Presented to the Faculty \\ Of the University of Alaska Fairbanks \\ In Partial Fulfillment of the Requirements \\ For the Degree of
}

MASTER OF SCIENCE IN ENGINEERING

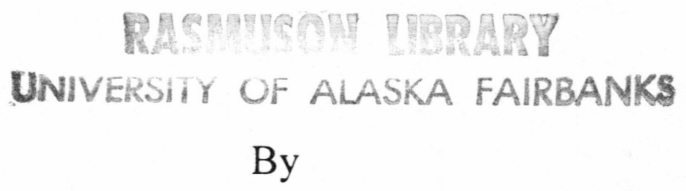

James Alfred Wright

Fairbanks, Alaska

December 2001

175 


\begin{abstract}
In today's competitive business environment, reducing operating cost means dollars to the bottom line. One way that a drilling company can reduce operating cost is by optimizing energy use at the mud pumps. The mud pumps are massive pieces of equipment that are the backbone of the cutting's removal system. Optimizing the hydraulics program is one way to reduce mud pump operating cost.

Bit hydraulics plays an important role in the drilling process. The beneficial action of the fluid's cleaning the bottom hole and the bit teeth, and carrying particles into the annulus is well-established '. A variety of hydraulic optimization designs are available, however, in this study the efficiency and cost effectiveness of two methods are compared: Jet Impact force and Hydraulic Horsepower. Both methods have a fundamental objective to maximize the available hydraulics to provide optimum cleaning but Jet Impact method optimizes drilling cost better than Hydraulic Horsepower.
\end{abstract}




\section{Table of Contents}

Chapter

Page

Abstract

iii

List of Figures

vi

List of Tables

viii

Acknowledgment

$\mathrm{X}$

1. Introduction 1

1.1 Objectives 1

2. Literature Review 4

2.1 Previous Investigation 4

2.2 Selection of Study Parameters 7

3. The Theory of Drilling Hydraulics 9

3.1 Determination of a Particle Reynolds Number: $\quad 9$

3.2 Effects of Drag Coefficient 11

3.3 System Pressure Losses in a Circulating System 12

$\begin{array}{ll}\text { 3.3.1 Pressure Losses at The Bit } & 12\end{array}$

3.4 Bit Hydraulics Optimization $\quad 13$

3.4.1 Optimum Hydraulics Horsepower (HHP) 13

3.4.2 Optimum Jet Impact Force (JIF) 15 
4. Hydraulics Analysis in Rotary Drilling

4.1 Effects of Pressure Ratio and The Flow Exponent m 19

4.2 Analysis of Extended Nozzles on Rate of Penetration 26

4.3 Analysis of Blanked-Off Nozzles on Rate of Penetration 26

4.4 Analysis of Hole Size Ratio on Drilling Hydraulics 27

5. Energy and Maintenance Cost Equations for Mud Pump Operation

5.1 Minimum Cost Drilling: Drilling Company Perspective 31

5.2 Cost of Fuel Equation 32

5.3 Cost of Pump Maintenance Equation 35

$\begin{array}{ll}\text { 6. Economic Evaluation } & 37\end{array}$

6.1 Discussion of the Cost Comparison $\quad 37$

6.2 Example Problem $\quad 37$

7. Conclusions and Recommendations 50

$\begin{array}{ll}7.1 \text { Conclusions } & 50\end{array}$

7.2 Recommandation 51

8. Nomenclature $\quad 52$

9. References $\quad 55$

$\begin{array}{ll}\text { Appendix } & \mathbf{5 7}\end{array}$ 


\section{List of Figures}

Figures

1.1 The Hydraulic Principle 3

2.1 Cuttings Transport in Vertical Annulus $\quad 8$

$\begin{array}{ll}3.1 \text { Schematic of the Bit Nozzle } & 10\end{array}$

$\begin{array}{ll}\text { 4.1 Vertical Borehole Circulating System } & 20\end{array}$

4.2 Plot of Pressure Ratio vs. Optimum Diameter for HHP and JIF 24

4.3 Plot of Pressure Ratio vs. Optimum Diameter under Assumed and

Calculated Flow Exponent m for HHP 25

4.4. Plot of Hole Size Ratio vs. Pressure Ratio for Different Nozzle

$\begin{array}{ll}\text { Sizes using HHP } & 30\end{array}$

6.1 Plot of JIF vs. HHP for m=1.59 42

6.2 Plot of JIF vs. HHP for m=1.50 43

6.3 Plot of JIF vs. HHP for m=1.70 44

6.4 Plot of JIF vs. HHP for m=1.80 45

6.5 Plot of JIF vs. HHP for $m=1.90$ 
Figures

6.6 Plot of JIF vs. HHP for $\mathrm{m}=2.00$

6.7 Plot of JIF vs. HHP for $\mathrm{m}=2.10$

6.8 Plot of JIF vs. HHP for $\mathrm{m}=2.20$ 47

\section{Page}




\section{List of Tables}

Table

Page

4.1 Flow Exponent Values for Several Bit Nozzle Combinations for HHP

4.2 Hole Size Ratios and Pressure Ratio for HHP

6.1 Calculated Operating Cost for HHP and JIF

A.1 Nozzle Sizes and Equivalent Diameter

Two and Three Nozzle Bits

B-1 Optimization Results for Hydraulic Horsepower Method (10 gpm, Nozzle Size 10,10,10 assume $\mathrm{m}=1.8)$

B-2 Optimization Results for Hydraulic Horsepower Method (100 gpm, Nozzle Size 10,10,10 assume $\mathrm{m}=1.8)$

B-3 Optimization Results for Jet Impact Force Method

(10 gpm, Nozzle Size 10,10,10 assume $\mathrm{m}=1.8)$

B-4 Optimization Results for Jet Impact Force Method (100 gpm, Nozzle Size 10,10,10 assume $\mathrm{m}=1.8)$

B-5 Optimization Results for Hydraulic Horsepower Method (10 gpm, Nozzle Size 10,10,10 assume $\mathrm{m}=1.953)$

B-6 Optimization Results for Hydraulic Horsepower Method $(100 \mathrm{gpm}$, Nozzle Size 10,10,10 assume $\mathrm{m}=1.953)$ 
B-7 Optimization Results for Jet Impact Force Method (10 gpm, Nozzle Size 10,10,10 assume $\mathrm{m}=1.953)$

B-8 Optimization Results for Jet Impact Force Method $(100$ gpm, Nozzle Size 10,10,10 assume $\mathrm{m}=1.953)$ 65

D-1 Cost Comparison at Different Standpipe Pressures: $m=1.5$ 66

D-2 Cost Comparison at Different Standpipe Pressures: $m=1.6$ 67

D-3 Cost Comparison at Different Standpipe Pressures: $m=1.7$ 68

D-4 Cost Comparison at Different Standpipe Pressures: $m=1.8$ 69

D-5 Cost Comparison at Different Standpipe Pressures: $m=1.9$ 70

D-6 Cost Comparison at Different Standpipe Pressures: $m=2.0$ 71

D-7 Cost Comparison at Different Standpipe Pressures: $m=2.1$ 72

D-8 Cost Comparison at Different Standpipe Pressures: $m=2.2$ 73

D-9 Cost Comparison at Different Standpipe Pressures: $m=2.3$ 


\section{Acknoledgements}

I would like to thank my major advisor, Dr. Godwin A. Chukwu for his patient guidance and support. Also, I thank Dr. Santanu Khataniar and Dr. Tau Zhu for serving on my committee, giving professional direction and for their warm encouragement.

I would like to thank my wife Karla Wright for her incredible patience and loving support and wisdom. I would also like to thank Hariharan Ramakrishnam and Chinedu Franklyn Akwukwaegbu for their enormous assistance and support during the tenure of my study at the University of Alaska Fairbanks. Chinedu, Hari and myself had many brotherly moments at Sam's Sourdough and I will reflect fondly on those moments as some of the most special times of my life.

Finally, I want to express my gratitude to the Petroleum Engineering Department and the School of Mineral Engineering for the financial assistantship and also to all faculty, colleagues, and friends in UAF for their encouragement and advice. 


\section{Chapter 1}

\section{Introduction}

\subsection{Objectives}

The use of kinetic energy of drilling fluid circulation when drilling a well is important in the subject of drilling hydraulics. Drilling fluid is pumped into the hole using a mud pump, to the drillstring, and discharged through the bit nozzles to the formation. Carrying cuttings from the hole bottom through the annulus, the fluid returns to the surface where the cuttings are discharged passing through the solids removal equipment which are connected in series. The proper use of hydraulic practices can eliminate the problem of inefficient bottomhole cleaning. Figure 1.1 illustrates a visualization of the concept of the hydraulic principle. The essence of a good hydraulic system is to provide adequate hydraulic power to the fluid as it comes into contact with the formation. The bit nozzles provide the force to transport the cuttings to the surface as soon as the bit teeth crater and fracture the rock. The hydraulic action of the nozzles and the design of the bit face direct the cuttings toward junk slots located on the outside diameter of the bit. Both the nozzles and junk slots provide the basic flow pattern required to clean and cool the cutters and reduce the distance cuttings must travel to reach the borehole annulus. Insufficient hydraulic power leads to regrinding of the cuttings in the bottomhole, instead of transporting them to the surface. This hole cleaning deficiency can cause accumulation of cuttings in the bottomhole and consequently impede the rate of penetration. 
Different hydraulic design programs have been presented for controlling the flow of drilling fluid across the profile of the bit. The efforts of this study are to analyze the cost effectiveness of optimizing hydraulics using jet impact force and bit hydraulic horsepower. Optimum hydraulics programs can be designed on the basis of minimum drilling cost and this study looks at how these two hydraulic methods compare with respect to cost. Data required for this type of optimization are fuel and pump maintenance hourly cost.

According to Sutko $^{2}$, both hydraulic horsepower and jet impact force are excellent hole cleaning methods, and the rates of penetration are almost identical using either method. This study will also assume that the rate of penetration is the same for both methods. This allows for a straightforward comparison and determinations of mud pump energy cost and pump maintenance cost for both bit hydraulic conditions.

From conversations with the head engineer at Nabors Drilling, Wayne Rust ${ }^{3}$, the cost of all maintenance and energy are included in the daily rig rate. Because the cost of maintenance and energy are not directly represented in the standard drilling cost equation, the operator of the well may not consider optimizing energy cost and maintenance cost a priority. However, optimizing these cost would be of great interest to the drilling company. By reducing its own cost, the drilling company will be more competitive with its future bids, thus, indirectly reducing the operator's cost. 


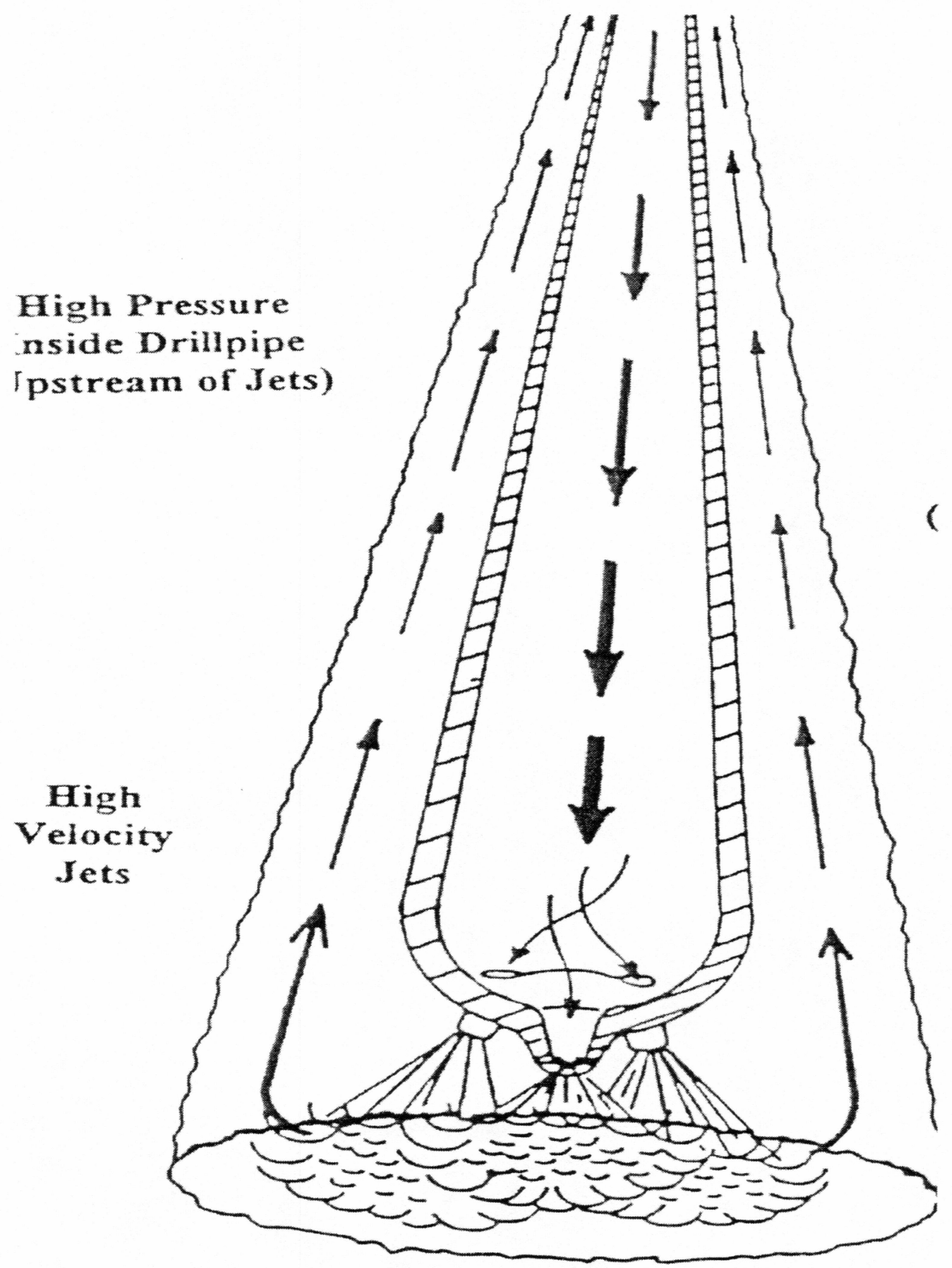

Figure 1.1: The Hydraulic Principle 


\section{Chapter 2}

\section{Literature Review}

This Literature review discusses the earlier efforts by various researchers in the understanding of how nozzle sizes and nozzle adaptations affect drilling objectives and drilling cost. The review also takes a look at the parameters that affect the penetration rate and the efficacy of cutting transportation for hole cleaning.

\subsection{Previous Investigation}

According to Adams ${ }^{4}$, a complete and comprehensive mud plan must be included in the well planning process. From experimental studies done by Belavadi and Chukwu ${ }^{5}$, transportation of cuttings is a mechanism, which is a vital factor for a good drilling program. They concluded that not only is it important to clean the surface of the bit properly, the cuttings must be properly lifted up the annulus to avoid slippage and regrinding both which retard penetration rate. Minimum hole cleaning with out the regrinding of cuttings is essential to maximize penetration rate. Moore ${ }^{6}$ stated that even today many operators do not recognize the importance of bottomhole cleaning. They may use jet bits, but the circulation program is so poorly designed that bottom-hole cleaning is no better than achieved with conventional bits. He further concluded that the ultimate objective is to reduce drilling costs. The most effective means of accomplishing this is through a drilling optimization approach to drilling. Lumnus ${ }^{7}$ reached this same conclusion in his studies of "Drilling Fluids Optimization." Figure 2-1 is a schematic of cuttings transport in a vertical annulus. 
Optimization using roller cone bit hydraulics has been debated for many years. There is still no consensus of opinion on what parameter should be optimized (bit hydraulics or jet impact) to provide maximum rate of penetration. Because Kendal and Goins $^{8}$ felt that as little as 50 percent of the possible effects at the bit are used in most drilling projects, they presented derivations that established criteria for maximizing hydraulic horsepower, and jet impact within constraints imposed on pump horsepower and discharge pressure. Evaluation by hydraulic horsepower is based on the power expended as the fluid flows through the nozzles. The parameter optimized by the impact force method is the force produced by momentum change after the fluid exits the nozzles and reaches the bottom of the hole. Eckel $^{8}$ recommended maximizing Reynolds number function associated with jet velocities based on laboratory results in microbit drilling studies that considered viscosity effects. Bizanti ${ }^{9}$ created a Reynolds Number Criterion system based on some of the same work as $\mathrm{Eckel}^{8}$. Others have suggested maximizing Jet Velocity to achieve optimized hydraulics. Smalling and $\mathrm{Key}^{10}$ concluded that maximum jet impact pressure in the formation explained observed effects of extended nozzles and blanked nozzles and that it is the key parameter in hydraulic optimization.

Many other researchers have suggested optimizing hydraulics by extending nozzles and using blanked nozzles. According to Sutko ${ }^{11}$, present day methods can be made more efficient by lowering cost and by better utilization of the hydraulic energy. He contented that better use of energy is obtained by using two nozzles instead of three. Surface pressure and annular velocity can be reduced without a loss in penetration rate, or, by maintaining current annular velocities and surface pressure, hole cleaning can be increased. Sutko ${ }^{11}$ also stated that jet impact force and hydraulic horsepower are the best 
technique and they can practically achieve the same efficiency in hole cleaning. He also did some work with Myers ${ }^{12}$, which showed improvements in bottom-hole cleaning by using extended nozzles. However, according to Adams ${ }^{4}$, the extra cost of the custom machine work required on the bit, and because the extended nozzles tend to break-off in field operations, extended nozzles may be unjustifiable.

Most proposed optimization criteria consider pump-operating conditions to be fixed. That is, they seek to maximize rate of penetration within prescribed constraints on flow rate, and pump horsepower. Studies performed by Doiron and Deane ${ }^{1}$ showed that hydraulic horsepower and jet impact force have values within 92 percent of their maximum values when either parameter is maximized. This is one reason why it has been difficult to prove the superiority of either condition or the closely related conditions of maximum cross flow velocity or impact pressure in field or laboratory drilling tests. In practice, any of these optimization criteria can be expected to give good results. However, any of these criteria can result in poor bit hydraulics when effects of the pump operating constraints are ignored.

Even though many papers have been written on the merits of different hydraulic optimization techniques, very little has been published about the economic impacts of optimizing these different hydraulic systems. Mitska and Skalle ${ }^{13}$ considered the effects of pump constraints and suggested conditions for maximizing effective rate of penetration by including lost drilling time due to pump failures at higher discharge pressures. However, drilling cost was not considered in their analysis. Doiron and Deane $^{1}$ evaluated the work of Mitska and Skalle ${ }^{13}$ on drilling economics. They concluded 
that modest increase in standpipe pressure could result in large percentage increases in hydraulic horsepower, which results to improvement in rate of penetration.

\subsection{Selection of Study Parameters}

The objective of this work is to analyze and compare the economics of using the Hydraulic Horsepower method and the Jet Impact Force for optimizing hydraulics for hole cleaning. From the determination of optimum bit nozzle sizes for efficient borehole cleaning for both Hydraulic Horsepower and Jet Impact Force, the cost for each optimum method was determined, analyzed and the results were used for comparative study of the two methods. 


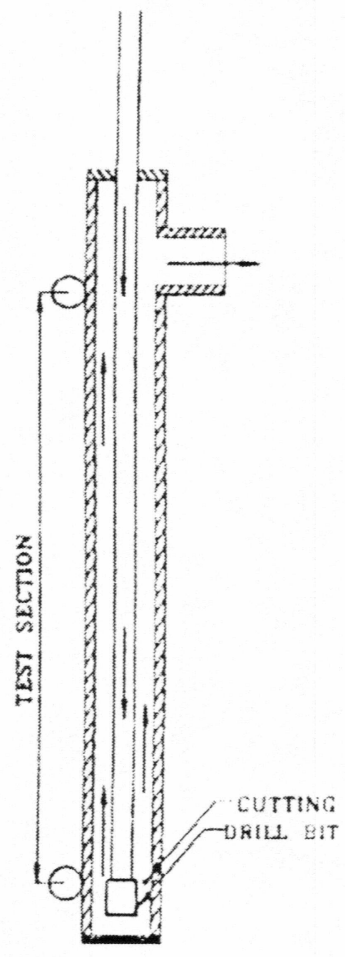

A. HIOW DIRECTION

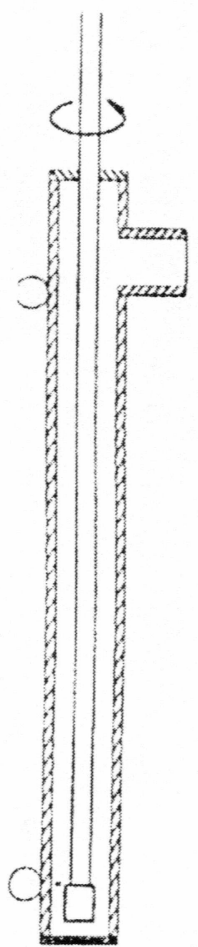

2. DEGIN OUSEHYATION

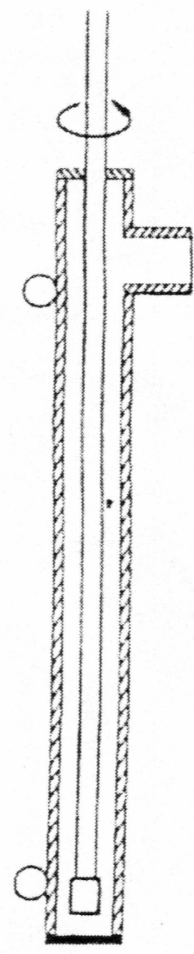

NUTTING BEING THANSPORTED

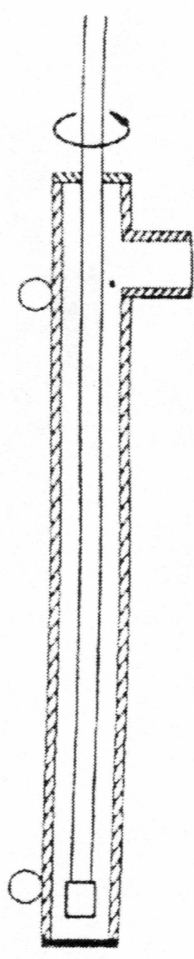

D. END OBSERVATION

Figure 2.1: Cuttings Transport in Vertical Annulus 


\section{Chapter 3}

\section{The Theory of Drilling Hydraulics}

Drilling hydraulics is a subject associated with the kinetic energy of fluid circulation when drilling a borehole. In drilling operations, drilling fluid is initially discharged from the mud pump, passes through surface connection, enters the drillstring, and discharges into the bottomhole via the bit nozzles. The fluid returns to the surface carrying cuttings from the bottomhole via the annulus. Figure 3.1 shows the schematic of the bit nozzle. Bit hydraulics is related to the effects of number and sizes of the nozzles, and the jet velocity of drilling fluid passing through the bit nozzles, and the pressure loss across these bit nozzles.

\subsection{Determination of a Particle Reynolds Number:}

Particle Reynolds number is a dimensionless group used to determine the fluids flow regime or profile. The equation used to determine the particle Reynolds number as a function of slip velocity of the solid, which is given by equation 3.1.

$$
N_{\mathrm{re}}=\frac{15.47 \rho V_{s o} d_{s}}{\mu_{a}}
$$

Where, 


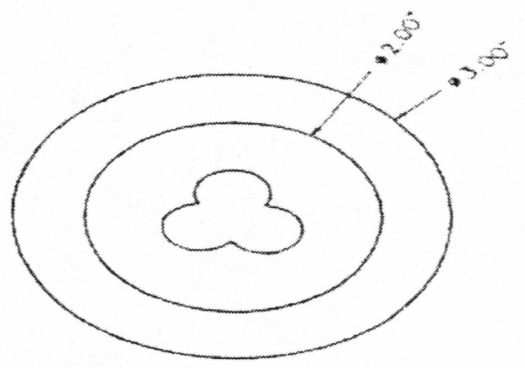

TOP VIEW
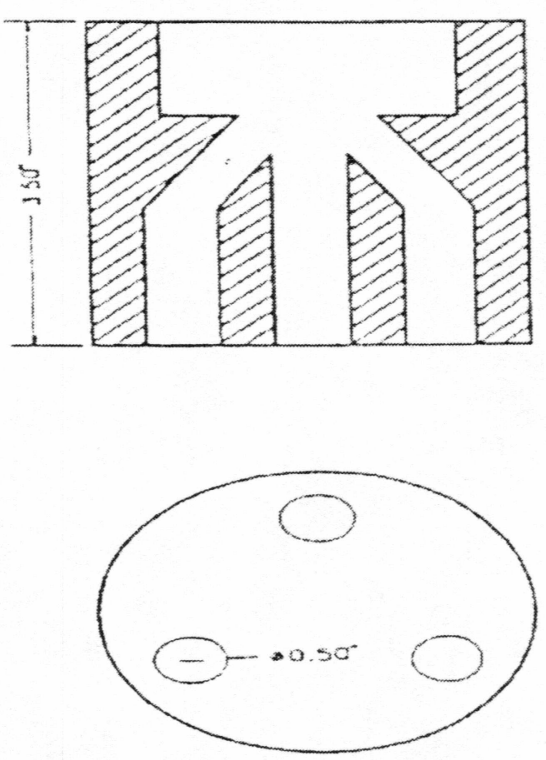

BOTTOM VIEW

Figure 3.1: Schematic of the Bit Nozzle 


$$
\mu_{a}=\left[\left(\frac{2.4 V_{a}}{D i-d_{o}}\right)\left(2 n+\left(\frac{1}{3 n}\right)\right)\right]^{n}\left[\frac{200 K\left(D i-d_{o}\right)}{V_{a}}\right]
$$

and,

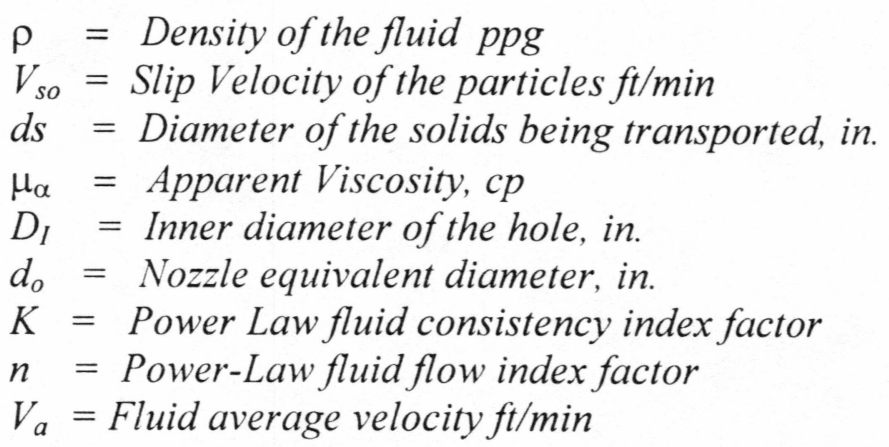

\subsection{Effects of Drag Coefficient}

Drag coefficient is a measure of the magnitude of frictional forces acting on the moving solid in a liquid medium. Empirical equations had been used to compute the drag coefficient as a function of particle Reynolds number.

$$
\begin{array}{ccrl}
C_{d}=1.5 & \text { for } & N_{r e}>300 \\
C_{d}=22 /\left(N_{r e}\right)^{0.5} & \text { for } & 3<N_{r e}<300 \\
C_{d}=40 /\left(N_{r e}\right)^{0.5} & \text { for } & N_{r e}>3
\end{array}
$$




\subsection{System Pressure Losses in a Circulating System}

The pressure losses in the entire circulating system can be obtained as:

$$
P=\Delta P_{s y c}=\Delta P_{s c}+\Delta P_{d p i n}+\Delta P_{d c i n}+\Delta P_{d p a}+\Delta P_{d c a}+\Delta P_{b}
$$

The system pressure loss is therefore made up of the pressure loss across the bit $\left(\Delta \mathrm{P}_{\mathrm{b}}\right)$, and the parasitic or circulating pressure loss $\left(\left(\Delta P_{c}\right)\right.$, that is,

$$
P=\Delta P_{s y c}=\Delta P_{c}+\Delta P_{b}
$$

Where,

$$
\Delta P_{c}=\Delta P_{d p i n}+\Delta P_{d c i n}+\Delta P_{d p a}+\Delta P_{d c a}+\Delta P_{\text {surface }}
$$

\subsubsection{Pressure losses at the Bit}

The pressure drop across the bit has a number of practical applications, which include:

1. Enabling the engineer to select nozzle sizes to optimize the hydraulic horsepower or impact force at the bit. This improves cuttings removal and bottomhole cleaning.

2. Providing a means of comparing observed standpipe pressure with the total circulated pressure drop. This enables the pump volumetric efficiency to be estimated. A drop in volumetric efficiency usually gives an early warning of pump failure. 


\subsection{Bit Hydraulics Optimization}

\subsubsection{Optimum Hydraulic Horsepower(HHP)}

The hydraulic horsepower at the bit can be determined from the relationship given in equation 3.9 .

$$
H H P=\frac{\Delta P_{b} Q}{1714}
$$

The expression of HHP in terms of pump pressure and circulating pressure loss can be obtained from equation 3.10.

$$
H H P=\frac{Q\left(P_{p}-\Delta P_{c}\right)}{1714}
$$

Although, the circulating pressure losses are directly proportional to the flowrate of drilling fluid, the relationship may not be linear, and therefore the relationship can be expressed as:

$$
\Delta P_{c}=k Q^{m}
$$

Due to difference in wellbore geometry, the relationship above can be expressed:

$$
\Delta P_{c}=K^{\prime} Q^{m}
$$

where $\mathrm{m}$ is the flow exponent constant, and $\mathrm{K}^{\prime}$ is a constant representing mud properties and wellbore geometry. 
Substituting equation 3.12 for $\Delta \mathrm{P}_{\mathrm{c}}$ into equation 3.10 , the relationship of equation 3.13 is obtained.

$$
H H P=\frac{P_{p} Q-K^{\prime} Q^{m+1}}{1714}
$$

which can be expressed as:

$$
H H P=\left(\frac{1}{1714}\right)\left[P_{p} Q-K^{\prime} Q Q^{m}\right]
$$

The flowrate at which the bit horsepower is maximized is obtained by differentiating equation 3.14 with respect to flowrate, as follows:

$$
\frac{\partial(h h p)}{\partial Q}=\left(\frac{1}{1714}\right)\left[P_{p}-(m+1) K^{\prime} Q^{m}\right]=0
$$

Rearranging equation 3.15 , the relationship of pump pressure and circulating pressure loss can be expressed as:

$$
P_{p}=(m+1) K^{\prime} Q^{m}=(m+1) \Delta P_{c}
$$

or,

$$
\frac{\partial(h h p)}{\partial Q}=0 \quad \text { when } P_{p}=(m+1) \Delta P_{c}
$$

Therefore at optimum pump pressure, the optimum circulating pressure losses $\left.\Delta P_{c}\right)_{\text {opt }}$ can be expressed as:

$$
\Delta P_{c(o p t)}=\left(\frac{1}{m+1}\right) P_{p}
$$


And the optimum pressure drop across the bit can be expressed ass:

$$
\Delta P_{b(o p t)}=P_{p}-\Delta P_{c(o p t)}=\left(\frac{m}{m+1}\right) P_{p}
$$

The optimum flowrate can then be expressed as:

$$
Q_{(o p t)}=\left(\frac{\Delta p_{c(o p t)}}{K^{\prime}}\right)^{\frac{1}{m}}
$$

The optimum nozzle sizes can be calculated from equation 3.21 as:

$$
d_{(o p t)}=\left[\frac{17.3 \rho Q_{(o p t)}^{2}}{K^{\prime}}\right]^{0.25}
$$

\subsubsection{Optimum Jet Impact Force(JIF)}

The jet impact force indicates the force exerted on the formation through the jet nozzle. The impact force developed by the bit can be expressed as:

$$
F_{j}=0.01823 C_{d} Q\left(\rho \Delta P_{b}\right)^{0.5}
$$

The JIF is related to the fluid flowrate and nozzle velocity by:

$$
F_{j}=\frac{\rho Q V_{n}}{60 g}=\frac{\rho Q V_{n}}{1932}
$$

But,

$$
\Delta P_{b}=\frac{\rho V^{2} n}{1120}
$$

Where the nozzle velocity can be determined from: 


$$
V_{n}=\left(\frac{1120 \Delta P_{h}}{\rho}\right)^{0.5}
$$

Substituting equation 3.24 and 3.25 into equation 3.23 ,

$$
F_{j}=\frac{\rho Q K_{1} \Delta P_{b}^{0.5}}{60 g}=K_{2}\left[Q^{2}\left(P_{p}-K^{\prime} Q^{m}\right)\right]^{0.5}
$$

where,

$$
K_{2}=\frac{\rho K_{1}}{60 g} \text { and } K_{1}=\sqrt{\frac{1120}{\rho_{m}}}
$$

The flowrate at which JIF is maximized is obtained by differentiating equation 3.27 with respect to flowrate, as follows:

$$
\frac{\partial F_{j}}{\partial Q}=K_{2}\left[Q\left(P_{p}-K^{\prime} Q^{m}\right)\right]^{0.5}=0
$$

That is,

$$
2 Q P_{p}-(m+2) K Q^{m+1}=0
$$

or,

$$
2 Q P_{p}=(m+2) K^{\prime} Q^{m+1}
$$

Which can be simplified to obtain:

$$
P_{p}=\left(\frac{m+2}{2}\right) \Delta P_{c(o p t)}
$$


The optimum circulating pressure loss can then be obtained as:

$$
\Delta P_{c(o p t)}==\left(\frac{2}{m+2}\right) P_{p}
$$

Similarly, the optimum pressure loss across the bit can be obtained from:

$$
\begin{aligned}
& \Delta P_{b(\text { opt })}=P_{p}-\Delta P_{c(o p t)} \\
& \Delta P_{b(\text { opt })}=P_{p}-\left(\frac{2}{m+2}\right) P_{p} \\
& \Delta P_{b(\text { opt })}=\left(\frac{m}{m+2}\right) P_{p}
\end{aligned}
$$

The optimum flowrate can then be expressed as:

$$
Q_{(o p t)}=\left(\frac{\Delta P_{c(o p t)}}{K^{\prime}}\right)^{\frac{1}{m}}
$$

The optimum nozzle sizes can be obtained from the following equation: 


$$
d_{(o p t)}=\left(\frac{17.3 \rho Q^{2}{ }_{(o p t)}}{K^{\prime}}\right)^{0.25}
$$

The specification of common nozzle sizes and their equivalent diameters are listed in appendix table A.1. 


\section{Chapter 4}

\section{Hydraulics Analysis in Rotary Drilling}

\subsection{Effects of Pressure Ratio and The Flow Exponent m}

The determination of pressure losses in the circulating system has been an objective of technology for almost as many years as rotary drilling has been in existence. The first dedicated efforts to determine the pressure losses in fluid circulating systems developed when drilling hydraulics was introduced in 1948. A schematic diagram of the drilling fluid circulating system is shown in Figure 4.1. The total pressure loss in the entire circulating system is recorded on the surface pressure gauge. The summation of these pressures was presented in Equation 3.6.

$$
\Delta \mathrm{P}_{\mathrm{s}}=\Delta \text { Ps.c. }+\Delta \mathrm{P}_{\mathrm{dp}}+\Delta \mathrm{P}_{\mathrm{dc}}+\Delta \mathrm{P}_{\mathrm{b}}+\Delta \mathrm{P}_{\mathrm{dca}}+\Delta \mathrm{P}_{\mathrm{dpa}}
$$

During drilling operations, an increase in hole depth will affect the pressure losses in both the drillstring and the wellbore annulus. To maintain the designed 


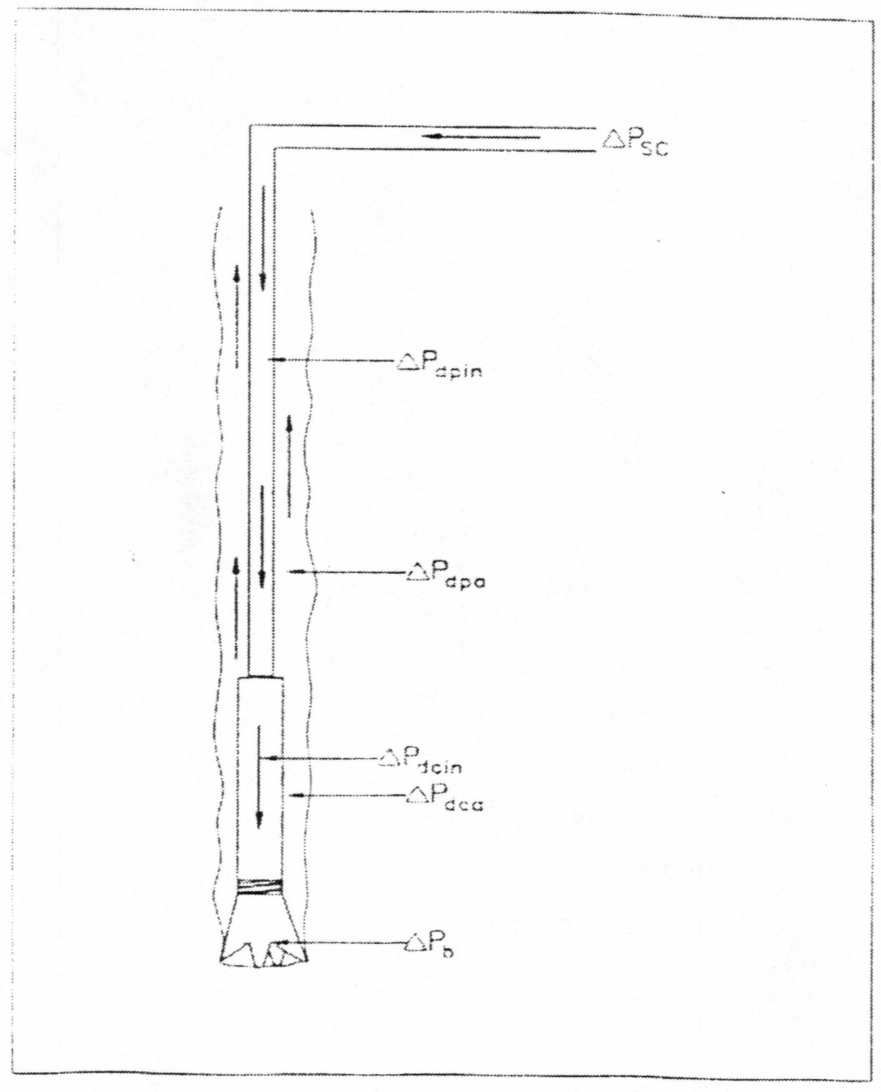

Figure 4.1: Vertical Borehole Circulating System 
optimized drilling program, an increase in well depth will not change the pressure drop across the bit, however, it can greatly alter the circulation pressure loss of the system. There is a circulating pressure loss as depth increases. From the ratio of the pressure drop across the bit to the circulating pressure loss $\Delta \mathrm{P}_{\mathrm{b}} / \Delta \mathrm{P}_{\mathrm{c}}$, the optimum flowrate and optimum nozzle diameter can be calculated.

As discussed in Chapter 3, pressure loss relates to circulation rate as shown in Equation 4.2 and 4.3 .

$$
\mathrm{P}_{\mathrm{C}}=\mathrm{KQ}^{\mathrm{m}}
$$

and,

$$
P_{b}=K^{\prime} Q^{2} / A_{N}^{2}
$$

In equation 4.2 , the exponent $\mathrm{m}$ is known as the flow exponent. A common assumption in the oil field is that the flow exponent, $\mathrm{m}$, is 1.8. However, the following equation from chapter 3 shows that it can be calculated by using data from the previous bit run.

$$
\mathrm{m}=\log \left(\mathrm{P}_{\mathrm{c}} / \mathrm{P}_{\mathrm{b}}\right) / \log \left(\mathrm{Q}_{1} / \mathrm{Q}_{2}\right)
$$

Using equations that were presented in chapter 3 tables B-1 through B-5 were tabulated for pressure ratio vs. optimum diameter. Graphical representations are also shown in figures 4.1 through 4.5. At different values of $\mathrm{m}$, the ratio of pressure loss across the bit to the circulating pressure drop was calculated. The tables also present 
values of $\Delta \mathrm{P}(\mathrm{opt}), \Delta \mathrm{P}_{\mathrm{C}}$ (opt), $\mathrm{Q}(\mathrm{opt}), \mathrm{d}(\mathrm{opt})$ for both the Hydraulic Horsepower and Jet Impact Force. Data in tables B-1 through B-5 were obtained using the assumed flow exponent value $(\mathrm{m})$ of 1.8 . The calculated flow exponent from table $4.1\left(\mathrm{Lim}^{14}\right)$ also give the pressure losses across the bit and the flow exponent $\mathrm{m}$ for different nozzle combinations.

Figure 4.2 shows that the original nozzle sizes of $10,10,10$ are the optimum sizes to be used under Hydraulic Horsepower method at a pressure ratio of 1.8 and Jet Impact Force method at a pressure ratio of 0.9 . The figure also shows a comparison of the Hydraulic Horsepower and Jet Impact Force methods at an assumed "m" value of 1.8. Figure 4.3 is a comparison of the oil field assumption of $\mathrm{m}=1.8$ and calculated $\mathrm{m}=1.953$. Figure 4.4 is the comparison of the assumed value of $\mathrm{m}$ to the calculated value of $\mathrm{m}$ under Jet Impact Force method. These two graphs show that the results of using an assumed value of $m$ is in close agreement with the calculated value of $m$, even though the value of the calculated $\mathrm{m}$ is much more reliable.

Figure 4.5 shows the relationship of the optimum nozzle sizes $d(o p t)$ to the pressure ratio under the Hydraulic Horsepower method. Figure 4.6 shows the relationship of the optimum nozzle sizes d(opt) to the pressure ratio under the Jet Impact Force method. The three graphs indicate that as the pressure ratio increases, larger bit nozzles using hydraulic horsepower are needed. 


\begin{tabular}{|c|c|c|}
\hline $\begin{array}{l}\text { Nozzle } \\
\text { Size }\end{array}$ & $\begin{array}{l}\text { Pressure Drop } \\
\text { at Bit }\end{array}$ & $\begin{array}{c}\text { Flow } \\
\text { Exponent } \mathrm{m}\end{array}$ \\
\hline $11,11,11$ & 0.846 & 1.949 \\
\hline $10,10.10$ & 1.451 & 1.953 \\
\hline $9,10,10$ & 1.653 & $1.95 \overline{9}$ \\
\hline $9,9,10$ & 1.902 & 1.964 \\
\hline$\overline{9}, \overline{9}, \overline{9}$ & 2.211 & 1.969 \\
\hline $8,9,9$ & 2.556 & 1.973 \\
\hline $8,8,9$ & 2.989 & 1.977 \\
\hline $8,8,8$ & 3.542 & $1.981^{-}$ \\
\hline
\end{tabular}

Table 4.1: Flow Exponent Values for Several Bit Nozzle Combinations for HHP 


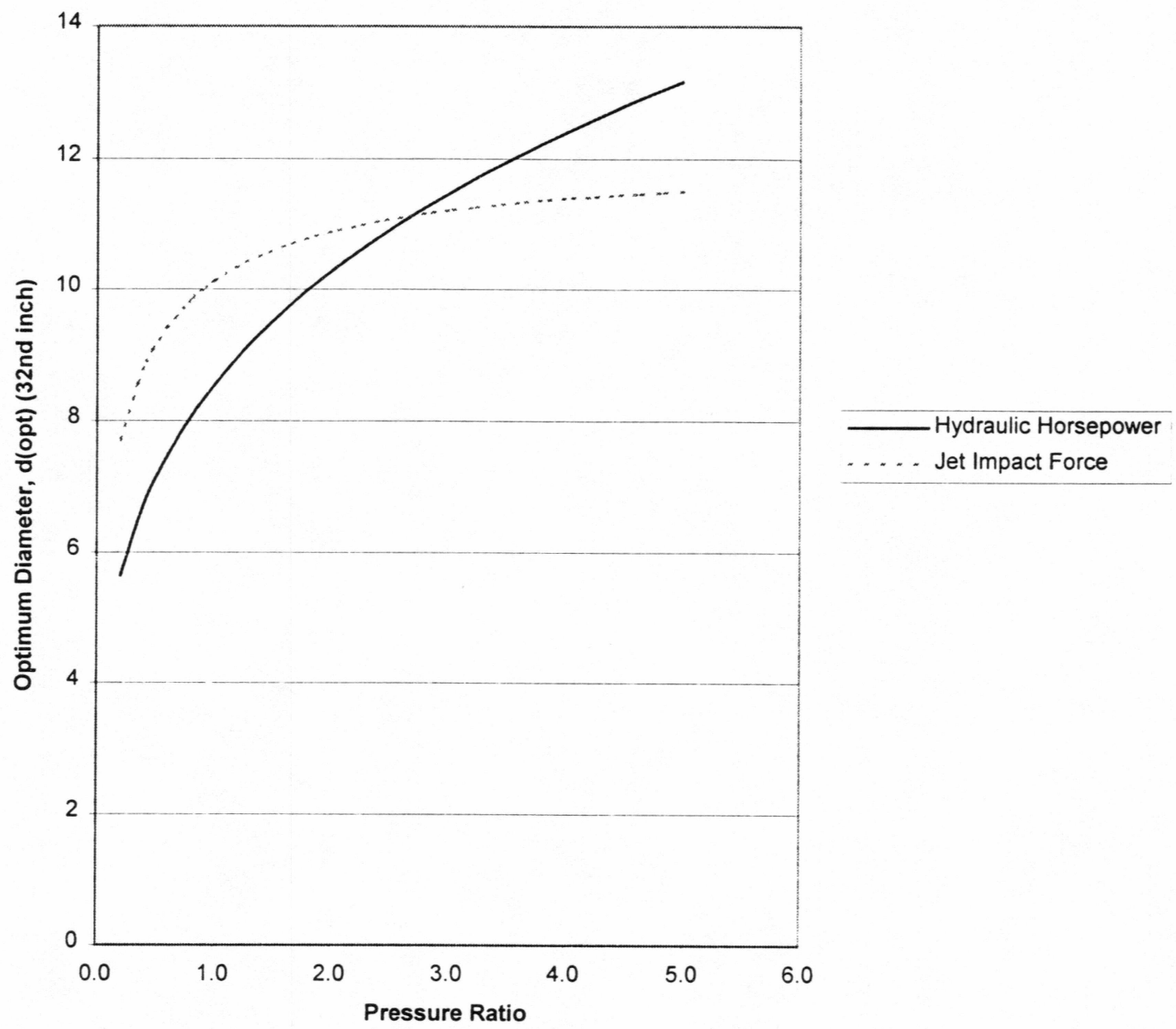

Figure 4.2: Plot of Pressure Ratio vs. Optimum Diameter for HHP and JIF 


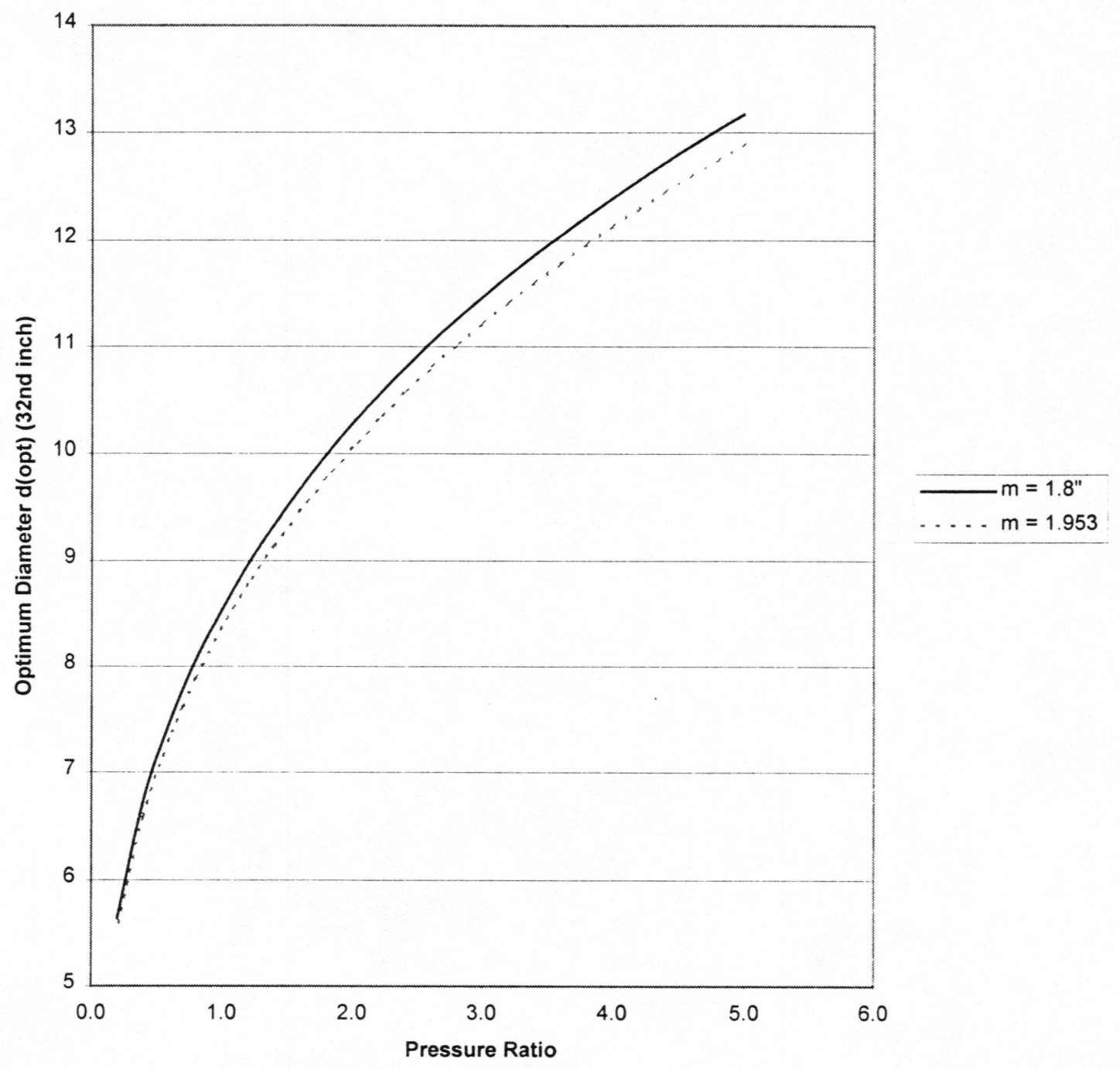

Figure 4.3: Plot of Pressure Ratio vs. Optimum Diameter under Assumed and Calculated Flow Exponent m, for HHP 


\subsection{Analysis of Extended Nozzles on Rate of Penetration}

The concept of extending the nozzles in three cone bits is an old practice. However, the practice is still experimental. Laboratory results by Sutko and Myers ${ }^{2}$ shows that improvements in bottom-hole cleaning have resulted from extended nozzles. Field tests have confirmed the laboratory results. However, it is difficult to prevent the breakage of extended nozzles in field operations; and because of the custom work necessary to create extended nozzles, these nozzles are more expensive.

The economic feasibility of extended nozzles will have to be determined in field operation. However, many investigators conclude that extended nozzles are not feasible. Extended nozzles will increase bottom-hole cleaning and this advantage will have to offset occasional extended nozzle breakage and high bit cost.

\subsection{Analysis of Blanked-Off Nozzles on Rate of Penetration}

Using one blank nozzle is a common industry practice. The practice was started to prevent the need for very small jets in some hydraulic programs. For example, two 3/8-inch jets are about equal to three $5 / 16$-inch jets and in many cases might be preferable because of the potential plugging of the smaller jets. The question arises whether bottomhole cleaning will be affected by using two instead of three nozzles.

A study by Sutko and Myers ${ }^{2}$ indicated that bottom-hole cleaning would be improved at constant power levels by reducing the number of nozzles. Field work by Sutko and Myers $^{2}$ has shown improvements in drilling rates, at constant power levels, when using two instead of three bit nozzles. They noted that there have been reports of 
overheating in bearings using only one jet and some isolated reports of the same problem using two jets.

In general, there seems to be no disadvantage of using two instead of three nozzles in three cone bits. The largest advantage of using two bit nozzles appears to be a reduction in the danger of plugging when compared to the same area divided among three nozzles.

\subsection{Analysis of Hole Size Ratio on Drilling Hydraulics}

It was shown in section 4.1 of this chapter that the ratio of the circulating pressure loses to the pressure losses across the bit is a key factor that determines the optimum drilling hydraulic parameter. The effect of annular clearance in drilling hydraulics is very important.

Circulating pressure losses in a system depend on the hole and drillstring geometry. Commonly, in an ideal circulating system, the flow regimes inside the drill pipe and drill collar are most often turbulent, and the flow regimes in the annular area are most likely laminar. The flow regime in the drillstring allows sufficient kinetic energy from the pump to be delivered to the bit nozzles, and the laminar flow in the annulus is to transport the cuttings back to the surface.

A hypothetical oil field condition is adopted to aid in computation for analyzing the ratio of the drill pipe to the hole size, often known as the hole size ratio $(\alpha)$ and defined by equation 4.5 : 


$$
\alpha=d_{0} / D_{I}
$$

Table 4.2 shows the computed results of pressure ratio at different hole size ratios which is plotted and shown in figure 4.4. The figure shows that for different nozzle sizes, as the hole size ratio decreases, the pressure ratio also decreases. From the results shown in section 4.1, at optimum hydraulic conditions, the pressure ratio of Hydraulic Horsepower method is 1.8 and that of the Jet Impact Force method is 0.9. Figure 4.5 shows that the smaller hole size ratio approaches the optimized hydraulic condition wherein the pressure ratio approach both 1.8 and 0.9 for Hydraulic Horsepower and Jet Impact Force, respectively. Figure 4.4 provides additional information that when a specific bit nozzle is in use, employing the suitable diameter sizes of drill pipe can assist in hydraulic optimization. The smaller hole size ratio favors optimization of drilling hydraulics. 


\begin{tabular}{|c|r|r|r|r|r|r|}
\hline Nozzle Size & $12,12,12$ & $12,12,13$ & $13,13,13$ & $14,14,14$ & $14,15,15$ & $15,15,16$ \\
\hline $\begin{array}{c}\text { Hole Size } \\
\text { Ratio } \alpha\end{array}$ & Pressure ratio $\Delta \mathbf{P}_{\mathrm{b}} / \Delta \mathbf{P}_{\mathrm{c}}$ \\
\hline 0.367 & 2.04 & 1.82 & 1.48 & 1.10 & 0.91 & 0.76 \\
\hline 0.408 & 3.03 & 2.70 & 2.20 & 1.63 & 1.35 & 1.13 \\
\hline 0.449 & 4.01 & 3.58 & 2.91 & 2.16 & 1.79 & 1.50 \\
\hline 0.49 & 4.86 & 4.34 & 3.53 & 2.62 & 2.17 & 1.82 \\
\hline 0.531 & 5.51 & 4.92 & 4.00 & 2.92 & 2.46 & 2.06 \\
\hline 0.571 & 5.95 & 5.32 & 4.32 & 3.21 & 2.66 & 2.23 \\
\hline
\end{tabular}

Table 4.2 Hole Size Ratios and Pressure Ratio for HHP 


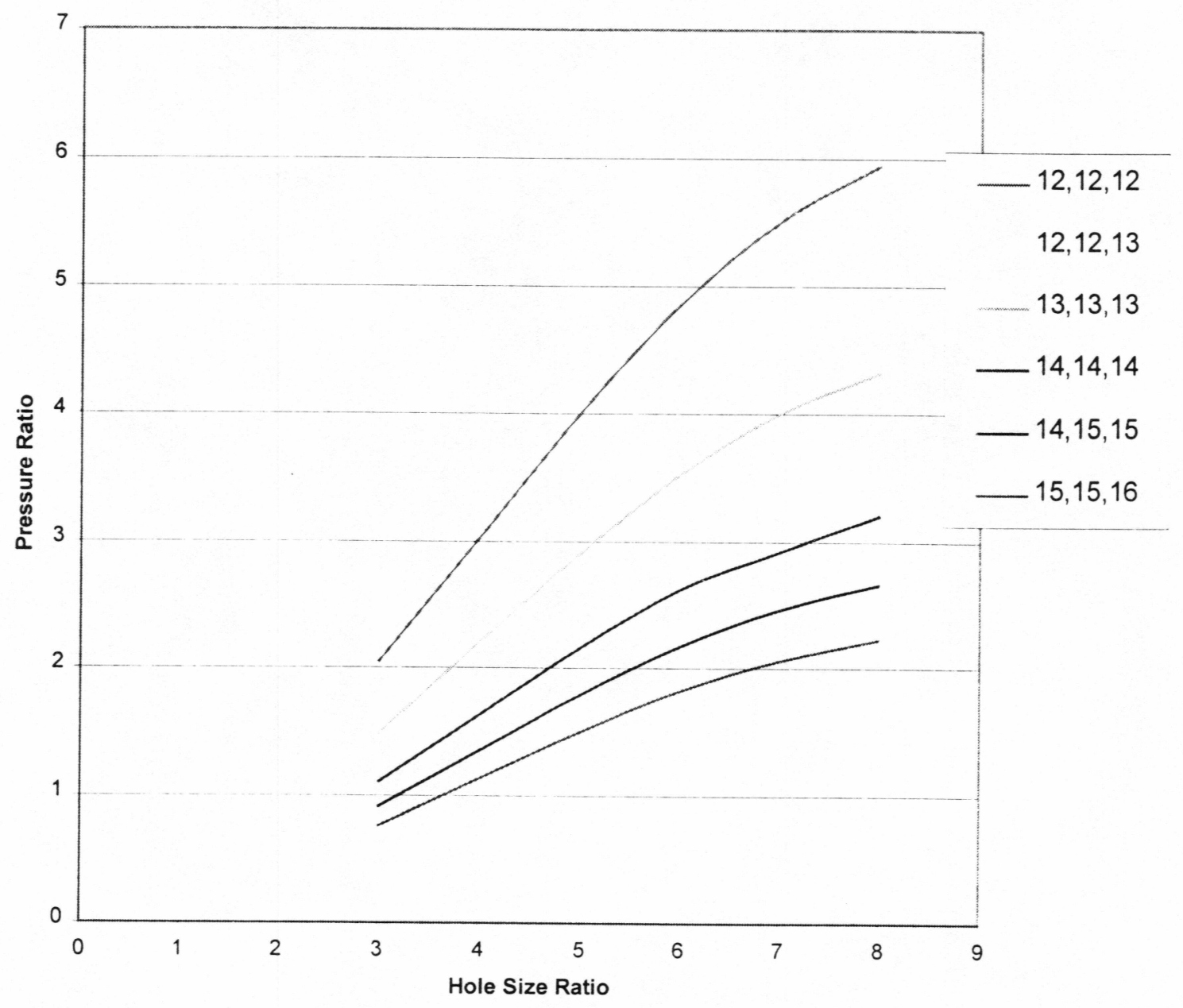

Figure 4.4 Plot of Hole Size Ratio vs. Pressure Ratio for Different Nozzle Sizes using HHP. 


\section{Chapter 5}

\section{Energy and Maintenance Cost Equations for Mud Pump Operation}

\subsection{Minimum Cost Drilling: Drilling Company Perspective}

The purpose of this section is to show that an optimum hydraulics program can be designed on the basis of minimum drilling costs. Data required for this type of optimization are fuel usage and cost as well as pump maintenance cost. In differential equation form, the drilling cost equation is:

$$
\begin{aligned}
& \frac{\partial y}{\partial x}=c(x) \quad \text { where } \mathrm{c}=\text { cost per foot } \\
& \mathrm{y}=\text { cost } \\
& \mathrm{x}=\text { footage }
\end{aligned}
$$

The standard drilling cost equation for determining the cost of drilling a foot of hole is:

$$
C_{T}=\frac{C_{B}+C_{R}(T+t)}{F}
$$

where,

$$
\begin{aligned}
C_{T} & =\text { cost of drilling cost of a foot of hole } \quad S / f t \\
C_{B} & =\text { bit cost }, S \\
C_{R} & =\text { rig cost } S / h r \\
t & =\text { rotating time hrs (hours on bottom with one bit) } \\
T & =\text { round trip time, hrs } \\
F & =\text { Total footage of hole drilled per bit run, } f t
\end{aligned}
$$


According to Rust ${ }^{3}$, the cost of all maintenance and energy are included in the daily rig rate. Because the cost of maintenance and energy are not directly represented in the standard drilling cost equation, the operator of the well may not consider optimizing energy cost and maintenance cost a priority. However, optimizing these cost would be of great interest to the drilling company. By reducing its own cost, the drilling company will be more competitive with its future bids, thus, indirectly optimizing the operator's cost.

\subsection{Cost of Fuel Equation}

According to Nelson ${ }^{15}$, using a typical specific consumption value of diesel engines of $.38 \mathrm{lb} /(\mathrm{hp}-\mathrm{hr}), 80 \%$ power transmission efficiency, and $85 \%$ pump efficiency, an estimate of hydraulic horsepower output cost of about .04 cents per horsepower hour with diesel fuel cost in 1965 of 18 cents/gal. Therefore, fuel cost to provide the pump hydraulic horsepower can be expressed as:

$$
\begin{aligned}
& \qquad D=(H H P) f=0.04 H H P \\
& f=\text { output cost per horsepower hour } \\
& D=\text { Fuel cost per hour } S / h r
\end{aligned}
$$

Equation 5.3 presents a problem in that it contains a constant of (.04) which is based on a cost of 18 cents per gallon and again, it was created 35 year ago. A two-step process can bring the constant to represent today's cost.

1. Determine a yearly rate of increase for the price of fuel over the last 35 years, and

2. Use Present Worth Method to correct the .04 constant. 
First, to determine the yearly rate of increase (interest rate) the future value is normalized to present value using equation 5.4 .

$$
(F / P, i \%, N)=(1+i)^{N}
$$

where, F - Future Worth of Money

P - Present Worth of Money

$\mathrm{N}$ - number of compounding periods

i - effective interest rate per period

(F/P,i\%,N)- Present Worth Factor (PWF)

but,

$$
P W F=(1+i)^{N}
$$

solving for $\mathrm{i}$,

$$
\begin{aligned}
& \ln (P W F)=N \ln (1+i) \\
& \ln (1+i)=\frac{\ln (P W F)}{N} \\
& e^{\ln (1+i)}=e^{\frac{\ln (P W F)}{N}} \\
& i=e^{\frac{\ln (P W F)}{N}}-1
\end{aligned}
$$

Using a current diesel fuel price of $\$ 1.65$ per gallon, the present worth factor can be determined.

$$
P W F=\frac{\text { Future }}{\text { Present }}
$$




$$
P W F=\frac{1.65}{.18}=9.17
$$

solving for i,

$$
i=e^{\frac{\ln (9.17)}{35}}-1=.0654
$$

Over the last 35 years diesel fuel prices have risen almost twice (6.5\%)the annual rate of inflation compared to an average rate of inflation of $3.85 \%$ ( US Census Bureau: Statistical Abstract of the US) ${ }^{16}$.

With the annual rate having been determined, the Present Worth in the fuel cost equation can be obtained from;

$$
\begin{aligned}
& N P W=P\left(\frac{F}{P}, i \%, N\right) \text { Net Present Worth } \\
& N P W=P\{1+i)^{N} \\
& N P W=.04(1.0654)^{35}=.350 \text { cents }
\end{aligned}
$$

The cost of fuel equation becomes;

$$
D=(H H P) f=0.350 H H P
$$




\subsection{Cost of Pump Maintenance Equation}

According to the work of Doiron and Deane ${ }^{1}$, a relationship for pump parts replacement cost as a function of standpipe pressure over a range of 1500 to 3500 psi. is:

$$
P_{p r}=Z\left(\frac{P_{p r}}{P_{s t}}\right)^{p q}
$$

where, $P q=1.52$ Constant

$Z=$ cost per operating hour

$P_{p r}=$ Pump replacement cost

$P_{s t}=1500$ psi minimum standpipe pressure

According to Dorion and Deane ${ }^{1}$, a rough estimate of the average rig pump replacement cost per operating hour is $\$ 5.00 / \mathrm{hr}$. Because this value is from research done in 1980 by Dorion and Deane ${ }^{1}$, a NPW(Net Present Worth) calculation based on inflation over the last 20 years of $3.85 \%$ (US Census Bureau: Statistical Abstract of the US) ${ }^{16}$ needs to be evaluated.

$$
N P W=P(F / P, i \%, N)
$$

where,

$$
\begin{aligned}
& F=\text { Future Worth } \\
& P=\text { Present } \text { Worth } \$ 5.00 \\
& I=\text { Interest } 3.85 \% \\
& N=\text { Number of Periods } 20 \text { years }
\end{aligned}
$$

In equation form, this formula is:

$$
P(F / P, i \%, N)=P(1+i)^{N}
$$

This gives a NPW of:

$$
N P W=5.00(1+0.04)^{20}=\$ 10.96
$$


This cost is based on cost of fluid end expendables only and assumes no additional rig down time for more frequent replacement of expendables. It is assumed that pump maintenance can be conducted during normal down time periods such as waiting on cement time.

Doiron and Deane's ${ }^{1}$ equation can be expressed in terms of Horsepower, as shown below. The pump hydraulic horsepower is expressed as;

$$
\begin{aligned}
& H H P=\frac{P_{p Q}}{1714} \\
& P_{p}=\frac{1714 H H P}{Q}
\end{aligned}
$$

Therefore,

$$
P_{p r}=Z\left(\frac{1714 H H P}{1500 Q}\right)^{p q} \$ / \mathrm{hr}
$$

The total cost equation for maintenance and fuel is:

$$
C_{1}=0.350 H H P+10.96\left(\frac{1.143 H H P}{Q}\right)^{1.52} \$ / \mathrm{hr}
$$

Equation 5.22 can be used to evaluate the total cost for either hydraulic optimization technique as a function of fuel, and pump maintenance cost. 


\section{Chapter 6}

\section{Economic Evaluation}

\subsection{Discussion of The Cost Comparison}

In this section, an example problem is presented and a cost comparison for Jet Impact Force and Hydraulic Horsepower is shown. Using equations that are presented in chapters 4 and 5, a cost comparison between operating the mud pump for maximum optimized jet impact force and hydraulic horsepower is presented. An assumption is made in the example problem that the motor is directly driving the mud pump and that no generator or DC current is being supplied.

\subsection{Example Problem}

Given a well drilled to 11,200 feet with a 12 inch bit that has 3 nozzles of $16 / 32$ inch each. The drill string was made up of 10,600 feet drill pipe, 5-1/2 inch O.D. and 4.35 inch I.D. and drill collars of 600 feet. 10 inch O.D. and 3 inch I.D. The mud used had the following properties:

$$
\mathrm{MW}=11.8 \mathrm{ppg} \text { Pump, Pressure at } 462 \mathrm{gpm}=1800 \mathrm{psi} .
$$

The pump was slowed down and additional pressure measurements were made as follows:

$$
\begin{aligned}
& 300 \text { gpm at } P_{p}=850 \text { psi } \\
& 200 \text { gpm at } P_{p}=430 \text { psi }
\end{aligned}
$$




\section{Solution:}

Assuming the next bit run lasts 8 hours, determine the Mud pump cost for;

(a) Jet Impact Force

(b) Bit Hydraulic Horsepower

From equation 3.21, $\quad \Delta P_{b}=\frac{17.3 \rho q^{2}}{d_{c v}{ }^{4}}$

At 462 gpm

$$
\Delta P_{b}=\frac{17.3(11.8)\left((462)^{2}\right.}{16^{4}}=665 p s i
$$

At $300 \mathrm{gpm}$

$$
\Delta P_{2}=280 \text { psi using equation } 3.21
$$

At 200 gpm

$$
\Delta P_{3}=125 \text { psi using equation } 3.21
$$

Where $\Delta P_{2}$ and $\Delta P_{3}$ are the change in bit pressure at 300 and $200 \mathrm{gpm}$, respectiviely.

and,

$$
\begin{aligned}
& \Delta P_{c 1}=1800-665=1135 p s i \\
& \Delta P_{c 2}=850-280=570 p s i \\
& \Delta P_{c 3}=430-125=305 p s i
\end{aligned}
$$

The value of $m$ is obtained as:

$$
m=\frac{\log 1135-\log 570}{\log 462-\log 300}=1.59
$$

\section{Jet Impact force:}

From equation:

$$
\Delta P_{c}=\frac{2}{m+2} P_{p}=\left(\frac{2}{3.59}\right) 1800=1003 p s i
$$




$$
\begin{aligned}
& \Delta P_{\text {bopt }}=1800-1003=797 \mathrm{psi} \\
& q_{\text {opt }}=\left(\frac{P_{o p t}}{P_{s}}\right)^{1 / 2} q=427 \mathrm{gpm}
\end{aligned}
$$

\section{Hydraulic Horsepower:}

From equation:

$$
\begin{aligned}
& \Delta P_{\text {copt }}=\frac{1}{m+1} P_{p}=\left(\frac{1}{2.59}\right) 1800=695 \mathrm{psi} \\
& \Delta P_{\text {bopt }}=1800-1003=797 \mathrm{psi} \\
& q_{\text {opt }}=\left(\frac{P_{\text {opt }}}{P_{s}}\right)^{1 / 2} q=427 \mathrm{gpm}
\end{aligned}
$$

Recalling equation 3.9;

$$
\mathrm{HHP}=\left(\mathrm{q}_{\text {opt }}\right)\left(\Delta \mathrm{P}_{\text {bopt }}\right) / 1714
$$

Substituting the values of $\mathrm{q}_{\text {opt }}$ and $\Delta \mathrm{P}_{\text {bopt, }}$ data of table 6.1 are obtained. 


\section{Cost Comparison between JIF and HHP:}

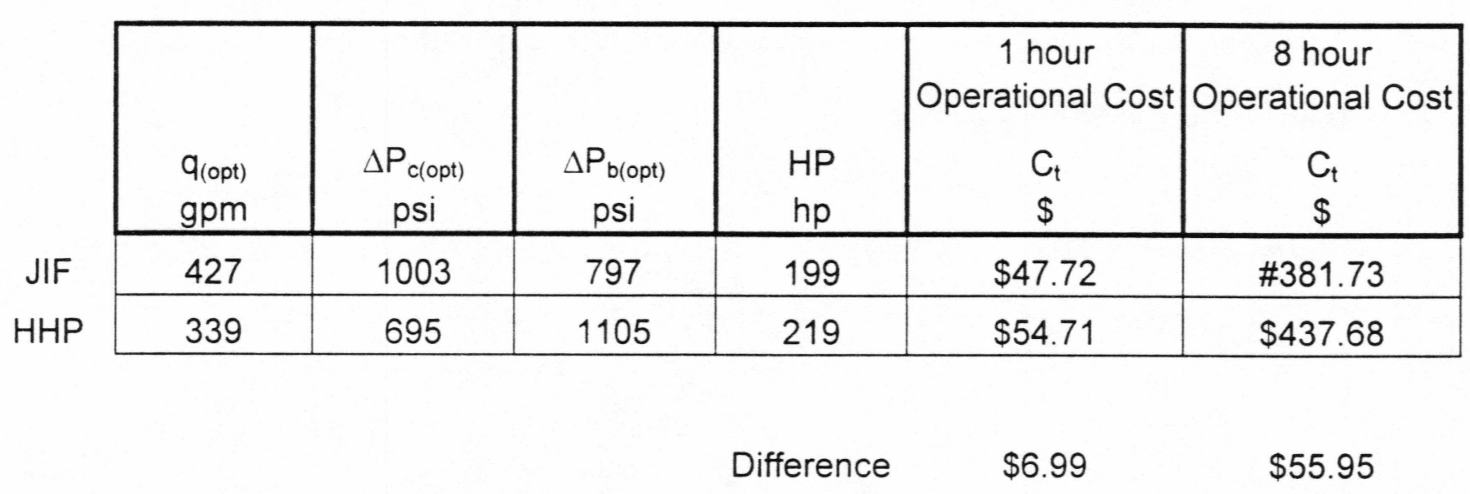

Table 6.1: Calculated Operating Cost for HHP and JIF.

The total costs was calculated using equation 5.22.

$$
C_{t}=0.350 H H P+10.96\left(\frac{1.143 H H P}{Q}\right)^{1.52} \$ / \mathrm{hr}
$$

To find the cost for one hour of operation optimizing for JIF, the following shows result using equation 5.22:

$$
C_{1}=0.350 \times 199+10.96\left(\frac{1.143 \times 199}{427}\right)^{1.52}=\$ 47.72
$$

This table is based on a fuel cost of $\$ 1.65$ per gallon. If it is assumed that the value of $\mathrm{m}$ does not change, the effect of increasing the standpipe pressure and how it 
changes the comparison between the two different methods can be noticed. Table 6.1 shows how the change in standpipe pressure affects several different variables, and ultimately, the cost comparison. Figure 6.1 gives a graphical representation of the data.

Figures 6.2 through 6.8 show the effect of change in $m$ and standpipe pressure values and how they relate to costs of optimization using hydraulic horsepower and jet impact force. Tabular data similar to figures 6.2 through 6.8 are shown in tables D2 through D8 of the appendix.

It is quite noticeable that the difference in cost between JIF and HHP widens as the standpipe pressure requirement increase. At higher pressures, the HHP method costs rise at steeper rate than do the costs for JIF. This is of great interest in coiled tubing drilling. In coiled tubing drilling, standpipe pressure rarely drops below 3000 psi. Also, the small working space mandates the smallest available generators and/or engine. The greater flow rate requirements may have an impact on mud pump size and drive requirements. 
$\$ 180.00$

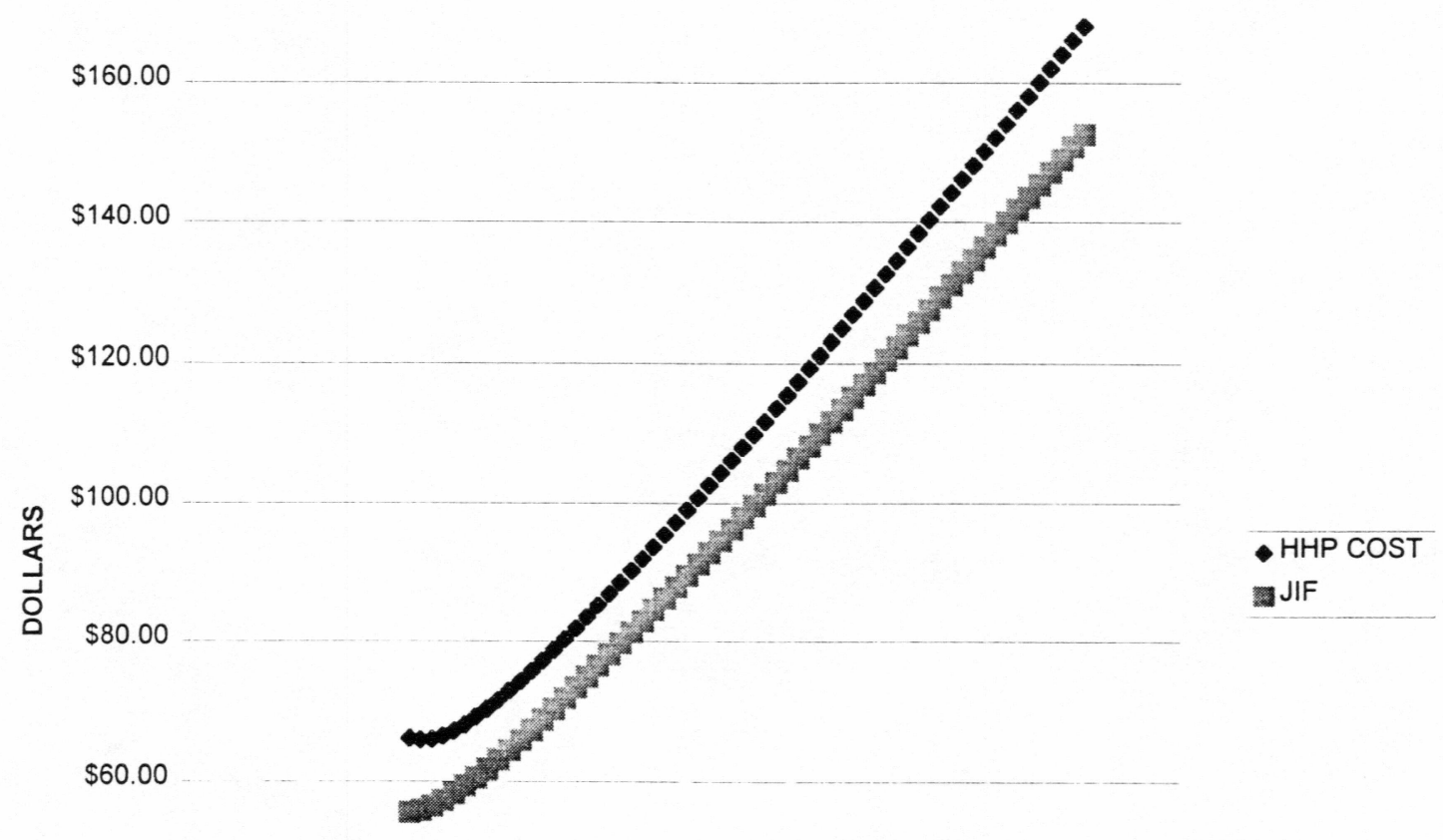

$\$ 40.00$

$\$ 20.00$

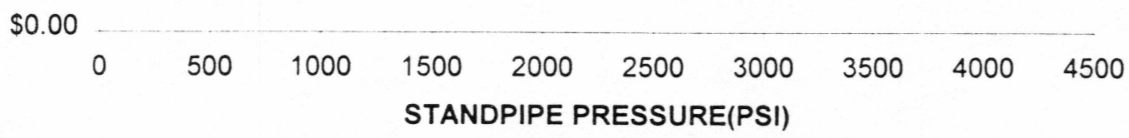

Figure 6.1: Plot of JIF vs. HHP for $\mathrm{m}=1.59$ 
$\$ 180.00$

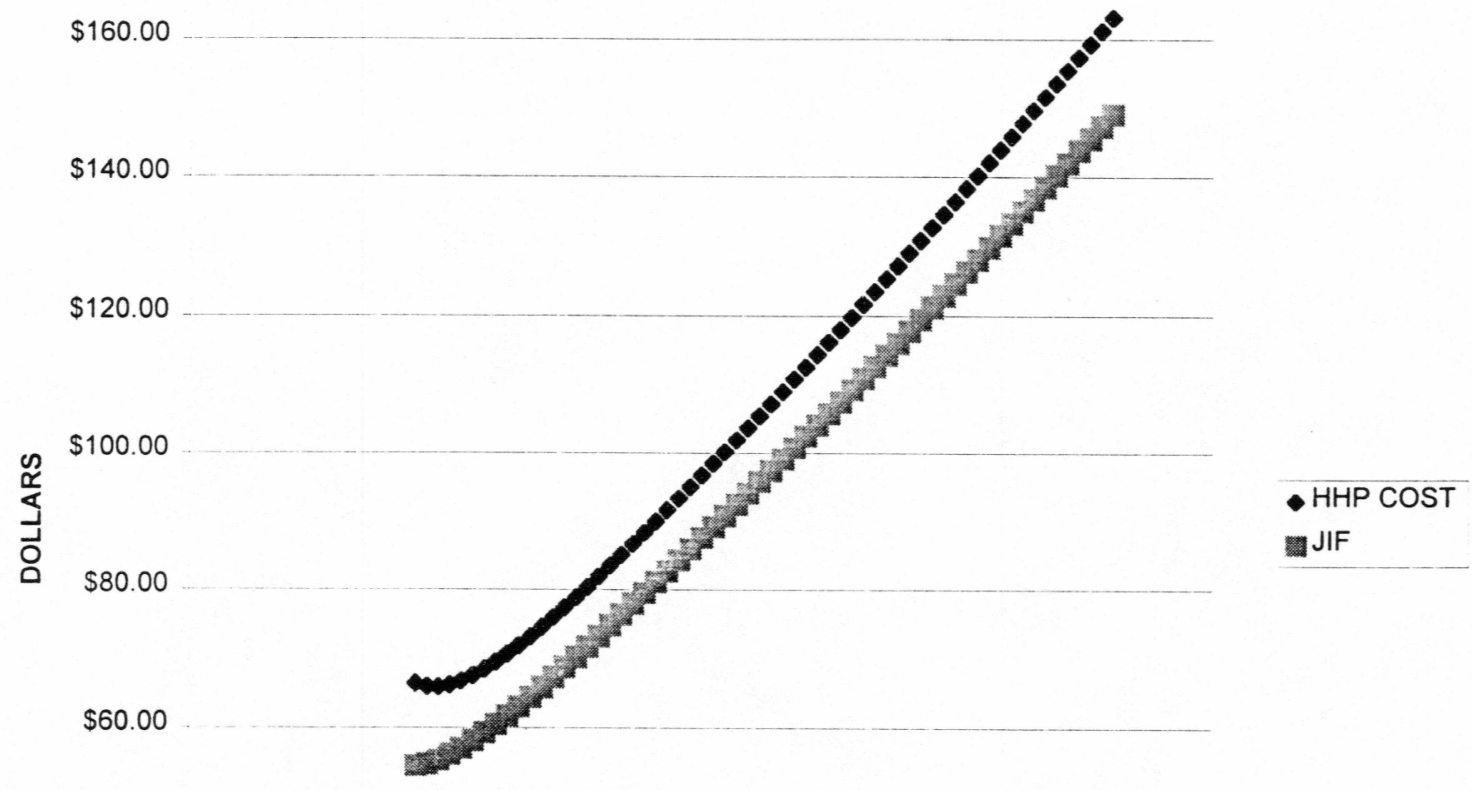

$\$ 40.00$

$\$ 20.00$

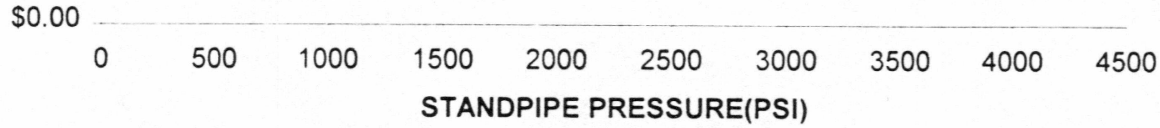

Figure 6.2: Plot of JIF vs. HHP $m=1.50$ 


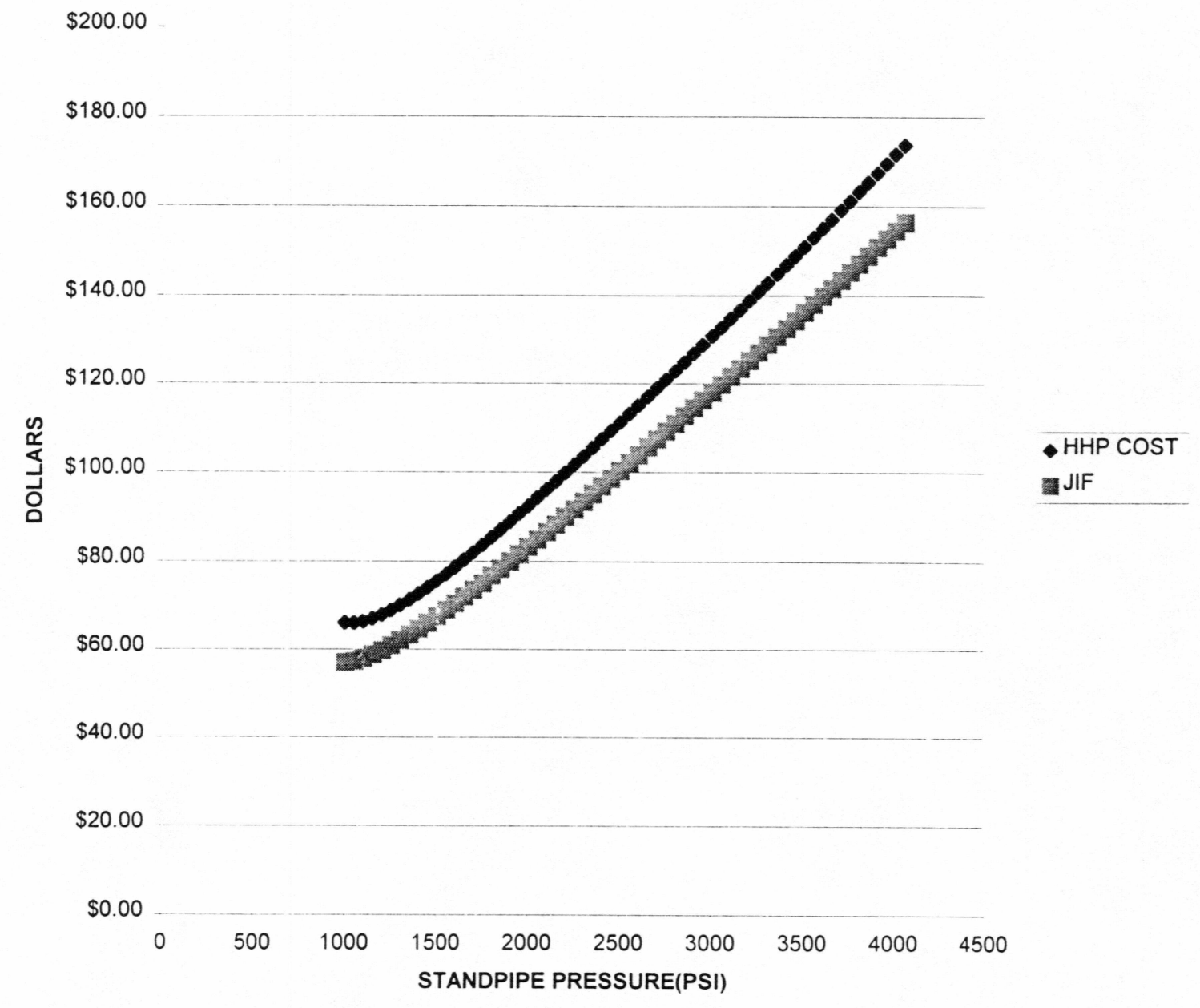

Figure 6.3: Plot of JIF vs. HHP for $m=1.70$ 
$\$ 200.00$

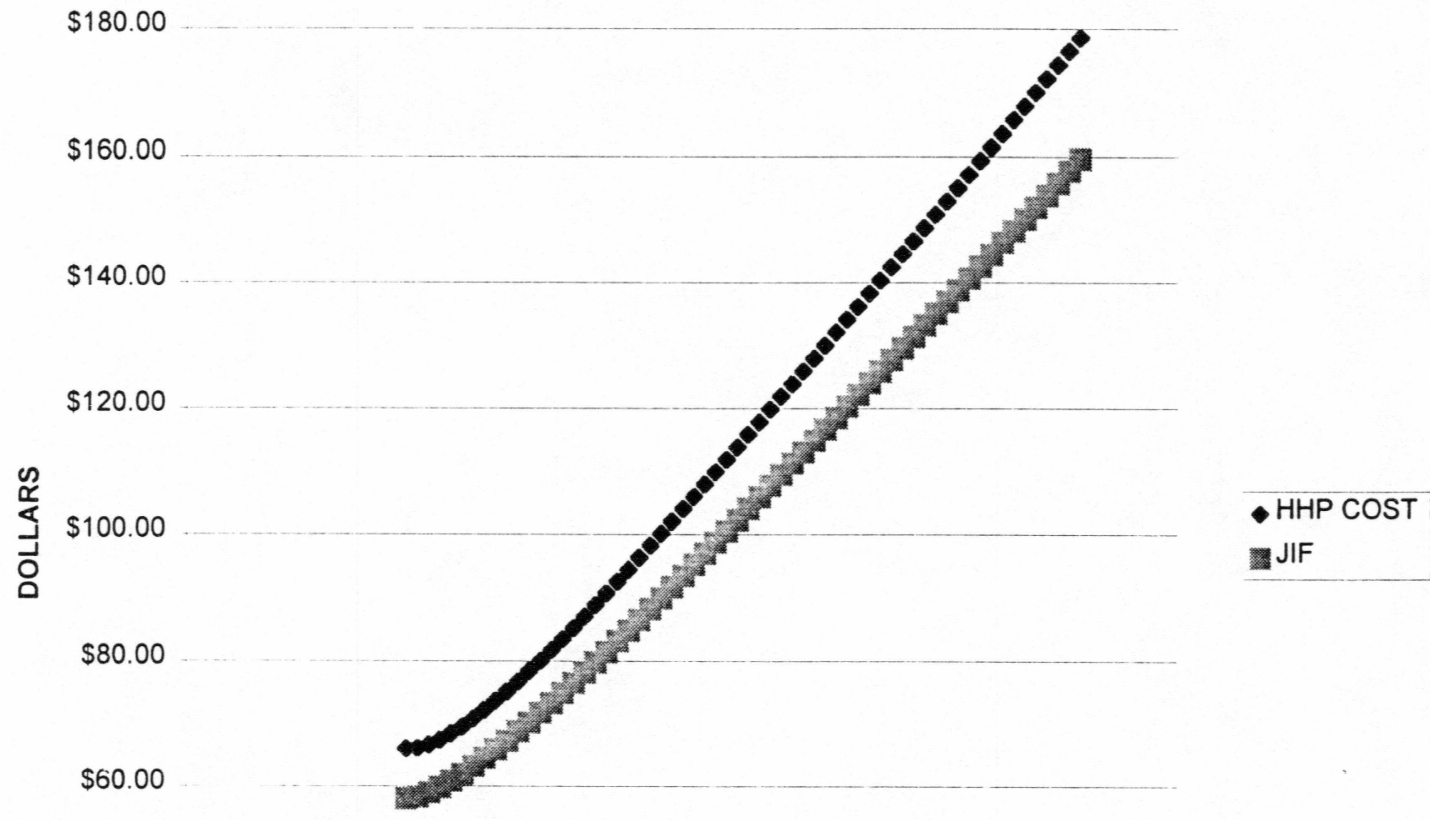

$\$ 40.00$

$\$ 20.00$

$\$ 0.00$

$\begin{array}{llllllllll}0 & 500 & 1000 & 1500 & 2000 & 2500 & 3000 & 3500 & 4000 & 4500 \\ & \text { STANDPIPE PRESSURE(PSI) }\end{array}$

Figure 6.4: Plot of JIF vs. HHP for $\mathrm{m}=1.80$ 
$\$ 200.00$

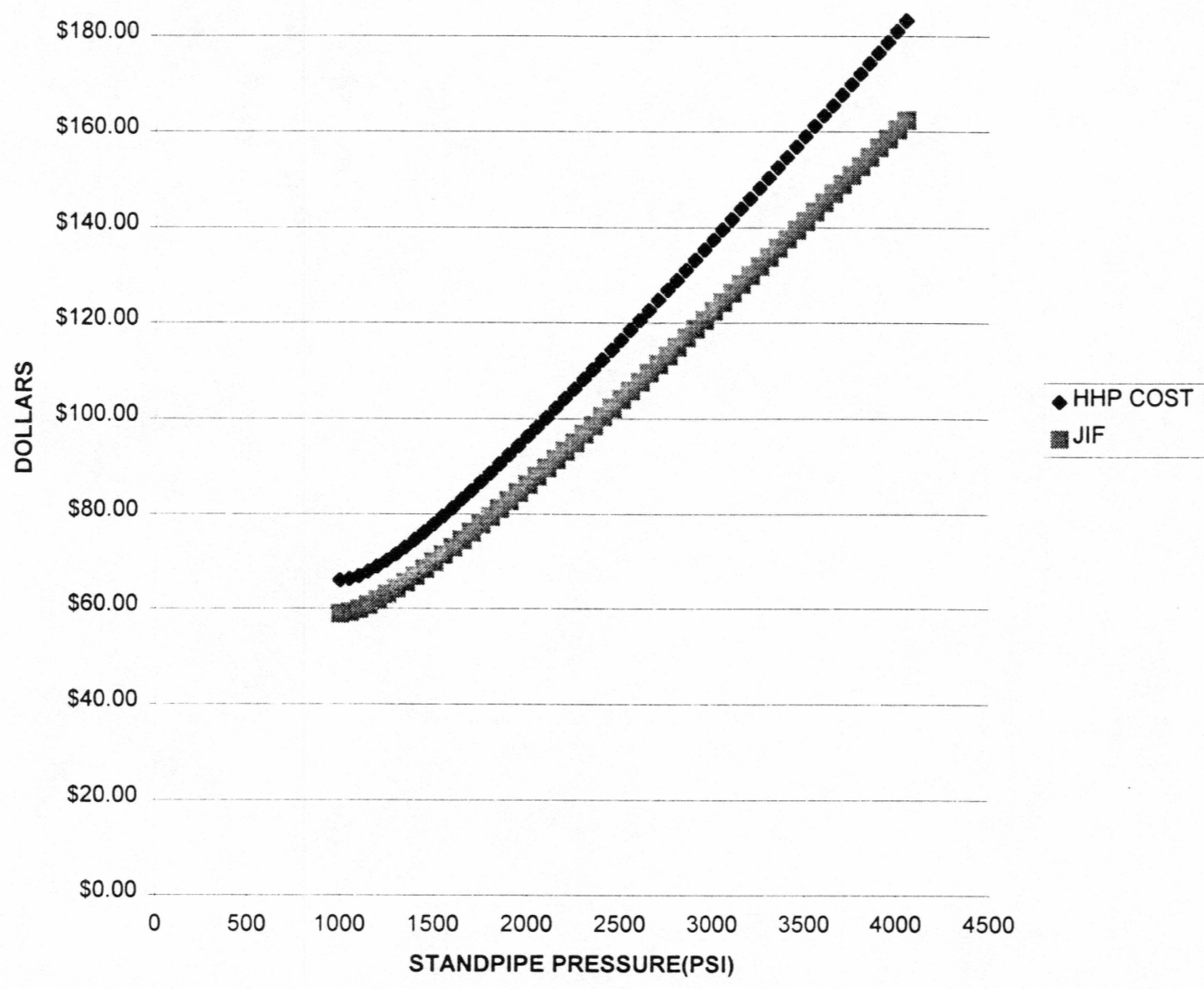

Figure 6.5: Plot of JIF vs. HHP for $\mathrm{m}=1.90$ 
$\$ 200.00$

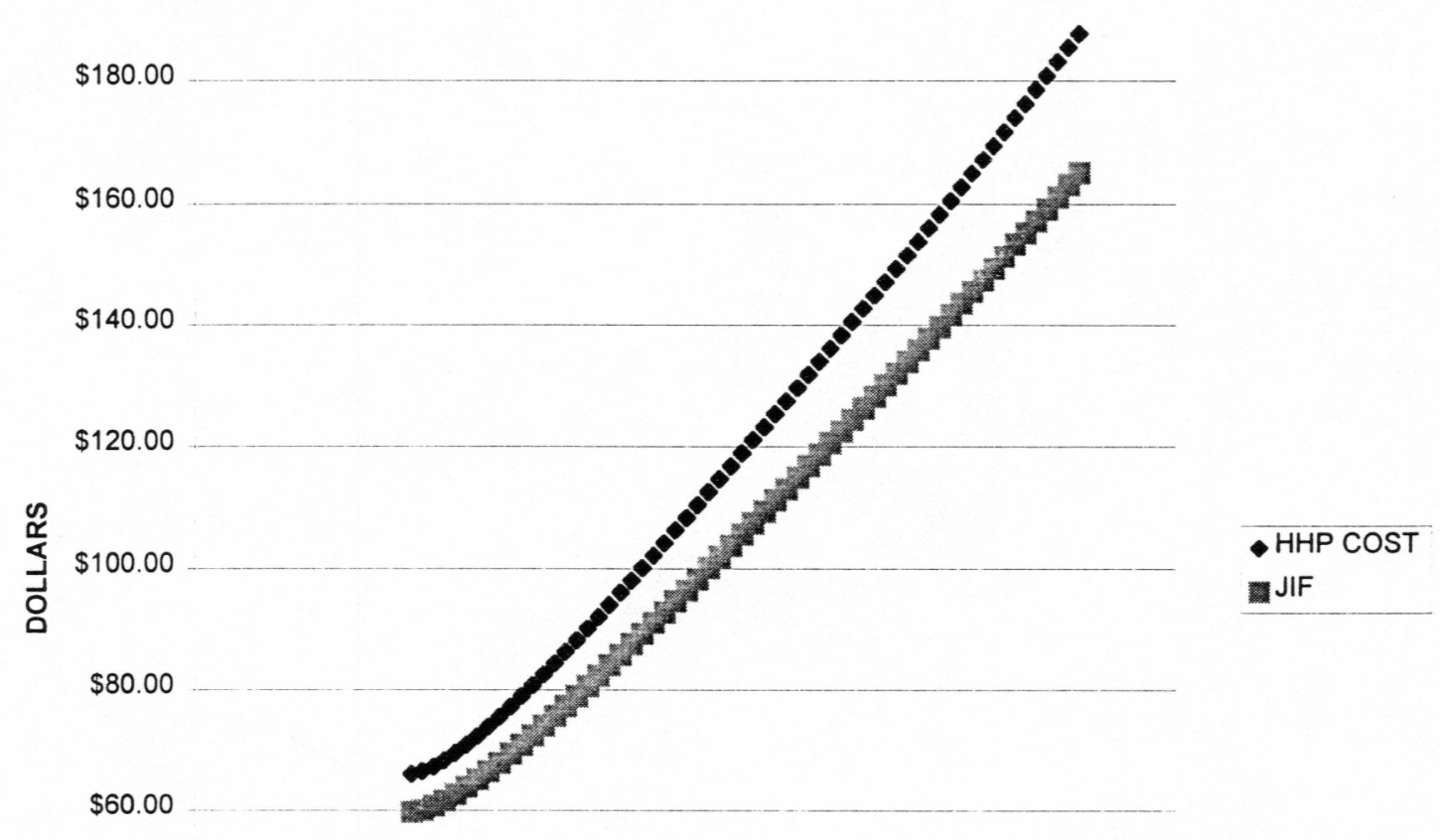

$\$ 40.00$

$\$ 20.00$

$\$ 0.00$

$0 \quad 500 \quad 1000$

$\begin{array}{lllllll}1500 & 2000 \quad 2500 \quad 3000 & 3500 & 4000 \quad 4500\end{array}$

STANDPIPE PRESSURE(PSI)

Figure 6.6: Plot of JIF vs. HHP for $m=2.00$ 
$\$ 250.00$

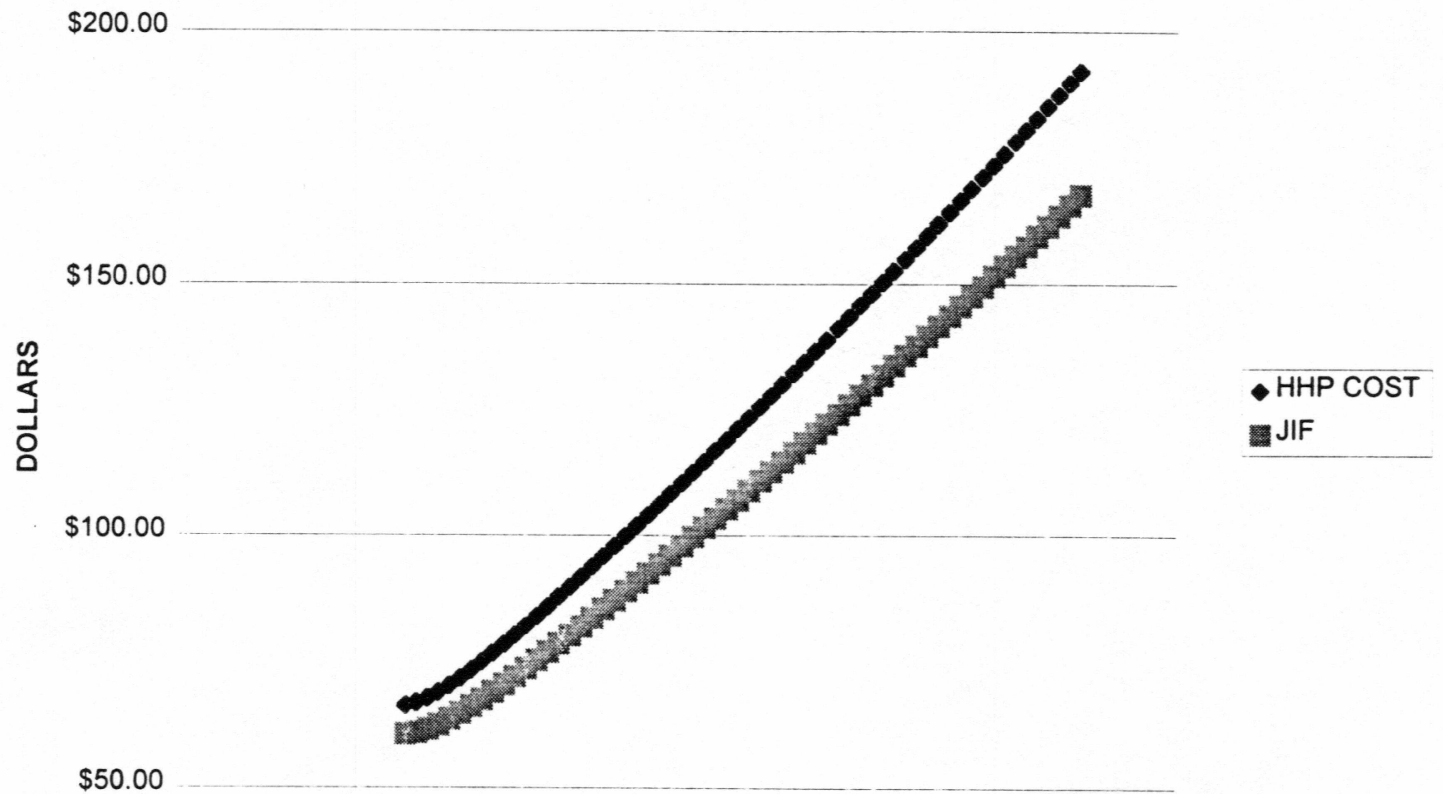

\begin{tabular}{|c|c|c|c|c|c|c|c|c|c|}
\hline 0 & 500 & 1000 & 1500 & 2000 & 2500 & 3000 & 3500 & 4000 & 4500 \\
\hline \multicolumn{10}{|c|}{ STANDPIPE PRESSURE(PSI) } \\
\hline
\end{tabular}

Figure 6.7: Plot of JIF vs. HHP for $\mathrm{m}=2.10$ 
$\$ 250.00$

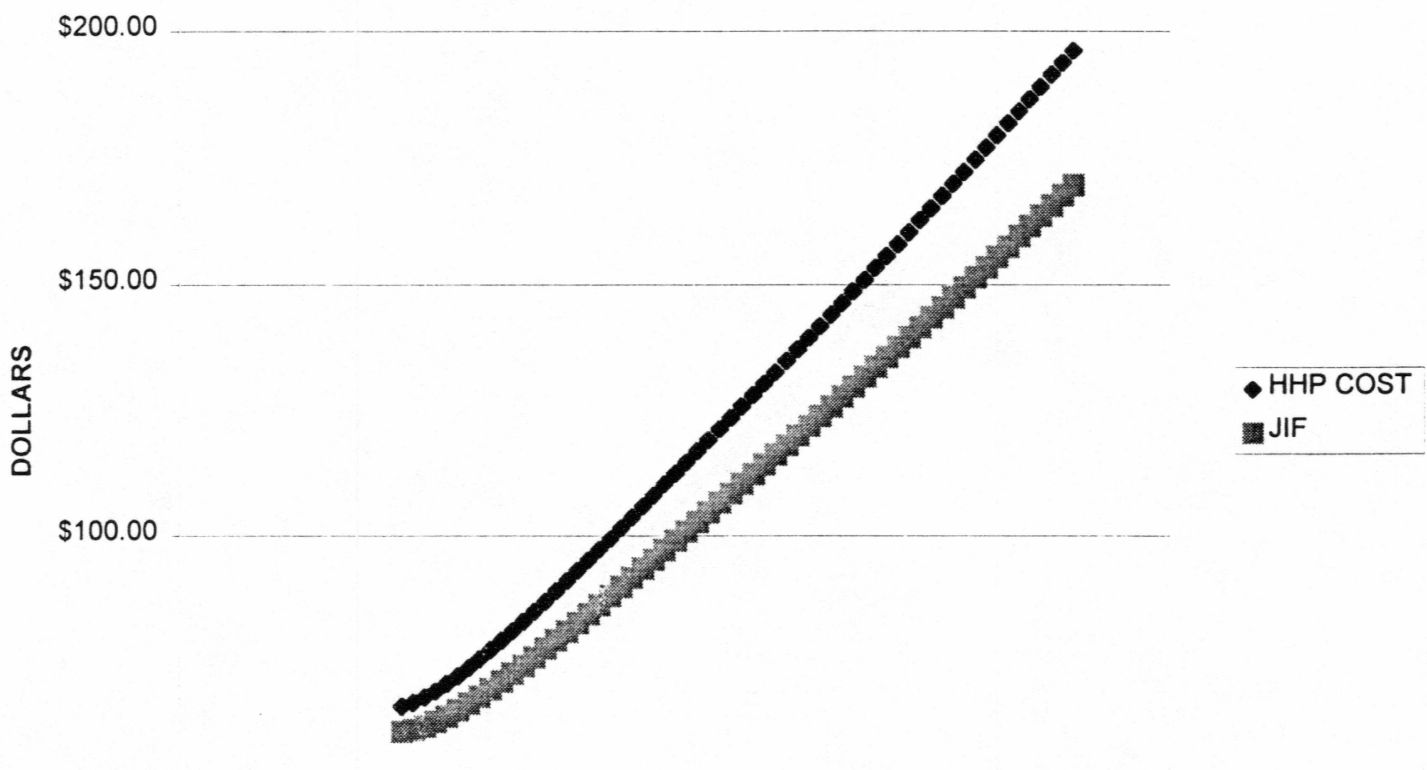

$\$ 50.00$

$\$ 0.00$

0

500

1000

15002000

$4000 \quad 4500$

STANDPIPE PRESSURE(PSI)

Figure 6.8: Plot of JIF vs. HHP for $\mathrm{m}=2.20$ 


\section{Chapter 7}

\section{Conclusions and Recommendations}

This study showed that optimum hydraulic programs can be designed on the basis of minimum drilling cost. Data required for this type of optimization are fuel and pump maintenance hourly costs. Even though the operator of the well may not realize the savings from the proposed program directly, but over a period of time, may realize indirectly from more competitive bid proposals submitted by the drilling company who is trying to optimize pump maintenance and fuel cost.

\subsection{Conclusions:}

The conclusions of this study are summarized as follows:

1. Under similar drilling conditions, Optimizing for JIF is more cost effective than optimizing for HHP.

2. The example problem shows an expected savings of about $\$ 6.99$ per hour of Mud Pump Operation.

3. The study shows that for $\mathrm{m}$ values greater than 1.8 the cost savings optimizing for JIF versus HHP are greater.

4. The study shows that for m values less than 1.6 the cost to optimize for JIF and HHP are equal. 


\subsection{Recommendations:}

Given that some rigs cost as much as thirty five thousand dollars $(\$ 35,000.00)$ per day to operate, savings of $\$ 6.99$ will not be given any real consideration. Using these data to convince an operating companies drilling engineer to change his drilling optimization program from HHP to JIF would not be prudent. However, what may be a concern is the possible need for larger pieces of equipment, which may cause great problems for a small coiled tubing drilling rig. 


\section{Chapter 8}

NOMENCLATURE

\begin{tabular}{|c|c|c|}
\hline$A_{n}$ & $=$ & Cross sectional area of the nozzle, in ${ }^{2}$ \\
\hline $\mathrm{C}_{\mathrm{b}}$ & $=$ & Bit cost, $\$$ \\
\hline $\mathrm{C}_{\mathrm{d}}$ & $=$ & Drag coefficient. \\
\hline $\mathrm{C}_{\mathrm{r}}$ & $=$ & Rig cost, $\$$ \\
\hline $\mathrm{C}_{\mathrm{t}}$ & $=$ & Cost per foot, $\$ / \mathrm{ft}$ \\
\hline $\mathrm{D}$ & $=$ & Mud pump fuel cost \\
\hline$d_{c}$ & $=$ & Nozzle equivalent diameter, in. \\
\hline$d_{s}$ & $=$ & Solid diameter, in. \\
\hline$D_{i}$ & $=$ & Inner diameter of the hole, in. \\
\hline$d_{i}$ & $=$ & Inner diameter of the drillstrings, in. \\
\hline $\mathrm{d}_{\mathrm{o}}$ & $=$ & Outer diameter of the drillstring, in. \\
\hline $\mathrm{d}(\mathrm{opt})$ & $=$ & Optimum nozzle diameter, in. \\
\hline g & $=$ & Gravitational acceleration. \\
\hline$f$ & $=$ & Output cost per horsepower, $\$ / \mathrm{hp}$ \\
\hline $\mathrm{F}$ & $=$ & Future Worth of Money,\$ \\
\hline $\mathrm{F}_{\mathrm{j}, \mathrm{JIF}}$ & $=$ & Jet impact force, $\mathrm{lb}_{\mathrm{f}}$ \\
\hline HHP & $=$ & Hydraulic horsepower, hp. \\
\hline i & $=$ & Effective interest rate, $\%$ \\
\hline $\mathrm{k}$ & $=$ & Power-law consistency index, \\
\hline
\end{tabular}


$l b_{f}-\sec ^{n} / 100 f t^{2}$.

$\mathrm{K}_{1}$

Constant representing $\sqrt{\frac{1120}{\rho_{m}}}$.

$\mathrm{K}_{2}$

Constant representing $\frac{\rho_{m} k_{1}}{60 g}$.

K'

$=$

Mud weight and wellbore constant

L

$=$

Drillpipe length, $\mathrm{ft}$.

$\mathrm{m}$

$=$

Parasitic pressure loss exponent.

n

$=$

Power-law fluid flow index.

$\mathrm{N}$

$=$

Number of compounding periods

NPW

$=$

Net Present Worth,\$

$\mathrm{N}_{\text {rp }}$

$=$

Particle Reynolds Number.

$\mathrm{P}$

$=$

Present Worth of Money,\$

$\Delta \mathrm{P}_{\mathrm{a}}$

$=$

Pressure loss at the annulus, psi.

$\Delta \mathrm{P}_{\mathrm{b}}$

$=$

Pressure drop across the bit, psi.

$\Delta \mathrm{P}_{\mathrm{b}}(\mathrm{opt})$

$=$

Optimum pressure drop across the bit, psi.

$\Delta \mathrm{P}_{\mathrm{c}}$

$=$

Circulating pressure loss,psi.

$\Delta \mathrm{P}_{\mathrm{c}}(\mathrm{opt})$

$=$

Optimum circulating pressure loss, psi.

$\Delta \mathrm{P}_{\text {dca }}$

$=$

Pressure loss at the drill collar annulus, psi.

$\Delta \mathrm{P}_{\text {dcin }}$

$=$

Pressure loss inside the drill collar,psi.

$\Delta \mathrm{P}_{\mathrm{dpa}}$

$=$

Pressure loss at the drillpipe annulus, psi.

$\Delta \mathrm{P}_{\text {dpin }}$

$=$ 


\begin{tabular}{|c|c|c|}
\hline$P_{p}$ & $=$ & Pump pressure, psi. \\
\hline$\Delta \mathrm{P}_{\mathrm{sc}}$ & $=$ & $\begin{array}{l}\text { Pressure loss due to surface connection, } \\
\text { psi. }\end{array}$ \\
\hline$\Delta \mathrm{P}_{\text {sys }}$ & $=$ & System pressure loss, psi. \\
\hline PWF & $=$ & Present Worth Factor, $\$$ \\
\hline $\mathrm{t}$ & $=$ & Rotating time, t. \\
\hline $\mathrm{T}$ & $=$ & Round trip time, hrs. \\
\hline Q & $=$ & Volumetric flowrate of drilling fluid, gpm. \\
\hline $\mathrm{Q}_{\text {(opt) }}$ & $=$ & Optimum flowrate of drilling fluid, gpm. \\
\hline V & $=$ & $\begin{array}{l}\text { Velocity of drilling fluid in drillstrings, } \\
\text { fpm. }\end{array}$ \\
\hline $\mathrm{V}_{\mathrm{a}}$ & $=$ & Annular velocity of drilling fluid, fpm. \\
\hline$\alpha$ & $=$ & Ratio of hole size to drillstring \\
\hline
\end{tabular}




\section{Chapter 9}

\section{References}

1. Dorion, R., and Deane, R., "Optimization of PDC Bit Hydraulics by Fluid Simulation," $60^{\text {th }}$ Annual Technical Conference and Exhibition of the Society of Petroleum Engineers, Las Vegas, Nevada, September 22-25, 1985.

2. Sutko A.A. and Myer, G.M. "The Effect of Nozzle Size, Number, and Extension on the Pressure Distribution under a Tricone Bit,” JPT,(Nov. 1971), P1299-1304.

3. Rust, Wayne, Personal Interview, Engineering Department, Nabors Alaska Drilling, May 1999.

4. Adams, N.J. "Drilling Engineering, A Complete Well Planning Approach," Pennwell Publishing Company. 1985.

5. Belavadi, M.N. and Chukwu, G.A. "Experimental Study of Parameters Affecting Cuttings Transportation in a Vertical Wellbore Annulus," SPE 27880, Presented at the Western Regional Meeting Held in Long Beach, California, March 23, 1994.

6. Moore, P.L. "Drilling Practices Manual," Tulsa, Petroleum Publishing Company. 1974.

7. Lumnus, T.M., "Diamond-Bit Hydraulic Model," SPE \# 17184, September 1989.

8. Eckel J.R. "Microbit Studies of the Effect of Fluid Properties and Hydraulics on Drilling Rate,”JPT, (April 1969), P541-546.

9. Bizanti, Mohamed and Makki, J.F. and Jackson, L.G. and Caruthers, R.M., Bit Hydraulics Optimization Using Reynolds Number Criteria," SPE \# 16465, 1985. 
10. Smalling, D.A. and Key, T.A. "Optimization of Jet Bit Hydraulics Using Impact Pressure," SPE 8440, 54 $4^{\text {th }}$ Annual Fall Technical Conference and Exhibition, Las Vegas, Nevada, Sept. 23-26, 1979.

11. Sutko, A.A. "Drilling Hydraulics-A Study of Chip Removal Force Under a Full-Size Jet Bit," Society of Petroleum Engineers Journal (Aug. 1973), P233-238.

12. Myers, Kenneth F., "A New Approach to Rotary Drilling Hydraulics," SPE paper \# 3530, New Orleans, October 1971.

13. Miska, S. and Skalle, P. "Theoretical description of a New Method of Optical Program Design," Society of Petroleum Engineers Journal, August, 1981, pp425434.

14. Lim, Kien Kim, "Analysis of Hydraulic Horsepower and Jet Impact Force," Mater Thesis, University of Alaska: Fairbanks, 1994.

15. Nelson, E.A., "Factors Affecting Cuttings Removal During Rotary Drilling," SPE \# 1687, June 1967.

16. U.S. Census Bureau, Administration and Customer Division, "Statistical Abstract of the United States Statistical Compendia Branch,” February 10,2000. 


\section{APPENDIX}

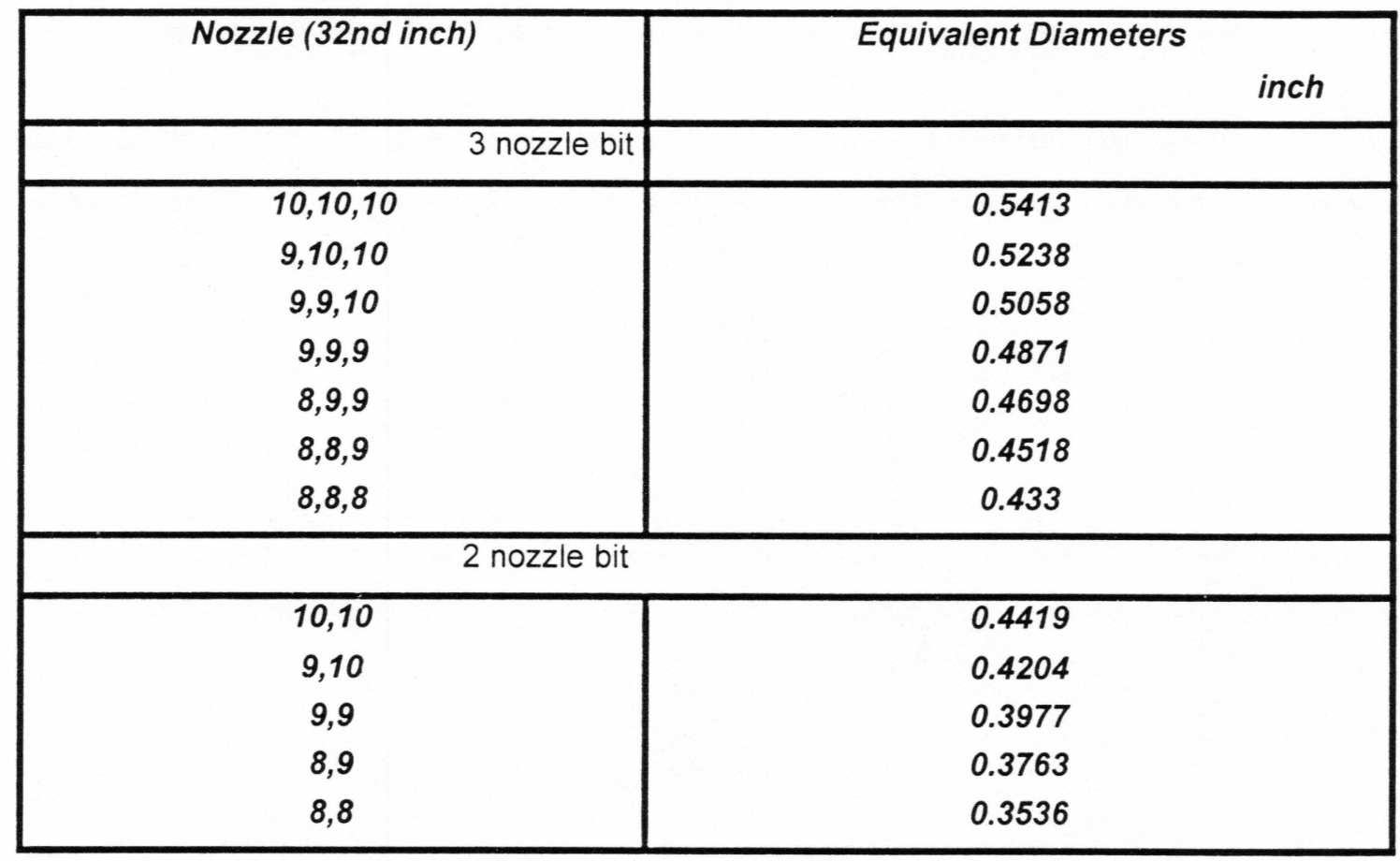

Table A-1 Nozzle Sizes and Equivalent Diameters Two and Three Nozzle Bits 


\begin{tabular}{||c|c|c|c|c|c|c|c|c||}
\hline \hline $\mathbf{P}_{\mathrm{b}} / \mathbf{P}_{\mathbf{c}}$ & $\mathbf{P}_{\mathrm{b}}$ & $\mathbf{P}_{\mathrm{c}}$ & $\mathbf{P}_{\mathbf{p}}$ & $\mathbf{P}_{\mathrm{c}}$ (opt) & $\mathbf{P}_{\mathrm{b}}$ (opt) & $\mathbf{K}^{\prime}$ & $\mathbf{Q}$ (opt) & $\mathbf{d}$ (opt) \\
\hline 5.0 & 1.451 & 0.290 & 1.741 & 0.622 & 1.119 & 0.00460 & 15.27 & 13.17 \\
\hline 4.8 & 1.451 & 0.302 & 1.753 & 0.626 & 1.127 & 0.00479 & 14.99 & 13.03 \\
\hline 4.6 & 1.451 & 0.315 & 1.766 & 0.631 & 1.135 & 0.00500 & 14.70 & 12.88 \\
\hline 4.4 & 1.451 & 0.330 & 1.781 & 0.636 & 1.145 & 0.00523 & 14.40 & 12.72 \\
\hline 4.2 & 1.451 & 0.345 & 1.796 & 0.642 & 1.155 & 0.00547 & 14.10 & 12.56 \\
\hline 4.0 & 1.451 & 0.363 & 1.814 & 0.648 & 1.166 & 0.00575 & 13.80 & 12.39 \\
\hline 3.8 & 1.451 & 0.382 & 1.833 & 0.654 & 1.178 & 0.00605 & 13.49 & 12.22 \\
\hline 3.6 & 1.451 & 0.403 & 1.854 & 0.662 & 1.192 & 0.00639 & 13.18 & 12.04 \\
\hline 3.4 & 1.451 & 0.427 & 1.878 & 0.671 & 1.207 & 0.00676 & 12.85 & 11.86 \\
\hline 3.2 & 1.451 & 0.453 & 1.904 & 0.68 & 1.224 & 0.00719 & 12.53 & 11.67 \\
\hline 3.0 & 1.451 & 0.484 & 1.934 & 0.691 & 1.244 & 0.00766 & 12.19 & 11.46 \\
\hline 2.8 & 1.451 & 0.518 & 1.969 & 0.703 & 1.266 & 0.00821 & 11.85 & 11.25 \\
\hline 2.6 & 1.451 & 0.558 & 2.009 & 0.717 & 1.291 & 0.00884 & 11.50 & 11.03 \\
\hline 2.4 & 1.451 & 0.605 & 2.055 & 0.734 & 1.321 & 0.00958 & 11.14 & 10.79 \\
\hline 2.2 & 1.451 & 0.659 & 2.110 & 0.754 & 1.357 & 0.01045 & 10.77 & 10.54 \\
\hline 2.0 & 1.451 & 0.725 & 2.176 & 0.777 & 1.399 & 0.01150 & 10.39 & 10.28 \\
\hline 1.8 & 1.451 & 0.806 & 2.257 & 0.806 & 1.451 & 0.01277 & 10.00 & 9.99 \\
\hline 1.6 & 1.451 & 0.907 & 2.358 & 0.842 & 1.516 & 0.01437 & 9.60 & 9.68 \\
\hline 1.4 & 1.451 & 1.036 & 2.487 & 0.888 & 1.599 & 0.01642 & 9.18 & 9.34 \\
\hline 1.2 & 1.451 & 1.209 & 2.660 & 0.95 & 1.710 & 0.01916 & 8.75 & 8.97 \\
\hline 1.0 & 1.451 & 1.451 & 2.902 & 1.036 & 1.865 & 0.02299 & 8.30 & 8.54 \\
\hline 0.8 & 1.451 & 1.814 & 3.264 & 1.116 & 2.098 & 0.02874 & 7.82 & 8.06 \\
\hline 0.6 & 1.451 & 2.418 & 3.869 & 1.382 & 2.487 & 0.03883 & 7.33 & 7.47 \\
\hline 0.4 & 1.451 & 3.627 & 5.078 & 1.814 & 3.264 & 0.05748 & 6.80 & 6.73 \\
\hline 0.2 & 1.451 & 7.254 & 8.705 & 3.109 & 5.596 & 0.11497 & 6.25 & 5.63 \\
\hline
\end{tabular}

Table B-1 Optimization Results for Hydraulic Horsepower Method (10 gpm Nozzle Sizes 10,10,10, $\mathrm{m}=1.8$ ) 


\begin{tabular}{|c|c|c|c|c|c|c|c|c||}
\hline $\mathbf{P}_{\mathrm{b}} / \mathbf{P}_{\mathbf{c}}$ & $\mathbf{P}_{\mathrm{b}}$ & $\mathbf{P}_{\mathrm{c}}$ & $\mathbf{P}_{\mathrm{p}}$ & $\mathbf{P}_{\mathrm{c}}$ (opt) & $\mathbf{P}_{\mathrm{b}}$ (opt) & $\mathbf{K}^{\prime}$ & $\mathbf{Q}$ (opt) & $\mathbf{d}(\mathbf{o p t})$ \\
\hline 5.0 & 144.5 & 28.89 & 173.35 & 61.911 & 111.441 & 0.00726 & 152.72 & 13.19 \\
\hline 4.8 & 144.5 & 30.10 & 174.56 & 62.341 & 112.214 & 0.00756 & 149.87 & 13.04 \\
\hline 4.6 & 144.5 & 31.40 & 175.86 & 62.809 & 113.056 & 0.00789 & 146.97 & 12.89 \\
\hline 4.4 & 144.5 & 32.83 & 177.29 & 63.319 & 113.973 & 0.00825 & 144.03 & 12.73 \\
\hline 4.2 & 144.5 & 34.40 & 178.86 & 63.877 & 114.978 & 0.00864 & 141.05 & 12.57 \\
\hline 4.0 & 144.5 & 36.12 & 180.58 & 64.491 & 116.084 & 0.00907 & 138.01 & 12.41 \\
\hline 3.8 & 144.5 & 38.02 & 182.48 & 65.170 & 117.306 & 0.00955 & 134.91 & 12.24 \\
\hline 3.6 & 144.5 & 40.13 & 184.59 & 65.924 & 118.664 & 0.01008 & 131.76 & 12.06 \\
\hline 3.4 & 144.5 & 42.49 & 186.95 & 66.767 & 120.181 & 0.01067 & 128.54 & 11.87 \\
\hline 3.2 & 144.5 & 45.14 & 189.60 & 67.716 & 121.888 & 0.01134 & 125.26 & 11.68 \\
\hline 3.0 & 144.5 & 48.15 & 192.61 & 68.790 & 123.823 & 0.01210 & 121.91 & 11.48 \\
\hline 2.8 & 144.5 & 51.59 & 196.05 & 70.019 & 126.034 & 0.01296 & 118.49 & 11.26 \\
\hline 2.6 & 144.5 & 55.56 & 200.02 & 71.436 & 128.585 & 0.01396 & 114.98 & 11.04 \\
\hline 2.4 & 144.5 & 60.19 & 204.65 & 73.090 & 131.562 & 0.01512 & 111.39 & 10.80 \\
\hline 2.2 & 144.5 & 65.66 & 210.12 & 75.044 & 135.079 & 0.01649 & 107.70 & 10.55 \\
\hline 2.0 & 144.5 & 72.23 & 216.69 & 77.389 & 139.301 & 0.01814 & 103.91 & 10.29 \\
\hline 1.8 & 144.5 & 80.26 & 224.72 & 80.256 & 144.460 & 0.02016 & 100.00 & 10.00 \\
\hline 1.6 & 144.5 & 90.29 & 234.75 & 83.838 & 150.909 & 0.02268 & 95.97 & 9.69 \\
\hline 1.4 & 144.5 & 103.19 & 247.65 & 88.445 & 159.201 & 0.02592 & 91.79 & 9.35 \\
\hline 1.2 & 144.5 & 120.38 & 264.84 & 94.587 & 170.256 & 0.03024 & 87.46 & 8.98 \\
\hline 1.0 & 144.5 & 144.46 & 288.92 & 103.186 & 185.734 & 0.03629 & 82.95 & 8.55 \\
\hline 0.8 & 144.5 & 180.58 & 325.04 & 116.084 & 208.951 & 0.04536 & 78.23 & 8.07 \\
\hline 0.6 & 144.5 & 240.77 & 385.23 & 137.581 & 247.646 & 0.06048 & 73.28 & 7.48 \\
\hline 0.4 & 144.5 & 361.15 & 505.61 & 180.575 & 325.035 & 0.09072 & 68.04 & 6.73 \\
\hline 0.2 & 144.5 & 722.30 & 866.76 & 309.557 & 557.203 & 0.18143 & 62.46 & 5.64 \\
\hline
\end{tabular}

Table B-2 Optimization Results for Hydraulic Horsepower Method (100 gpm Nozzle Sizes 10,10,10, $\mathrm{m}=1.8$ ) 


\begin{tabular}{||c|c|c|c|c|c|c|c|c||}
\hline \hline & & & & & & & \\
$\mathbf{P}_{\mathbf{b}} / \mathbf{P}_{\mathbf{c}}$ & $\mathbf{P}_{\mathbf{b}}$ & $\mathbf{P}_{\mathbf{c}}$ & $\mathbf{P}_{\mathbf{p}}$ & $\mathbf{P}_{\mathbf{c}}$ (opt) & $\mathbf{P}_{\mathbf{b}}$ (opt) & $\mathbf{K}^{\prime}$ & $\mathbf{Q}$ (opt) & $\mathbf{d}(\mathbf{o p t})$ \\
\hline 5.0 & 1.451 & 0.290 & 1.741 & 0.916 & 0.825 & 0.01452 & 10.00 & 11.50 \\
\hline 4.8 & 1.451 & 0.302 & 1.753 & 0.923 & 0.830 & 0.01462 & 10.00 & 11.48 \\
\hline 4.6 & 1.451 & 0.315 & 1.766 & 0.93 & 0.837 & 0.01473 & 10.00 & 11.46 \\
\hline 4.4 & 1.451 & 0.330 & 1.781 & 0.937 & 0.843 & 0.01485 & 10.00 & 11.44 \\
\hline 4.2 & 1.451 & 0.345 & 1.796 & 0.945 & 0.851 & 0.01498 & 10.00 & 11.41 \\
\hline 4.0 & 1.451 & 0.363 & 1.814 & 0.954 & 0.859 & 0.01513 & 10.00 & 11.39 \\
\hline 3.8 & 1.451 & 0.382 & 1.833 & 0.965 & 0.868 & 0.01529 & 10.00 & 11.36 \\
\hline 3.6 & 1.451 & 0.403 & 1.854 & 0.976 & 0.878 & 0.01546 & 10.00 & 11.33 \\
\hline 3.4 & 1.451 & 0.427 & 1.878 & 0.988 & 0.889 & 0.01566 & 10.00 & 11.29 \\
\hline 3.2 & 1.451 & 0.453 & 1.904 & 1.002 & 0.902 & 0.01588 & 10.00 & 11.25 \\
\hline 3.0 & 1.451 & 0.484 & 1.934 & 1.018 & 0.916 & 0.01614 & 10.00 & 11.21 \\
\hline 2.8 & 1.451 & 0.518 & 1.969 & 1.036 & 0.933 & 0.01642 & 10.00 & 11.16 \\
\hline 2.6 & 1.451 & 0.558 & 2.009 & 1.057 & 0.952 & 0.01676 & 10.00 & 11.10 \\
\hline 2.4 & 1.451 & 0.605 & 2.055 & 1.082 & 0.974 & 0.01714 & 10.00 & 11.04 \\
\hline 2.2 & 1.451 & 0.659 & 2.110 & 1.111 & 1.000 & 0.01760 & 10.00 & 10.96 \\
\hline 2.0 & 1.451 & 0.725 & 2.176 & 1.145 & 1.031 & 0.01815 & 10.00 & 10.88 \\
\hline 1.8 & 1.451 & 0.806 & 2.257 & 1.188 & 1.069 & 0.01883 & 10.00 & 10.78 \\
\hline 1.6 & 1.451 & 0.907 & 2.358 & 1.241 & 1.117 & 0.01967 & 10.00 & 10.66 \\
\hline 1.4 & 1.451 & 1.036 & 2.487 & 1.309 & 1.178 & 0.02075 & 10.00 & 10.52 \\
\hline 1.2 & 1.451 & 1.209 & 2.660 & 1.4 & 1.260 & 0.02219 & 10.00 & 10.35 \\
\hline 1.0 & 1.451 & 1.451 & 2.902 & 1.527 & 1.374 & 0.02420 & 10.00 & 10.13 \\
\hline 0.9 & 1.451 & 1.612 & 3.063 & 1.612 & 1.451 & 0.02555 & 10.00 & 9.99 \\
\hline 0.8 & 1.451 & 1.814 & 3.264 & 1.718 & 1.546 & 0.02723 & 10.00 & 9.83 \\
\hline 0.6 & 1.451 & 2.418 & 3.869 & 2.036 & 1.833 & 0.03227 & 10.00 & 9.42 \\
\hline 0.4 & 1.451 & 3.627 & 5.078 & 2.673 & 2.405 & 0.04424 & 10.00 & 8.80 \\
\hline 0.2 & 1.451 & 7.254 & 8.705 & 4.581 & 4.123 & 0.07261 & 10.00 & 7.69 \\
\hline & & & & & & & & \\
\hline \hline
\end{tabular}

Table B-3 Optimization Results for Jet Impact Force Method (10 gpm Nozzle Sizes 10,10,10, $\mathrm{m}=1.8$ ) 


\begin{tabular}{|c|c|c|c|c|c|c|c|c|}
\hline$P_{b} / P_{c}$ & $P_{b}$ & $P_{c}$ & $P_{p}$ & $P_{c}$ (opt) & $P_{b}$ (opt) & $\mathrm{K}^{\prime}$ & $Q$ (opt) & $d(o p t)$ \\
\hline 5.0 & 144.5 & 28.89 & 173.35 & 91.238 & 82.144 & 0.02292 & 100.00 & 11.52 \\
\hline 4.8 & 144.5 & 30.10 & 174.56 & 91.871 & 82.684 & 0.02308 & 100.00 & 11.50 \\
\hline 4.6 & 144.5 & 31.40 & 175.86 & 92.560 & 83.304 & 0.02325 & 100.00 & 11.48 \\
\hline 4.4 & 144.5 & 32.83 & 177.29 & 93.311 & 83.980 & 0.02344 & 100.00 & 11.45 \\
\hline 4.2 & 144.5 & 34.40 & 178.86 & 94.134 & 84.721 & 0.02365 & 100.00 & 11.43 \\
\hline 4.0 & 144.5 & 36.12 & 180.58 & 95.039 & 85.536 & 0.02387 & 100.00 & 11.40 \\
\hline 3.8 & 144.5 & 38.02 & 182.48 & 96.040 & 86.436 & 0.02412 & 100.00 & 11.37 \\
\hline 3.6 & 144.5 & 40.13 & 184.59 & 97.151 & 87.436 & 0.02440 & 100.00 & 11.34 \\
\hline 3.4 & 144.5 & 42.49 & 186.95 & 98.394 & 88.554 & 0.02472 & 100.00 & 11.30 \\
\hline 3.2 & 144.5 & 45.14 & 189.60 & 99.791 & 89.812 & 0.02507 & 100.00 & 11.26 \\
\hline 3.0 & 144.5 & 48.15 & 192.61 & 101.375 & 91.238 & 0.02546 & 100.00 & 11.22 \\
\hline 2.8 & 144.5 & 51.59 & 196.05 & 103.186 & 92.867 & 0.02592 & 100.00 & 11.17 \\
\hline 2.6 & 144.5 & 55.56 & 200.02 & 105.274 & 94.747 & 0.02644 & 100.00 & 11.11 \\
\hline 2.4 & 144.5 & 60.19 & 204.65 & 107.711 & 96.940 & 0.02706 & 100.00 & 11.05 \\
\hline 2.2 & 144.5 & 65.66 & 210.12 & 110.591 & 99.532 & 0.02778 & 100.00 & 10.98 \\
\hline 2.0 & 144.5 & 72.23 & 216.69 & 114.047 & 102.643 & 0.02865 & 100.00 & 10.89 \\
\hline 1.8 & 144.5 & 80.26 & 224.72 & 118.271 & 106.444 & 0.02971 & 100.00 & 10.79 \\
\hline 1.6 & 144.5 & 90.29 & 234.75 & 123.551 & 111.196 & 0.03103 & 100.00 & 10.68 \\
\hline 1.4 & 144.5 & 103.19 & 247.65 & 130.340 & 117.306 & 0.03274 & 100.00 & 10.53 \\
\hline 1.2 & 144.5 & 120.38 & 264.84 & 139.391 & 125.452 & 0.03501 & 100.00 & 10.36 \\
\hline 1.0 & 144.5 & 144.46 & 288.92 & 152.063 & 136.857 & 0.03820 & 100.00 & 10.14 \\
\hline 0.9 & 144.5 & 160.51 & 304.97 & 160.511 & 144.460 & 0.04032 & 100.00 & 10.00 \\
\hline 0.8 & 144.5 & 180.58 & 325.04 & 171.071 & 153.964 & 0.04297 & 100.00 & 9.84 \\
\hline 0.6 & 144.5 & 240.77 & 385.23 & 202.751 & 182.476 & 0.05093 & 100.00 & 9.43 \\
\hline 0.4 & 144.5 & 361.15 & 505.61 & 266.111 & 239.499 & 0.06684 & 100.00 & 8.81 \\
\hline 0.2 & 144.5 & 722.30 & 866.76 & 456.189 & 410.571 & 0.11146 & 100.00 & 7.70 \\
\hline
\end{tabular}

Table B-4 Optimization Results for Jet Impact Force Method (100 gpm Nozzle Sizes 10,10,10, $\mathrm{m}=1.8$ ) 


\begin{tabular}{||c|c|c|c|c|c|c|c|c||}
\hline \hline $\mathbf{P}_{\mathrm{b}} / \mathbf{P}_{\mathbf{c}}$ & $\mathbf{P}_{\mathrm{b}}$ & $\mathbf{P}_{\mathrm{c}}$ & $\mathbf{P}_{\mathrm{p}}$ & $\mathbf{P}_{\mathrm{c}}$ (opt) & $\mathbf{P}_{\mathrm{b}}$ (opt) & $\mathbf{K}^{\prime}$ & $\mathbf{Q}$ (opt) & $\mathbf{d}(\mathbf{o p t})$ \\
\hline 5.0 & 1.451 & 0.290 & 1.741 & 0.590 & 1.151 & 0.00460 & 14.83 & 12.89 \\
\hline 4.8 & 1.451 & 0.302 & 1.753 & 0.594 & 1.159 & 0.00479 & 14.55 & 12.74 \\
\hline 4.6 & 1.451 & 0.315 & 1.766 & 0.598 & 1.168 & 0.00500 & 14.27 & 12.60 \\
\hline 4.4 & 1.451 & 0.330 & 1.781 & 0.603 & 1.178 & 0.00523 & 13.98 & 12.45 \\
\hline 4.2 & 1.451 & 0.345 & 1.796 & 0.608 & 1.188 & 0.00547 & 13.69 & 12.29 \\
\hline 4.0 & 1.451 & 0.363 & 1.814 & 0.614 & 1.199 & 0.00575 & 13.40 & 12.13 \\
\hline 3.8 & 1.451 & 0.382 & 1.833 & 0.621 & 1.212 & 0.00605 & 13.10 & 11.96 \\
\hline 3.6 & 1.451 & 0.403 & 1.854 & 0.628 & 1.226 & 0.00639 & 12.79 & 11.78 \\
\hline 3.4 & 1.451 & 0.427 & 1.878 & 0.636 & 1.242 & 0.00676 & 12.48 & 11.60 \\
\hline 3.2 & 1.451 & 0.453 & 1.904 & 0.645 & 1.259 & 0.00719 & 12.16 & 11.41 \\
\hline 3.0 & 1.451 & 0.484 & 1.934 & 0.655 & 1.279 & 0.00766 & 11.84 & 11.21 \\
\hline 2.8 & 1.451 & 0.518 & 1.969 & 0.667 & 1.302 & 0.00821 & 11.50 & 11.01 \\
\hline 2.6 & 1.451 & 0.558 & 2.009 & 0.680 & 1.329 & 0.00884 & 11.16 & 10.79 \\
\hline 2.4 & 1.451 & 0.605 & 2.055 & 0.696 & 1.359 & 0.00958 & 10.81 & 10.56 \\
\hline 2.2 & 1.451 & 0.659 & 2.110 & 0.715 & 1.396 & 0.01045 & 10.46 & 10.31 \\
\hline 2.0 & 1.451 & 0.725 & 2.176 & 0.737 & 1.439 & 0.01150 & 10.09 & 10.05 \\
\hline 1.8 & 1.451 & 0.806 & 2.257 & 0.764 & 1.493 & 0.01277 & 9.71 & 9.77 \\
\hline 1.6 & 1.451 & 0.907 & 2.358 & 0.798 & 1.559 & 0.01437 & 9.32 & 9.47 \\
\hline 1.4 & 1.451 & 1.036 & 2.487 & 0.842 & 1.645 & 0.01642 & 8.91 & 9.14 \\
\hline 1.2 & 1.451 & 1.209 & 2.660 & 0.901 & 1.759 & 0.01916 & 8.49 & 8.77 \\
\hline 1.0 & 1.451 & 1.451 & 2.902 & 0.983 & 1.919 & 0.02299 & 8.05 & 8.36 \\
\hline 0.8 & 1.451 & 1.814 & 3.264 & 1.105 & 2.159 & 0.02874 & 7.60 & 7.88 \\
\hline 0.6 & 1.451 & 2.418 & 3.869 & 1.310 & 2.559 & 0.03883 & 7.11 & 7.31 \\
\hline 0.4 & 1.451 & 3.627 & 5.078 & 1.720 & 3.358 & 0.05748 & 6.61 & 6.58 \\
\hline 0.2 & 1.451 & 7.254 & 8.705 & 2.948 & 5.757 & 0.11497 & 6.06 & 5.51 \\
\hline & & & & & & & & \\
\hline \hline
\end{tabular}

Table B-5 Optimization Results for Hydraulic Horsepower Method (10 gpm Nozzle Sizes 10,10,10, $\mathrm{m}=1.953$ ) 


\begin{tabular}{||c|c|c|c|c|c|c|c|c||}
\hline \hline $\mathbf{P}_{\mathrm{b}} / \mathbf{P}_{\mathbf{c}}$ & $\mathbf{P}_{\mathrm{b}}$ & $\mathbf{P}_{\mathrm{c}}$ & $\mathbf{P}_{\mathrm{p}}$ & $\mathbf{P}_{\mathrm{c}}$ (opt) & $\mathbf{P}_{\mathrm{b}}$ (opt) & $\mathbf{K}^{\prime}$ & $\mathbf{Q}$ (opt) & $\mathbf{d}(\mathbf{o p t})$ \\
\hline 5.0 & 144.46 & 28.89 & 173.35 & 58.704 & 114.648 & 0.00726 & 148.27 & 12.90 \\
\hline 4.8 & 144.46 & 30.10 & 174.56 & 59.111 & 115.444 & 0.00756 & 145.50 & 12.76 \\
\hline 4.6 & 144.46 & 31.40 & 175.86 & 59.554 & 116.310 & 0.00789 & 142.69 & 12.61 \\
\hline 4.4 & 144.46 & 32.83 & 177.29 & 60.038 & 117.254 & 0.00825 & 139.84 & 12.46 \\
\hline 4.2 & 144.46 & 34.40 & 178.86 & 60.567 & 118.288 & 0.00864 & 136.94 & 12.30 \\
\hline 4.0 & 144.46 & 36.12 & 180.58 & 61.150 & 119.425 & 0.00907 & 133.99 & 12.14 \\
\hline 3.8 & 144.46 & 38.02 & 182.48 & 61.793 & 120.682 & 0.00955 & 130.98 & 11.97 \\
\hline 3.6 & 144.46 & 40.13 & 184.59 & 62.509 & 122.079 & 0.01008 & 127.92 & 11.80 \\
\hline 3.4 & 144.46 & 42.49 & 186.95 & 63.308 & 123.640 & 0.01067 & 124.80 & 11.61 \\
\hline 3.2 & 144.46 & 45.14 & 189.60 & 64.207 & 125.397 & 0.01134 & 121.62 & 11.43 \\
\hline 3.0 & 144.46 & 48.15 & 192.61 & 65.226 & 127.39 & 0.01210 & 118.36 & 11.23 \\
\hline 2.8 & 144.46 & 51.59 & 196.05 & 66.391 & 129.662 & 0.01296 & 115.04 & 11.02 \\
\hline 2.6 & 144.46 & 55.56 & 200.02 & 67.735 & 132.287 & 0.01396 & 111.63 & 10.80 \\
\hline 2.4 & 144.46 & 60.19 & 204.65 & 69.303 & 135.349 & 0.01512 & 108.15 & 10.57 \\
\hline 2.2 & 144.46 & 65.66 & 210.12 & 71.156 & 138.968 & 0.01649 & 104.56 & 10.33 \\
\hline 2.0 & 144.46 & 72.23 & 216.69 & 73.380 & 143.310 & 0.01814 & 100.88 & 10.06 \\
\hline 1.8 & 144.46 & 80.26 & 224.72 & 76.097 & 148.618 & 0.02016 & 97.09 & 9.78 \\
\hline 1.6 & 144.46 & 90.29 & 234.75 & 79.495 & 155.253 & 0.02268 & 93.17 & 9.48 \\
\hline 1.4 & 144.46 & 103.19 & 247.65 & 83.862 & 163.783 & 0.02592 & 89.12 & 9.15 \\
\hline 1.2 & 144.46 & 120.38 & 264.84 & 89.686 & 175.157 & 0.03024 & 84.91 & 8.78 \\
\hline 1.0 & 144.46 & 144.46 & 288.92 & 97.839 & 191.081 & 0.03629 & 80.53 & 8.37 \\
\hline 0.8 & 144.46 & 180.58 & 325.04 & 110.069 & 214.966 & 0.04536 & 75.96 & 7.89 \\
\hline 0.6 & 144.46 & 240.77 & 385.23 & 130.453 & 254.774 & 0.06048 & 71.14 & 7.32 \\
\hline 0.4 & 144.46 & 361.15 & 505.61 & 171.219 & 334.391 & 0.09072 & 66.06 & 6.59 \\
\hline 0.2 & 144.46 & 722.30 & 866.76 & 293.518 & 573.242 & 0.18143 & 60.64 & 5.52 \\
\hline
\end{tabular}

Table B-6 Optimization Results for Hydraulic Horsepower Method (100 gpm Nozzle Sizes 10,10,10 , m=1.953) 


\begin{tabular}{|c|c|c|c|c|c|c|c|c|}
\hline $\mathbf{P}_{b} / P_{c}$ & $P_{b}$ & $\mathbf{P}_{\mathrm{c}}$ & $P_{p}$ & $P_{c}$ (opt) & $P_{b}$ (opt) & $K^{\prime}$ & $Q$ (opt) & $d(o p t)$ \\
\hline 5.0 & 1.451 & 0.290 & 1.741 & 0.881 & 0.860 & 0.01396 & 10.00 & 11.38 \\
\hline 4.8 & 1.451 & 0.302 & 1.753 & 0.887 & 0.866 & 0.01406 & 10.00 & 11.36 \\
\hline 4.6 & 1.451 & 0.315 & 1.766 & 0.894 & 0.873 & 0.01416 & 10.00 & 11.34 \\
\hline 4.4 & 1.451 & 0.330 & 1.781 & 0.901 & 0.880 & 0.01428 & 10.00 & 11.32 \\
\hline 4.2 & 1.451 & 0.345 & 1.796 & 0.909 & 0.887 & 0.01440 & 10.00 & 11.30 \\
\hline 4.0 & 1.451 & 0.363 & 1.814 & 0.918 & 0.896 & 0.01454 & 10.00 & 11.27 \\
\hline 3.8 & 1.451 & 0.382 & 1.833 & 0.927 & 0.905 & 0.01469 & 10.00 & 11.24 \\
\hline 3.6 & 1.451 & 0.403 & 1.854 & 0.938 & 0.916 & 0.01487 & 10.00 & 11.21 \\
\hline 3.4 & 1.451 & 0.427 & 1.878 & 0.95 & 0.928 & 0.01506 & 10.00 & 11.17 \\
\hline 3.2 & 1.451 & 0.453 & 1.904 & 0.963 & 0.941 & 0.01527 & 10.00 & 11.13 \\
\hline 3.0 & 1.451 & 0.484 & 1.934 & 0.979 & 0.956 & 0.01551 & 10.00 & 11.09 \\
\hline 2.8 & 1.451 & 0.518 & 1.969 & 0.996 & 0.973 & 0.01579 & 10.00 & 11.04 \\
\hline 2.6 & 1.451 & 0.558 & 2.009 & 1.016 & 0.992 & 0.01611 & 10.00 & 10.98 \\
\hline 2.4 & 1.451 & 0.605 & 2.055 & 1.04 & 1.015 & 0.01648 & 10.00 & 10.92 \\
\hline 2.2 & 1.451 & 0.659 & 2.110 & 1.068 & 1.043 & 0.01692 & 10.00 & 10.85 \\
\hline 2.0 & 1.451 & 0.725 & 2.176 & 1.101 & 1.075 & 0.01745 & 10.00 & 10.77 \\
\hline 1.8 & 1.451 & 0.806 & 2.257 & 1.142 & 1.115 & 0.01810 & 10.00 & 10.67 \\
\hline 1.6 & 1.451 & 0.907 & 2.358 & 1.193 & 1.165 & 0.01890 & 10.00 & 10.55 \\
\hline 1.4 & 1.451 & 1.036 & 2.487 & 1.258 & 1.229 & 0.01994 & 10.00 & 10.41 \\
\hline 1.2 & 1.451 & 1.209 & 2.660 & 1.346 & 1.314 & 0.02133 & 10.00 & 10.24 \\
\hline 1.0 & 1.451 & 1.451 & 2.902 & 1.468 & 1.134 & 0.02327 & 10.00 & 10.02 \\
\hline 0.9 & 1.451 & 1.612 & 3.063 & 1.55 & 1.513 & 0.02456 & 10.00 & 9.88 \\
\hline 0.8 & 1.451 & 1.814 & 3.264 & 1.652 & 1.613 & 0.02618 & 10.00 & 9.73 \\
\hline 0.6 & 1.451 & 2.418 & 3.869 & 1.957 & 1.911 & 0.03102 & 10.00 & 9.32 \\
\hline 0.4 & 1.451 & 3.627 & 5.078 & 2.569 & 2.509 & 0.04072 & 10.00 & 8.71 \\
\hline 0.2 & 1.451 & 7.254 & 8.705 & 4.404 & 4.301 & 0.06980 & 10.00 & 7.61 \\
\hline
\end{tabular}

Table B-7 Optimization Results for Jet Impact Force Method (10 gpm Nozzle Sizes 10,10,10, $\mathrm{m}=1.953$ ) 


\begin{tabular}{|c|c|c|c|c|c|c|c|c|}
\hline$P_{b} / P_{c}$ & $P_{b}$ & $P_{c}$ & $P_{p}$ & $P_{c}$ (opt) & $P_{b}$ (opt) & $\mathrm{K}^{\prime}$ & $Q$ (opt) & $d(o p t)$ \\
\hline 5.0 & 144.46 & 28.89 & 173.35 & 87.707 & 85.645 & 0.02203 & 100.00 & 11.40 \\
\hline 4.8 & 144.46 & 30.10 & 174.56 & 88.316 & 86.240 & 0.02218 & 100.00 & 11.38 \\
\hline 4.6 & 144.46 & 31.40 & 175.86 & 88.978 & 86.887 & 0.02235 & 100.00 & 11.36 \\
\hline 4.4 & 144.46 & 32.83 & 177.29 & 89.700 & 87.592 & 0.02253 & 100.00 & 11.33 \\
\hline 4.2 & 144.46 & 34.40 & 178.86 & 90.491 & 88.364 & 0.02273 & 100.00 & 11.31 \\
\hline 4.0 & 144.46 & 36.12 & 180.58 & 91.361 & 89.214 & 0.02295 & 100.00 & 11.28 \\
\hline 3.8 & 144.46 & 38.02 & 182.48 & 92.323 & 90.153 & 0.02319 & 100.00 & 11.25 \\
\hline 3.6 & 144.46 & 40.13 & 184.59 & 93.391 & 91.197 & 0.02346 & 100.00 & 11.22 \\
\hline 3.4 & 144.46 & 42.49 & 186.95 & 94.585 & 92.363 & 0.02376 & 100.00 & 11.18 \\
\hline 3.2 & 144.46 & 45.14 & 189.60 & 95.929 & 93.675 & 0.02410 & 100.00 & 11.14 \\
\hline 3.0 & 144.46 & 48.15 & 192.61 & 97.452 & 95.162 & 0.02448 & 100.00 & 11.10 \\
\hline 2.8 & 144.46 & 51.59 & 196.05 & 99.192 & 96.861 & 0.02492 & 100.00 & 11.05 \\
\hline 2.6 & 144.46 & 55.56 & 200.02 & 101.200 & 98.822 & 0.02542 & 100.00 & 11.00 \\
\hline 2.4 & 144.46 & 60.19 & 204.65 & 103.542 & 101.109 & 0.02601 & 100.00 & 10.93 \\
\hline 2.2 & 144.46 & 65.66 & 210.12 & 106.311 & 103.813 & 0.02670 & 100.00 & 10.86 \\
\hline 2.0 & 144.46 & 72.23 & 216.69 & 109.633 & 107.057 & 0.02754 & 100.00 & 10.78 \\
\hline 1.8 & 144.46 & 80.26 & 224.72 & 113.694 & 111.022 & 0.02856 & 100.00 & 10.68 \\
\hline 1.6 & 144.46 & 90.29 & 234.75 & 118.769 & 115.978 & 0.02983 & 100.00 & 10.56 \\
\hline 1.4 & 144.46 & 103.19 & 247.65 & 125.295 & 122.351 & 0.03147 & 100.00 & 10.42 \\
\hline 1.2 & 144.46 & 120.38 & 264.84 & 133.996 & 130.847 & 0.03366 & 100.00 & 10.25 \\
\hline 1.0 & 144.46 & 144.46 & 288.92 & 146.178 & 142.742 & 0.03672 & 100.00 & 10.03 \\
\hline 0.9 & 144.46 & 160.51 & 304.97 & 154.299 & 150.673 & 0.03876 & 100.00 & 9.90 \\
\hline 0.8 & 144.46 & 180.58 & 325.04 & 164.450 & 160.585 & 0.04131 & 100.00 & 9.74 \\
\hline 0.6 & 144.46 & 240.77 & 385.23 & 194.903 & 190.323 & 0.04896 & 100.00 & 9.33 \\
\hline 0.4 & 144.46 & 361.15 & 505.61 & 255.811 & 249.799 & 0.06426 & 100.00 & 8.72 \\
\hline 0.2 & 144.46 & 722.30 & 866.76 & 438.533 & 428.227 & 0.11015 & 100.00 & 7.62 \\
\hline
\end{tabular}

Table B-8 Optimization Results for Jet Impact Force Method (100 gpm Nozzle Sizes 10,10,10, m=1.953) 


\begin{tabular}{|c|c|c|c|c|c|c|c|c|c|c|}
\hline \multirow{4}{*}{$\begin{array}{c}\text { SP } \\
\text { PESS. }\end{array}$} & \multirow{4}{*}{$\begin{array}{l}\text { BIT OPT. } \\
\text { HHP(PSI) }\end{array}$} & \multicolumn{9}{|c|}{ OPTIMU OPTIMU } \\
\hline & & \multirow{3}{*}{$\begin{array}{l}\text { BIT OPT. } \\
\text { JIF(PSI) }\end{array}$} & \multirow{3}{*}{$\begin{array}{c}\text { CIRC. } \\
\text { HHP(PSI) }\end{array}$} & \multirow{3}{*}{$\begin{array}{c}\text { CIRC } \\
\text { JIF(PSI) }\end{array}$} & \multirow{2}{*}{\multicolumn{2}{|c|}{$\begin{array}{cc}M & M \\
J I F(G P M & H H P(G P\end{array}$}} & \multirow[t]{2}{*}{$\mathrm{HHP}$} & \multirow[t]{2}{*}{ JIF } & \multirow[t]{2}{*}{$\mathrm{HHP}$} & \multirow{3}{*}{$\begin{array}{l}\text { JIF } \\
\$\end{array}$} \\
\hline & & & & & & & & & & \\
\hline & & & & & ) & M) & $\mathrm{HP}$ & $\mathrm{HP}$ & $\$$ & \\
\hline 1000 & 614 & 443 & 386 & 557 & 596 & 505 & 181 & 154 & $\$ 66.15$ & $\$ 55.61$ \\
\hline 1050 & 644.7 & 465.15 & 405.3 & 584.85 & 569 & 477 & 179 & 155 & $\$ 65.86$ & $\$ 55.94$ \\
\hline 1100 & 675.4 & 487.3 & 424.6 & 612.7 & 548 & 455 & 179 & 156 & $\$ 66.02$ & $\$ 56.55$ \\
\hline 1150 & 706.1 & 509.45 & 443.9 & 640.55 & 531 & 437 & 180 & 158 & $\$ 66.49$ & $\$ 57.36$ \\
\hline 1200 & 736.8 & 531.6 & 463.2 & 668.4 & 516 & 422 & 181 & 160 & $\$ 67.21$ & $\$ 58.32$ \\
\hline 1250 & 767.5 & 553.75 & 482.5 & 696.25 & 504 & 409 & 183 & 163 & $\$ 68.10$ & $\$ 59.40$ \\
\hline 1300 & 798.2 & 575.9 & 501.8 & 724.1 & 493 & 398 & 186 & 166 & $\$ 69.14$ & $\$ 60.58$ \\
\hline 1350 & 828.9 & 598.05 & 521.1 & 751.95 & 484 & 389 & 188 & 169 & $\$ 70.29$ & $\$ 61.82$ \\
\hline 1400 & 859.6 & 620.2 & 540.4 & 779.8 & 476 & 381 & 191 & 172 & $\$ 71.54$ & $\$ 63.13$ \\
\hline 1450 & 890.3 & 642.35 & 559.7 & 807.65 & 469 & 373 & 194 & 176 & $\$ 72.86$ & $\$ 64.49$ \\
\hline 1500 & 921 & 664.5 & 579 & 835.5 & 462 & 367 & 197 & 179 & $\$ 74.24$ & $\$ 65.89$ \\
\hline 1550 & 951.7 & 686.65 & 598.3 & 863.35 & 456 & 361 & 201 & 183 & $\$ 75.68$ & $\$ 67.33$ \\
\hline 1600 & 982.4 & 708.8 & 617.6 & 891.2 & 451 & 356 & 204 & 187 & $\$ 77.16$ & $\$ 68.79$ \\
\hline 1650 & 1013.1 & 730.95 & 636.9 & 919.05 & 446 & 351 & 208 & 190 & $\$ 78.69$ & $\$ 70.29$ \\
\hline 1700 & 1043.8 & 753.1 & 656.2 & 946.9 & 442 & 347 & 211 & 194 & $\$ 80.25$ & $\$ 71.80$ \\
\hline 1750 & 1074.5 & 775.25 & 675.5 & 974.75 & 438 & 343 & 215 & 198 & $\$ 81.84$ & $\$ 73.34$ \\
\hline 1800 & 1105.2 & 797.4 & 694.8 & 1002.6 & 434 & 339 & 219 & 202 & $\$ 83.47$ & $\$ 74.90$ \\
\hline 1850 & 1135.9 & 819.55 & 714.1 & 1030.45 & 431 & 336 & 223 & 206 & $\$ 85.11$ & $\$ 76.47$ \\
\hline 1900 & 1166.6 & 841.7 & 733.4 & 1058.3 & 428 & 333 & 227 & 210 & $\$ 86.78$ & $\$ 78.06$ \\
\hline 1950 & 1197.3 & 863.85 & 752.7 & 1086.15 & 425 & 330 & 231 & 214 & $\$ 88.47$ & $\$ 79.67$ \\
\hline 2000 & 1228 & 886 & 772 & 1114 & 422 & 327 & 235 & 218 & $\$ 90.18$ & $\$ 81.28$ \\
\hline 2050 & 1258.7 & 908.15 & 791.3 & 1141.85 & 419 & 325 & 239 & 222 & $\$ 91.90$ & $\$ 82.91$ \\
\hline 2100 & 1289.4 & 930.3 & 810.6 & 1169.7 & 417 & 323 & 243 & 226 & $\$ 93.64$ & $\$ 84.54$ \\
\hline 2150 & 1320.1 & 952.45 & 829.9 & 1197.55 & 415 & 320 & 247 & 231 & $\$ 95.40$ & $\$ 86.19$ \\
\hline 2200 & 1350.8 & 974.6 & 849.2 & 1225.4 & 413 & 318 & 251 & 235 & $\$ 97.17$ & $\$ 87.84$ \\
\hline 2250 & 1381.5 & 996.75 & 868.5 & 1253.25 & 411 & 316 & 255 & 239 & $\$ 98.95$ & $\$ 89.51$ \\
\hline 2300 & 1412.2 & 1018.9 & 887.8 & 1281.1 & 409 & 315 & 259 & 243 & $\$ 100.74$ & $\$ 91.18$ \\
\hline 2350 & 1442.9 & 1041.05 & 907.1 & 1308.95 & 407 & 313 & 263 & 247 & $\$ 102.54$ & $\$ 92.86$ \\
\hline 2400 & 1473.6 & 1063.2 & 926.4 & 1336.8 & 406 & 311 & 268 & 252 & $\$ 104.36$ & $\$ 94.54$ \\
\hline 2450 & 1504.3 & 1085.35 & 945.7 & 1364.65 & 404 & 310 & 272 & 256 & $\$ 106.18$ & $\$ 96.23$ \\
\hline 2500 & 1535 & 1107.5 & 965 & 1392.5 & 402 & 308 & 276 & 260 & $\$ 108.02$ & $\$ 97.93$ \\
\hline 2550 & 1565.7 & 1129.65 & 984.3 & 1420.35 & 401 & 307 & 280 & 264 & $\$ 109.86$ & $\$ 99.63$ \\
\hline 2600 & 1596.4 & 1151.8 & 1003.6 & 1448.2 & 400 & 306 & 285 & 269 & $\$ 111.71$ & $\$ 101.34$ \\
\hline 2650 & 1627.1 & 1173.95 & 1022.9 & 1476.05 & 398 & 304 & 289 & 273 & $\$ 113.57$ & $\$ 103.06$ \\
\hline
\end{tabular}

Table D-1 Cost Comparison at Different Standpipe Pressures: $\mathrm{m}=1.5$ 


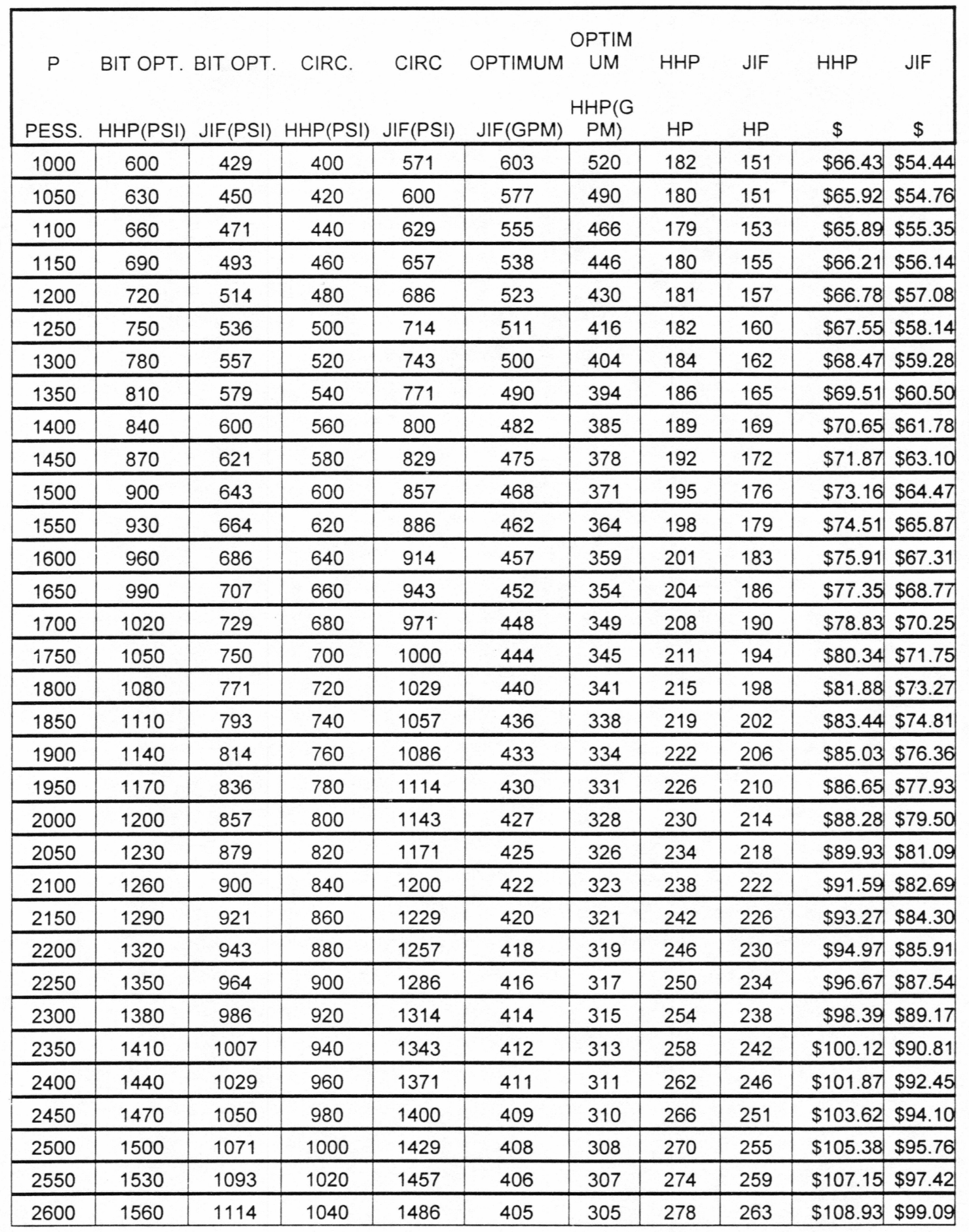

Table D-2 Cost Comparison at Different Standpipe Pressures: m=1.6 


\begin{tabular}{|c|c|c|c|c|c|c|c|c|c|c|}
\hline $\begin{array}{c}\text { SP } \\
\text { PESS. }\end{array}$ & $\begin{array}{c}\text { BIT } \\
\text { OPT. } \\
\text { HHP(PSI } \\
\text { ) }\end{array}$ & $\begin{array}{l}\text { BIT OPT. } \\
\text { JIF(PSI) }\end{array}$ & $\mathrm{HHP}(\mathrm{PSI})$ & CIRC & $\begin{array}{c}\text { OPTIMU } \\
M\end{array}$ & OPTIMUM & $\mathrm{HHP}$ & JIF & $\mathrm{HHP}$ & JIF \\
\hline 1000 & 630 & 459 & 370 & 541 & 587 & 490 & 180 & 157 & $\$ 65.94$ & $\$ 56.88$ \\
\hline 1050 & 661 & 482 & 389 & 568 & 561 & 465 & 179 & 158 & $\$ 65.90$ & $\$ 57.22$ \\
\hline 1100 & 693 & 505 & 407 & 595 & 540 & 445 & 180 & 159 & $\$ 66.26$ & $\$ 57.84$ \\
\hline 1150 & 724 & 528 & 426 & 622 & 523 & 428 & 181 & 161 & $\$ 66.91$ & $\$ 58.68$ \\
\hline 1200 & 756 & 551 & 444 & 649 & 509 & 414 & 183 & 164 & $\$ 67.78$ & $\$ 59.67$ \\
\hline 1250 & 787 & 574 & 463 & 676 & 497 & 403 & 185 & 166 & $\$ 68.82$ & $\$ 60.78$ \\
\hline 1300 & 819 & 597 & 481 & 703 & 486 & 393 & 187 & 169 & $\$ 69.98$ & $\$ 61.98$ \\
\hline 1350 & 850 & 620 & 500 & 730 & 477 & 384 & 190 & 173 & $\$ 71.26$ & $\$ 63.26$ \\
\hline 1400 & 881 & 643 & 519 & 757 & 469 & 376 & 194 & 176 & $\$ 72.62$ & $\$ 64.60$ \\
\hline 1450 & 913 & 666 & 537 & 784 & 462 & 370 & 197 & 179 & $\$ 74.05$ & $\$ 66.00$ \\
\hline 1500 & 944 & 689 & 556 & 811 & 455 & 364 & 200 & 183 & $\$ 75.54$ & $\$ 67.43$ \\
\hline 1550 & 976 & 712 & 574 & 838 & 450 & 358 & 204 & 187 & $\$ 77.08$ & $\$ 68.91$ \\
\hline 1600 & 1007 & 735 & 593 & 865 & 444 & 353 & 208 & 191 & $\$ 78.66$ & $\$ 70.41$ \\
\hline 1650 & 1039 & 758 & 611 & 892 & 440 & 349 & 211 & 194 & $\$ 80.29$ & $\$ 71.94$ \\
\hline 1700 & 1070 & 781 & 630 & 919 & 435 & 345 & 215 & 198 & $\$ 81.95$ & $\$ 73.50$ \\
\hline 1750 & 1102 & 804 & 648 & 946 & 431 & 341 & 219 & 202 & $\$ 83.63$ & $\$ 75.08$ \\
\hline 1800 & 1133 & 827 & 667 & 973 & 428 & 338 & 223 & 206 & $\$ 85.35$ & $\$ 76.67$ \\
\hline 1850 & 1165 & 850 & 685 & 1000 & 424 & 335 & 227 & 210 & $\$ 87.08$ & $\$ 78.29$ \\
\hline 1900 & 1196 & 873 & 704 & 1027 & 421 & 332 & 232 & 215 & $\$ 88.84$ & $\$ 79.92$ \\
\hline 1950 & 1228 & 896 & 722 & 1054 & 418 & 329 & 236 & 219 & $\$ 90.62$ & $\$ 81.56$ \\
\hline 2000 & 1259 & 919 & 741 & 1081 & 416 & 327 & 240 & 223 & $\$ 92.42$ & $\$ 83.22$ \\
\hline 2050 & 1291 & 942 & 759 & 1108 & 413 & 324 & 244 & 227 & $\$ 94.23$ & $\$ 84.89$ \\
\hline 2100 & 1322 & 965 & 778 & 1135 & 411 & 322 & 249 & 231 & $\$ 96.05$ & $\$ 86.57$ \\
\hline 2150 & 1354 & 988 & 796 & 1162 & 409 & 320 & 253 & 236 & $\$ 97.90$ & $\$ 88.25$ \\
\hline 2200 & 1385 & 1011 & 815 & 1189 & 407 & 318 & 257 & 240 & $\$ 99.75$ & $\$ 89.95$ \\
\hline 2250 & 1417 & 1034 & 833 & 1216 & 405 & 317 & 262 & 244 & $\$ 101.62$ & $\$ 91.66$ \\
\hline 2300 & 1448 & 1057 & 852 & 1243 & 403 & 315 & 266 & 248 & $\$ 103.49$ & $\$ 93.37$ \\
\hline 2350 & 1480 & 1080 & 870 & 1270 & 401 & 313 & 270 & 253 & $\$ 105.38$ & $\$ 95.10$ \\
\hline 2400 & 1511 & 1103 & 889 & 1297 & 399 & 312 & 275 & 257 & $\$ 107.28$ & $\$ 96.82$ \\
\hline 2450 & 1543 & 1126 & 907 & 1324 & 398 & 310 & 279 & 261 & $\$ 109.19$ & $\$ 98.56$ \\
\hline 2500 & 1574 & 1149 & 926 & 1351 & 396 & 309 & 284 & 266 & $\$ 111.11$ & $\$ 100.30$ \\
\hline 2550 & 1606 & 1172 & 944 & 1378 & 395 & 308 & 288 & 270 & $\$ 113.03$ & $\$ 102.05$ \\
\hline 2600 & 1637 & 1195 & 963 & 1405 & 394 & 306 & 293 & 274 & $\$ 114.97$ & $\$ 103.80$ \\
\hline
\end{tabular}

Table D-3 Cost Comparison at Different Standpipe Pressures: $\mathrm{m}=1.7$ 


\begin{tabular}{|c|c|c|c|c|c|c|c|c|c|c|}
\hline PESS. & BIT OPT. & BIT OPT. & $\mathrm{HHP}(\mathrm{PSI})$ & $\begin{array}{c}\text { CIRC } \\
\text { JIF(PSI) }\end{array}$ & $\begin{array}{c}\text { OPTIMU } \\
\mathrm{M} \\
\mathrm{JIF}(\mathrm{GPM} \\
\text { ) }\end{array}$ & $\begin{array}{l}\text { OPTIMUM } \\
\text { HHP(GPM) }\end{array}$ & $\mathrm{HHP}$ & JIF & HHP & JIF \\
\hline 1000 & 643 & 474 & 357 & 526 & 579 & 479 & 180 & 160 & $\$ 65.87$ & $\$ 57.91$ \\
\hline 1050 & 675 & 497 & 375 & 553 & 554 & 455 & 179 & 161 & $\$ 66.01$ & $\$ 58.26$ \\
\hline 1100 & 707 & 521 & 393 & 579 & 533 & 437 & 180 & 162 & $\$ 66.54$ & $\$ 58.91$ \\
\hline 1150 & 739 & 545 & 411 & 605 & 516 & 421 & 182 & 164 & $\$ 67.33$ & $\$ 59.76$ \\
\hline 1200 & 771 & 568 & 429 & 632 & 502 & 408 & 184 & 166 & $\$ 68.33$ & $\$ 60.77$ \\
\hline 1250 & 804 & 592 & 446 & 658 & 490 & 398 & 186 & 169 & $\$ 69.48$ & $\$ 61.91$ \\
\hline 1300 & 836 & 616 & 464 & 684 & 480 & 388 & 189 & 172 & $\$ 70.76$ & $\$ 63.14$ \\
\hline 1350 & 868 & 639 & 482 & 711 & 471 & 380 & 192 & 176 & $\$ 72.14$ & $\$ 64.44$ \\
\hline 1400 & 900 & 663 & 500 & 737 & 463 & 373 & 196 & 179 & $\$ 73.59$ & $\$ 65.81$ \\
\hline 1450 & 932 & 687 & 518 & 763 & 456 & 367 & 199 & 183 & $\$ 75.11$ & $\$ 67.23$ \\
\hline 1500 & 964 & 711 & 536 & 789 & 449 & 361 & 203 & 186 & $\$ 76.69$ & $\$ 68.70$ \\
\hline 1550 & 996 & 734 & 554 & 816 & 444 & 356 & 207 & 190 & $\$ 78.32$ & $\$ 70.20$ \\
\hline 1600 & 1029 & 758 & 571 & 842 & 438 & 351 & 211 & 194 & $\$ 79.99$ & $\$ 71.74$ \\
\hline 1650 & 1061 & 782 & 589 & 868 & 434 & 347 & 215 & 198 & $\$ 81.70$ & $\$ 73.30$ \\
\hline 1700 & 1093 & 805 & 607 & 895 & 430 & 344 & 219 & 202 & $\$ 83.44$ & $\$ 74.89$ \\
\hline 1750 & 1125 & 829 & 625 & 921 & 426 & 340 & 223 & 206 & $\$ 85.20$ & $\$ 76.50$ \\
\hline 1800 & 1157 & 853. & 643 & 947 & 422 & 337 & 227 & 210 & $\$ 86.99$ & $\$ 78.14$ \\
\hline 1850 & 1189 & 876 & 661 & 974 & 419 & 334 & 232 & 214 & $\$ 88.81$ & $\$ 79.78$ \\
\hline 1900 & 1221 & 900 & 679 & 1000 & 416 & 331 & 236 & 218 & $\$ 90.64$ & $\$ 81.45$ \\
\hline 1950 & 1254 & 924 & 696 & 1026 & 413 & 329 & 240 & 223 & $\$ 92.50$ & $\$ 83.12$ \\
\hline 2000 & 1286 & 947 & 714 & 1053 & 410 & 326 & 245 & 227 & $\$ 94.37$ & $\$ 84.82$ \\
\hline 2050 & 1318 & 971 & 732 & 1079 & 408 & 324 & 249 & 231 & $\$ 96.26$ & $\$ 86.52$ \\
\hline 2100 & 1350 & 995 & 750 & 1105 & 405 & 322 & 254 & 235 & $\$ 98.16$ & $\$ 88.23$ \\
\hline 2150 & 1382 & 1018 & 768 & 1132 & 403 & 320 & 258 & 240 & $\$ 100.07$ & $\$ 89.96$ \\
\hline 2200 & 1414 & 1042 & 786 & 1158 & 401 & 318 & 263 & 244 & $\$ 102.00$ & $\$ 91.69$ \\
\hline 2250 & 1446 & 1066 & 804 & 1184 & 399 & 317 & 267 & 248 & $\$ 103.94$ & $\$ 93.43$ \\
\hline 2300 & 1479 & 1089 & 821 & 1211 & 398 & 315 & 272 & 253 & $\$ 105.89$ & $\$ 95.18$ \\
\hline 2350 & 1511 & 1113 & 839 & 1237 & 396 & 314 & 276 & 257 & $\$ 107.85$ & $\$ 96.94$ \\
\hline 2400 & 1543 & 1137 & 857 & 1263 & 394 & 312 & 281 & 261 & $\$ 109.82$ & $\$ 98.71$ \\
\hline 2450 & 1575 & 1161 & 875 & 1289 & 393 & 311 & 286 & 266 & $\$ 111.80$ & $\$ 100.48$ \\
\hline 2500 & 1607 & 1184 & 893 & 1316 & 391 & 310 & 290 & 270 & $\$ 113.79$ & $\$ 102.26$ \\
\hline 2550 & 1639 & 1208 & 911 & 1342 & 390 & 308 & 295 & 275 & $\$ 115.79$ & $\$ 104.04$ \\
\hline
\end{tabular}

Table D-4 Cost Comparison at Different Standpipe Pressures: $m=1.8$ 


\begin{tabular}{|c|c|c|c|c|c|c|c|c|c|c|}
\hline $\begin{array}{l}\text { SP } \\
\text { PESS. }\end{array}$ & $\begin{array}{l}\text { BIT OPT. } \\
\text { HHP(PSI) }\end{array}$ & $\begin{array}{l}\text { BIT OPT. } \\
\text { JIF(PSI) }\end{array}$ & $\begin{array}{c}\text { CIRC. } \\
\text { HHP(PSI) }\end{array}$ & $\begin{array}{c}C I R C \\
\text { JIF(PSI) } \\
\end{array}$ & $\begin{array}{l}\text { OPTIMUM } \\
\text { JIF(GPM) }\end{array}$ & $\begin{array}{l}\text { OPTIMUM } \\
\text { HHP(GPM) }\end{array}$ & $\begin{array}{l}\mathrm{HHP} \\
\mathrm{HP}\end{array}$ & $\begin{array}{l}\text { JIF } \\
\text { HP }\end{array}$ & $\begin{array}{l}\mathrm{HHP} \\
\$ \\
\end{array}$ & $\begin{array}{c}\text { JIF } \\
\$ \\
\end{array}$ \\
\hline 1000 & 655 & 487 & 345 & 513 & 572 & 469 & 179 & 162 & $\$ 65.87$ & $\$ 58.85$ \\
\hline 1050 & 688 & 512 & 362 & 538 & 546 & 447 & 180 & 163 & $\$ 66.19$ & $\$ 59.21$ \\
\hline 1100 & 721 & 536 & 379 & 564 & 526 & 430 & 181 & 164 & $\$ 66.86$ & $\$ 59.87$ \\
\hline 1150 & 753 & 560 & 397 & 590 & 509 & 416 & 183 & 167 & $\$ 67.78$ & $\$ 60.74$ \\
\hline 1200 & 786 & 585 & 414 & 615 & 495 & 404 & 185 & 169 & $\$ 68.90$ & $\$ 61.77$ \\
\hline 1250 & 819 & 609 & 431 & 641 & 484 & 393 & 188 & 172 & $\$ 70.16$ & $\$ 62.92$ \\
\hline 1300 & 852 & 633 & 448 & 667 & 473 & 385 & 191 & 175 & $\$ 71.54$ & $\$ 64.18$ \\
\hline 1350 & 884 & 658 & 466 & 692 & 464 & 377 & 195 & 178 & $\$ 73.00$ & $\$ 65.51$ \\
\hline 1400 & 917 & 682 & 483 & 718 & 457 & 370 & 198 & 182 & $\$ 74.55$ & $\$ 66.90$ \\
\hline 1450 & 950 & 706 & 500 & 744 & 450 & 364 & 202 & 185 & $\$ 76.16$ & $\$ 68.35$ \\
\hline 1500 & 983 & 731 & 517 & 769 & 443 & 359 & 206 & 189 & $\$ 77.82$ & $\$ 69.85$ \\
\hline 1550 & 1016 & 755 & 534 & 795 & 438 & 354 & 210 & 193 & $\$ 79.53$ & $\$ 71.38$ \\
\hline 1600 & 1048 & 779 & 552 & 821 & 433 & 350 & 214 & 197 & $\$ 81.28$ & $\$ 72.94$ \\
\hline 1650 & 1081 & 804 & 569 & 846 & 428 & 346 & 218 & 201 & $\$ 83.06$ & $\$ 74.54$ \\
\hline 1700 & 1114 & 828 & 586 & 872 & 424 & 343 & 223 & 205 & $\$ 84.88$ & $\$ 76.15$ \\
\hline 1750 & 1147 & 853 & 603 & 897 & 420 & 339 & 227 & 209 & $\$ 86.72$ & $\$ 77.80$ \\
\hline 1800 & 1179 & 877 & 621 & 923 & 417 & 336 & 231 & 213 & $\$ 88.59$ & $\$ 79.46$ \\
\hline 1850 & 1212 & 901 & 638 & 949 & 413 & 333 & 236 & 217 & $\$ 90.47$ & $\$ 81.13$ \\
\hline 1900 & 1245 & 926 & 655 & 974 & 410 & 331 & 240 & 222 & $\$ 92.38$ & $\$ 82.83$ \\
\hline 1950 & 1278 & 950 & 672 & 1000 & 408 & 329 & 245 & 226 & $\$ 94.31$ & $\$ 84.54$ \\
\hline 2000 & 1310 & 974 & 690 & 1026 & 405 & 326 & 249 & 230 & $\$ 96.25$ & $\$ 86.26$ \\
\hline 2050 & 1343 & 999 & 707 & 1051 & 403 & 324 & 254 & 235 & $\$ 98.21$ & $\$ 88.00$ \\
\hline 2100 & 1376 & 1023 & 724 & 1077 & 400 & 322 & 259 & 239 & $\$ 100.18$ & $\$ 89.74$ \\
\hline 2150 & 1409 & 1047 & 741 & 1103 & 398 & 321 & 263 & 243 & $\$ 102.16$ & $\$ 91.50$ \\
\hline 2200 & 1441 & 1072 & 759 & 1128 & 396 & 319 & 268 & 248 & $\$ 104.16$ & $\$ 93.26$ \\
\hline 2250 & 1474 & 1096 & 776 & 1154 & 394 & 317 & 273 & 252 & $\$ 106.17$ & $\$ 95.04$ \\
\hline 2300 & 1507 & 1121 & 793 & 1179 & 392 & 316 & 278 & 257 & $\$ 108.19$ & $\$ 96.82$ \\
\hline 2350 & 1540 & 1145 & 810 & 1205 & 391 & 314 & 282 & 261 & $\$ 110.22$ & $\$ 98.61$ \\
\hline 2400 & 1572 & 1169 & 828 & 1231 & 389 & 313 & 287 & 265 & $\$ 112.26$ & $\$ 100.41$ \\
\hline 2450 & 1605 & 1194 & 845 & 1256 & 388 & 312 & 292 & 270 & $\$ 114.30$ & $\$ 102.22$ \\
\hline 2500 & 1638 & 1218 & 862 & 1282 & 386 & 310 & 297 & 274 & $\$ 116.36$ & $\$ 104.03$ \\
\hline 2550 & 1671 & 1242 & 879 & 1308 & 385 & 309 & 301 & 279 & $\$ 118.43$ & $\$ 105.85$ \\
\hline 2600 & 1703 & 1267 & 897 & 1333 & 384 & 308 & 306 & 283 & $\$ 120.50$ & $\$ 107.68$ \\
\hline 2650 & 1736 & 1291 & 914 & 1359 & 382 & 307 & 311 & 288 & $\$ 122.58$ & $\$ 109.51$ \\
\hline 2700 & 1769 & 1315 & 931 & 1385 & 381 & 306 & 316 & 292 & $\$ 124.67$ & $\$ 111.34$ \\
\hline
\end{tabular}

Table D-5 Cost Comparison at Different Standpipe Pressures: $\mathrm{m}=1.9$ 


\begin{tabular}{|c|c|c|c|c|c|c|c|c|c|c|}
\hline \multirow{3}{*}{$\begin{array}{c}\text { SP } \\
\text { PESS. }\end{array}$} & \multirow{3}{*}{$\begin{array}{l}\text { BIT OPT. } \\
\text { HHP(PSI) }\end{array}$} & \multirow{3}{*}{$\begin{array}{l}\text { BIT OPT. } \\
\text { JIF(PSI) }\end{array}$} & \multirow{3}{*}{$\begin{array}{c}\text { CIRC. } \\
\text { HHP(PSI) }\end{array}$} & \multirow{3}{*}{$\begin{array}{c}\text { CIRC } \\
\text { JIF(PSI) }\end{array}$} & \multirow{2}{*}{\multicolumn{3}{|c|}{$\begin{array}{c}\text { OPTIMUM OPTIMUM HHP } \\
\text { HHP(GPM }\end{array}$}} & \multirow{3}{*}{$\begin{array}{l}\text { JIF } \\
\text { HP } \\
\end{array}$} & \multirow{3}{*}{$\begin{array}{c}\text { HHP } \\
\$\end{array}$} & \multirow{3}{*}{$\begin{array}{l}\text { JIF } \\
\$ \\
\end{array}$} \\
\hline & & & & & & & & & & \\
\hline & & & & & JIF(GPM) & ) & $\mathrm{HP}$ & & & \\
\hline 1000 & 667 & 500 & 333 & 500 & 564 & 461 & 179 & 165 & $\$ 65.93$ & $\$ 59.69$ \\
\hline 1050 & 700 & 525 & 350 & 525 & 539 & 440 & 180 & 165 & $\$ 66.41$ & $\$ 60.06$ \\
\hline 1100 & 733 & 550 & 367 & 550 & 519 & 424 & 181 & 167 & $\$ 67.21$ & $\$ 60.73$ \\
\hline 1150 & 767 & 575 & 383 & 575 & 503 & 411 & 184 & 169 & $\$ 68.25$ & $\$ 61.62$ \\
\hline 1200 & 800 & 600 & 400 & 600 & 489 & 399 & 186 & 171 & $\$ 69.48$ & $\$ 62.67$ \\
\hline 1250 & 833 & 625 & 417 & 625 & 478 & 390 & 190 & 174 & $\$ 70.84$ & $\$ 63.84$ \\
\hline 1300 & 867 & 650 & 433 & 650 & 467 & 382 & 193 & 177 & $\$ 72.31$ & $\$ 65.12$ \\
\hline 1350 & 900 & 675 & 450 & 675 & 459 & 374 & 197 & 181 & $\$ 73.86$ & $\$ 66.47$ \\
\hline 1400 & 933 & 700 & 467 & 700 & 451 & 368 & 200 & 184 & $\$ 75.49$ & $\$ 67.89$ \\
\hline 1450 & 967 & 725 & 483 & 725 & 444 & 363 & 204 & 188 & $\$ 77.18$ & $\$ 69.36$ \\
\hline 1500 & 1000 & 750 & 500 & 750 & 438 & 358 & 209 & 192 & $\$ 78.92$ & $\$ 70.88$ \\
\hline 1550 & 1033 & 775 & 517 & 775 & 432 & 353 & 213 & 195 & $\$ 80.71$ & $\$ 72.44$ \\
\hline 1600 & 1067 & 800 & 533 & 800 & 427 & 349 & 217 & 199 & $\$ 82.53$ & $\$ 74.03$ \\
\hline 1650 & 1100 & 825 & 550 & 825 & 423 & 345 & 222 & 204 & $\$ 84.39$ & $\$ 75.65$ \\
\hline 1700 & 1133 & 850 & 567 & 850 & 419 & 342 & 226 & 208 & $\$ 86.27$ & $\$ 77.29$ \\
\hline 1750 & 1167 & 875 & 583 & 875 & 415 & 339 & 231 & 212 & $\$ 88.19$ & $\$ 78.96$ \\
\hline 1800 & 1200 & 900 & 600 & 900 & 411 & 336 & 235 & 216 & $\$ 90.12$ & $\$ 80.65$ \\
\hline 1850 & 1233 & 925 & 617 & 925 & 408 & 333 & 240 & 220 & $\$ 92.08$ & $\$ 82.36$ \\
\hline 1900 & 1267 & 950 & 633 & 950 & 405 & 331 & 244 & 225 & $\$ 94.05$ & $\$ 84.08$ \\
\hline 1950 & 1300 & 975 & 650 & 975 & 402 & 329 & 249 & 229 & $\$ 96.05$ & $\$ 85.82$ \\
\hline 2000 & 1333 & 1000 & 667 & 1000 & 400 & 326 & 254 & 233 & $\$ 98.06$ & $\$ 87.57$ \\
\hline 2050 & 1367 & 1025 & 683 & 1025 & 397 & 325 & 259 & 238 & $\$ 100.08$ & $\$ 89.33$ \\
\hline 2100 & 1400 & 1050 & 700 & 1050 & 395 & 323 & 264 & 242 & $\$ 102.12$ & $\$ 91.11$ \\
\hline 2150 & 1433 & 1075 & 717 & 1075 & 393 & 321 & 268 & 247 & $\$ 104.17$ & $\$ 92.90$ \\
\hline 2200 & 1467 & 1100 & 733 & 1100 & 391 & 319 & 273 & 251 & $\$ 106.23$ & $\$ 94.69$ \\
\hline 2250 & 1500 & 1125 & 750 & 1125 & 389 & 318 & 278 & 255 & $\$ 108.31$ & $\$ 96.50$ \\
\hline 2300 & 1533 & 1150 & 767 & 1150 & 387 & 316 & 283 & 260 & $\$ 110.39$ & $\$ 98.31$ \\
\hline 2350 & 1567 & 1175 & 783 & 1175 & 386 & 315 & 288 & 264 & $\$ 112.49$ & $\$ 100.13$ \\
\hline 2400 & 1600 & 1200 & 800 & 1200 & 384 & 314 & 293 & 269 & $\$ 114.59$ & $\$ 101.96$ \\
\hline 2450 & 1633 & 1225 & 817 & 1225 & 383 & 312 & 298 & 274 & $\$ 116.71$ & $\$ 103.80$ \\
\hline 2500 & 1667 & 1250 & 833 & 1250 & 381 & 311 & 303 & 278 & $\$ 118.83$ & $\$ 105.64$ \\
\hline 2550 & 1700 & 1275 & 850 & 1275 & 380 & 310 & 308 & 283 & $\$ 120.96$ & $\$ 107.49$ \\
\hline 2600 & 1733 & 1300 & 867 & 1300 & 379 & 309 & 313 & 287 & $\$ 123.10$ & $\$ 109.35$ \\
\hline 2650 & 1767 & 1325 & 883 & 1325 & 377 & 308 & 318 & 292 & $\$ 125.24$ & $\$ 111.21$ \\
\hline
\end{tabular}

Table D-6 Cost Comparison at Different Standpipe Pressures: $m=2.0$ 


\begin{tabular}{|c|c|c|c|c|c|c|c|c|c|c|}
\hline \multirow{2}{*}{$\begin{array}{c}\text { SP } \\
\text { PESS. }\end{array}$} & \multirow{2}{*}{$\begin{array}{l}\text { BIT OPT. } \\
\text { HHP(PSI) }\end{array}$} & \multirow{2}{*}{$\begin{array}{l}\text { BIT OPT. } \\
\text { JIF(PSI) }\end{array}$} & \multirow{2}{*}{$\begin{array}{c}\text { CIRC. } \\
\text { HHP(PSI) }\end{array}$} & \multirow{2}{*}{$\begin{array}{c}\text { CIRC } \\
\text { JIF(PSI) }\end{array}$} & \multirow{2}{*}{\multicolumn{3}{|c|}{$\begin{array}{c}\text { OPTIMUM OPTIMUM HHP } \\
\text { HHP(GPM }\end{array}$}} & \multirow{2}{*}{$\begin{array}{l}\text { JIF } \\
\text { HP }\end{array}$} & \multirow{2}{*}{$\begin{array}{c}\text { HHP } \\
\$\end{array}$} & \multirow{2}{*}{$\begin{array}{c}\text { JIF } \\
\$ \\
\end{array}$} \\
\hline & & & & & & & & & & \\
\hline 1000 & 677 & 512 & 323 & 488 & 557 & 454 & 179 & 167 & $\$ 66.04$ & $\$ 60.45$ \\
\hline 1050 & 711 & 538 & 339 & 512 & 533 & 435 & 180 & 167 & $\$ 66.66$ & $\$ 60.83$ \\
\hline 1100 & 745 & 563 & 355 & 537 & 513 & 419 & 182 & 169 & $\$ 67.59$ & $\$ 61.51$ \\
\hline 1150 & 779 & 589 & 371 & 561 & 497 & 407 & 185 & 171 & $\$ 68.74$ & $\$ 62.41$ \\
\hline 1200 & 813 & 615 & 387 & 585 & 483 & 396 & 188 & 173 & $\$ 70.06$ & $\$ 63.48$ \\
\hline 1250 & 847 & 640 & 403 & 610 & 472 & 387 & 191 & 176 & $\$ 71.51$ & $\$ 64.67$ \\
\hline 1300 & 881 & 666 & 419 & 634 & 462 & 379 & 195 & 179 & $\$ 73.07$ & $\$ 65.97$ \\
\hline 1350 & 915 & 691 & 435 & 659 & 453 & 372 & 199 & 183 & $\$ 74.71$ & $\$ 67.34$ \\
\hline 1400 & 948 & 717 & 452 & 683 & 445 & 366 & 203 & 186 & $\$ 76.41$ & $\$ 68.78$ \\
\hline 1450 & 982 & 743 & 468 & 707 & 439 & 361 & 207 & 190 & $\$ 78.18$ & $\$ 70.27$ \\
\hline 1500 & 1016 & 768 & 484 & 732 & 432 & 356 & 211 & 194 & $\$ 79.99$ & $\$ 71.82$ \\
\hline 1550 & 1050 & 794 & 500 & 756 & 427 & 352 & 216 & 198 & $\$ 81.85$ & $\$ 73.40$ \\
\hline 1600 & 1084 & 820 & 516 & 780 & 422 & 348 & 220 & 202 & $\$ 83.75$ & $\$ 75.01$ \\
\hline 1650 & 1118 & 845 & 532 & 805 & 418 & 345 & 225 & 206 & $\$ 85.67$ & $\$ 76.66$ \\
\hline 1700 & 1152 & 871 & 548 & 829 & 414 & 341 & 229 & 210 & $\$ 87.62$ & $\$ 78.33$ \\
\hline 1750 & 1185 & 896 & 565 & 854 & 410 & 338 & 234 & 214 & $\$ 89.60$ & $\$ 80.02$ \\
\hline 1800 & 1219 & 922 & 581 & 878 & 406 & 336 & 239 & 219 & $\$ 91.61$ & $\$ 81.73$ \\
\hline 1850 & 1253 & 948 & 597 & 902 & 403 & 333 & 244 & 223 & $\$ 93.63$ & $\$ 83.47$ \\
\hline 1900 & 1287 & 973 & 613 & 927 & 400 & 331 & 249 & 227 & $\$ 95.67$ & $\$ 85.21$ \\
\hline 1950 & 1321 & 999 & 629 & 951 & 397 & 329 & 253 & 232 & $\$ 97.73$ & $\$ 86.98$ \\
\hline 2000 & 1355 & 1024 & 645 & 976 & 395 & 327 & 258 & 236 & $\$ 99.80$ & $\$ 88.76$ \\
\hline 2050 & 1389 & 1050 & 661 & 1000 & 393 & 325 & 263 & 240 & $\$ 101.89$ & $\$ 90.55$ \\
\hline 2100 & 1423 & 1076 & 677 & 1024 & 390 & 323 & 268 & 245 & $\$ 103.99$ & $\$ 92.35$ \\
\hline 2150 & 1456 & 1101 & 694 & 1049 & 388 & 322 & 273 & 249 & $\$ 106.10$ & $\$ 94.16$ \\
\hline 2200 & 1490 & 1127 & 710 & 1073 & 386 & 320 & 278 & 254 & $\$ 108.23$ & $\$ 95.99$ \\
\hline 2250 & 1524 & 1152 & 726 & 1098 & 384 & 319 & 283 & 258 & $\$ 110.37$ & $\$ 97.82$ \\
\hline 2300 & 1558 & 1178 & 742 & 1122 & 383 & 317 & 288 & 263 & $\$ 112.51$ & $\$ 99.66$ \\
\hline 2350 & 1592 & 1204 & 758 & 1146 & 381 & 316 & 293 & 268 & $\$ 114.67$ & $\$ 101.51$ \\
\hline 2400 & 1626 & 1229 & 774 & 1171 & 380 & 315 & 298 & 272 & $\$ 116.84$ & $\$ 103.37$ \\
\hline 2450 & 1660 & 1255 & 790 & 1195 & 378 & 313 & 304 & 277 & $\$ 119.01$ & $\$ 105.23$ \\
\hline 2500 & 1694 & 1280 & 806 & 1220 & 377 & 312 & 309 & 281 & $\$ 121.20$ & $\$ 107.10$ \\
\hline 2550 & 1727 & 1306 & 823 & 1244 & 375 & 311 & 314 & 286 & $\$ 123.39$ & $\$ 108.98$ \\
\hline 2600 & 1761 & 1332 & 839 & 1268 & 374 & 310 & 319 & 291 & $\$ 125.59$ & $\$ 110.86$ \\
\hline 2650 & 1795 & 1357 & 855 & 1293 & 373 & 309 & 324 & 295 & $\$ 127.80$ & $\$ 112.75$ \\
\hline
\end{tabular}

Table D-7 Cost Comparison at Different Standpipe Pressures: $m=2.1$ 


\begin{tabular}{|c|c|c|c|c|c|c|c|c|c|c|}
\hline PESS. & BIT OPT. & BIT OPT. & $\mathrm{HHP}(\mathrm{PSI})$ & JIF(PSI) & OPTIMUM & $\begin{array}{c}\mathrm{HHP}(\mathrm{GPM} \\
)\end{array}$ & $\mathrm{HHP}$ & JIF & HHP & JIF \\
\hline 1000 & 688 & 524 & 313 & 476 & 551 & 448 & 180 & 168 & $\$ 66.19$ & $\$ 61.13$ \\
\hline 1050 & 722 & 550 & 328 & 500 & 526 & 430 & 181 & 169 & $\$ 66.94$ & $\$ 61.52$ \\
\hline 1100 & 756 & 576 & 344 & 524 & 507 & 415 & 183 & 170 & $\$ 67.98$ & $\$ 62.21$ \\
\hline 1150 & 791 & 602 & 359 & 548 & 491 & 403 & 186 & 173 & $\$ 69.23$ & $\$ 63.13$ \\
\hline 1200 & 825 & 629 & 375 & 571 & 477 & 393 & 189 & 175 & $\$ 70.64$ & $\$ 64.21$ \\
\hline 1250 & 859 & 655 & 391 & 595 & 466 & 385 & 193 & 178 & $\$ 72.18$ & $\$ 65.42$ \\
\hline 1300 & 894 & 681 & 406 & 619 & 456 & 377 & 197 & 181 & $\$ 73.82$ & $\$ 66.73$ \\
\hline 1350 & 928 & 707 & 422 & 643 & 448 & 371 & 201 & 185 & $\$ 75.53$ & $\$ 68.12$ \\
\hline 1400 & 963 & 733 & 438 & 667 & 440 & 365 & 205 & 188 & $\$ 77.31$ & $\$ 69.58$ \\
\hline 1450 & 997 & 760 & 453 & 690 & 433 & 360 & 209 & 192 & $\$ 79.15$ & $\$ 71.10$ \\
\hline 1500 & 1031 & 786 & 469 & 714 & 427 & 355 & 214 & 196 & $\$ 81.04$ & $\$ 72.66$ \\
\hline 1550 & 1066 & 812 & 484 & 738 & 422 & 351 & 218 & 200 & $\$ 82.96$ & $\$ 74.26$ \\
\hline 1600 & 1100 & 838 & 500 & 762 & 417 & 348 & 223 & 204 & $\$ 84.92$ & $\$ 75.90$ \\
\hline 1650 & 1134 & 864 & 516 & 786 & 413 & 344 & 228 & 208 & $\$ 86.91$ & $\$ 77.57$ \\
\hline 1700 & 1169 & 890 & 531 & 810 & 409 & 341 & 233 & 212 & $\$ 88.93$ & $\$ 79.26$ \\
\hline 1750 & 1203 & 917 & 547 & 833 & 405 & 338 & 238 & 217 & $\$ 90.97$ & $\$ 80.98$ \\
\hline 1800 & 1238 & 943 & 563 & 857 & 401 & 336 & 242 & 221 & $\$ 93.04$ & $\$ 82.71$ \\
\hline 1850 & 1272 & 969 & 578 & 881 & 398 & 333 & 247 & 225 & $\$ 95.12$ & $\$ 84.47$ \\
\hline 1900 & 1306 & 995 & 594 & 905 & 395 & 331 & 252 & 230 & $\$ 97.22$ & $\$ 86.24$ \\
\hline 1950 & 1341 & 1021 & 609 & 929 & 393 & 329 & 257 & 234 & $\$ 99.34$ & $\$ 88.03$ \\
\hline 2000 & 1375 & 1048 & 625 & 952 & 390 & 327 & 262 & 239 & $\$ 101.48$ & $\$ 89.83$ \\
\hline 2050 & 1409 & 1074 & 641 & 976 & 388 & 325 & 268 & 243 & $\$ 103.63$ & $\$ 91.65$ \\
\hline 2100 & 1444 & 1100 & 656 & 1000 & 386 & 324 & 273 & 248 & $\$ 105.79$ & $\$ 93.47$ \\
\hline 2150 & 1478 & 1126 & 672 & 1024 & 384 & 322 & 278 & 252 & $\$ 107.96$ & $\$ 95.31$ \\
\hline 2200 & 1513 & 1152 & 688 & 1048 & 382 & 321 & 283 & 257 & $\$ 110.15$ & $\$ 97.16$ \\
\hline 2250 & 1547 & 1179 & 703 & 1071 & 380 & 319 & 288 & 261 & $\$ 112.35$ & $\$ 99.02$ \\
\hline 2300 & 1581 & 1205 & 719 & 1095 & 378 & 318 & 293 & 266 & $\$ 114.55$ & $\$ 100.88$ \\
\hline 2350 & 1616 & 1231 & 734 & 1119 & 377 & 317 & 299 & 270 & $\$ 116.77$ & $\$ 102.76$ \\
\hline 2400 & 1650 & 1257 & 750 & 1143 & 375 & 316 & 304 & 275 & $\$ 119.00$ & $\$ 104.64$ \\
\hline 2450 & 1684 & 1283 & 766 & 1167 & 374 & 314 & 309 & 280 & $\$ 121.23$ & $\$ 106.53$ \\
\hline 2500 & 1719 & 1310 & 781 & 1190 & 372 & 313 & 314 & 284 & $\$ 123.47$ & $\$ 108.43$ \\
\hline 2550 & 1753 & 1336 & 797 & 1214 & 371 & 312 & 320 & 289 & $\$ 125.72$ & $\$ 110.33$ \\
\hline 2600 & 1788 & 1362 & 813 & 1238 & 370 & 311 & 325 & 294 & $\$ 127.98$ & $\$ 112.24$ \\
\hline 2650 & 1822 & 1388 & 828 & 1262 & 368 & 311 & 330 & 298 & $\$ 130.25$ & $\$ 114.16$ \\
\hline
\end{tabular}

Table D-8 Cost Comparison at Different Standpipe Pressures: $\mathrm{m}=2.2$ 


\begin{tabular}{|c|c|c|c|c|c|c|c|c|c|c|}
\hline \multirow{2}{*}{$\begin{array}{c}\text { SP } \\
\text { PESS. }\end{array}$} & \multirow{2}{*}{$\begin{array}{l}\text { BIT OPT. } \\
\text { HHP(PSI) }\end{array}$} & \multirow{2}{*}{$\begin{array}{l}\text { BIT OPT. } \\
\text { JIF(PSI) }\end{array}$} & \multirow{2}{*}{$\begin{array}{c}\text { CIRC. } \\
\text { HHP(PSI) }\end{array}$} & \multirow{2}{*}{$\begin{array}{c}\text { CIRC } \\
\text { JIF(PSI) } \\
\end{array}$} & \multirow{2}{*}{\multicolumn{3}{|c|}{$\begin{array}{c}\text { OPTIMUM OPTIMUM HHP } \\
\text { HHP(GPM }\end{array}$}} & \multirow{2}{*}{$\begin{array}{l}\text { JIF } \\
\text { HP } \\
\end{array}$} & \multirow{2}{*}{$\begin{array}{l}\mathrm{HHP} \\
\$ \\
\end{array}$} & \multirow{2}{*}{$\begin{array}{l}\text { JIF } \\
\$\end{array}$} \\
\hline & & & & & & & & & & \\
\hline 1000 & 688 & 524 & 313 & 476 & 551 & 448 & 180 & 168 & $\$ 66.19$ & $\$ 61.13$ \\
\hline 1050 & 722 & 550 & 328 & 500 & 526 & 430 & 181 & 169 & $\$ 66.94$ & $\$ 61.52$ \\
\hline 1100 & 756 & 576 & 344 & 524 & 507 & 415 & 183 & 170 & $\$ 67.98$ & $\$ 62.21$ \\
\hline 1150 & 791 & 602 & 359 & 548 & 491 & 403 & 186 & 173 & $\$ 69.23$ & $\$ 63.13$ \\
\hline 1200 & 825 & 629 & 375 & 571 & 477 & 393 & 189 & 175 & $\$ 70.64$ & $\$ 64.21$ \\
\hline 1250 & 859 & 655 & 391 & 595 & 466 & 385 & 193 & 178 & $\$ 72.18$ & $\$ 65.42$ \\
\hline 1300 & 894 & 681 & 406 & 619 & 456 & 377 & 197 & 181 & $\$ 73.82$ & $\$ 66.73$ \\
\hline 1350 & 928 & 707 & 422 & 643 & 448 & 371 & 201 & 185 & $\$ 75.53$ & $\$ 68.12$ \\
\hline 1400 & 963 & 733 & 438 & 667 & 440 & 365 & 205 & 188 & $\$ 77.31$ & $\$ 69.58$ \\
\hline 1450 & 997 & 760 & 453 & 690 & 433 & 360 & 209 & 192 & $\$ 79.15$ & $\$ 71.10$ \\
\hline 1500 & 1031 & 786 & 469 & 714 & 427 & 355 & 214 & 196 & $\$ 81.04$ & $\$ 72.66$ \\
\hline 1550 & 1066 & 812 & 484 & 738 & 422 & 351 & 218 & 200 & $\$ 82.96$ & $\$ 74.26$ \\
\hline 1600 & 1100 & 838 & 500 & 762 & 417 & 348 & 223 & 204 & $\$ 84.92$ & $\$ 75.90$ \\
\hline 1650 & 1134 & 864 & 516 & 786 & 413 & 344 & 228 & 208 & $\$ 86.91$ & $\$ 77.57$ \\
\hline 1700 & 1169 & 890 & 531 & 810 & 409 & 341 & 233 & 212 & $\$ 88.93$ & $\$ 79.26$ \\
\hline 1750 & 1203 & 917 & 547 & 833 & 405 & 338 & 238 & 217 & $\$ 90.97$ & $\$ 80.98$ \\
\hline 1800 & 1238 & 943 & 563 & 857 & 401 & 336 & 242 & 221 & $\$ 93.04$ & $\$ 82.71$ \\
\hline 1850 & 1272 & 969 & 578 & 881 & 398 & 333 & 247 & 225 & $\$ 95.12$ & $\$ 84.47$ \\
\hline 1900 & 1306 & 995 & 594 & 905 & 395 & 331 & 252 & 230 & $\$ 97.22$ & $\$ 86.24$ \\
\hline 1950 & 1341 & 1021 & 609 & 929 & 393 & 329 & 257 & 234 & $\$ 99.34$ & $\$ 88.03$ \\
\hline 2000 & 1375 & 1048 & 625 & 952 & 390 & 327 & 262 & 239 & $\$ 101.48$ & $\$ 89.83$ \\
\hline 2050 & 1409 & 1074 & 641 & 976 & 388 & 325 & 268 & 243 & $\$ 103.63$ & $\$ 91.65$ \\
\hline 2100 & 1444 & 1100 & 656 & 1000 & 386 & 324 & 273 & 248 & $\$ 105.79$ & $\$ 93.47$ \\
\hline 2150 & 1478 & 1126 & 672 & 1024 & 384 & 322 & 278 & 252 & $\$ 107.96$ & $\$ 95.31$ \\
\hline 2200 & 1513 & 1152 & 688 & 1048 & 382 & 321 & 283 & 257 & $\$ 110.15$ & $\$ 97.16$ \\
\hline 2250 & 1547 & 1179 & 703 & 1071 & 380 & 319 & 288 & 261 & $\$ 112.35$ & $\$ 99.02$ \\
\hline 2300 & 1581 & 1205 & 719 & 1095 & 378 & 318 & 293 & 266 & $\$ 114.55$ & $\$ 100.88$ \\
\hline 2350 & 1616 & 1231 & 734 & 1119 & 377 & 317 & 299 & 270 & $\$ 116.77$ & $\$ 102.76$ \\
\hline 2400 & 1650 & 1257 & 750 & 1143 & 375 & 316 & 304 & 275 & $\$ 119.00$ & $\$ 104.64$ \\
\hline 2450 & 1684 & 1283 & 766 & 1167 & 374 & 314 & 309 & 280 & $\$ 121.23$ & $\$ 106.53$ \\
\hline 2500 & 1719 & 1310 & 781 & 1190 & 372 & 313 & 314 & 284 & $\$ 123.47$ & $\$ 108.43$ \\
\hline 2550 & 1753 & 1336 & 797 & 1214 & 371 & 312 & 320 & 289 & $\$ 125.72$ & $\$ 110.33$ \\
\hline 2600 & 1788 & 1362 & 813 & 1238 & 370 & 311 & 325 & 294 & $\$ 127.98$ & $\$ 112.24$ \\
\hline 2650 & 1822 & 1388 & 828 & 1262 & 368 & 311 & 330 & 298 & $\$ 130.25$ & $\$ 114.16$ \\
\hline
\end{tabular}

Table D-9 Cost Comparison at Different Standpipe Pressures: $m=2.3$ 